Universidade de São Paulo

Instituto de Física e Química de SÃo Carlos

\title{
APROXIMAÇÃO DE CAMPO MÉDIO DO MODELO DE POTTS GENERALIZADO
}

Pedro Ricardo del Santoro

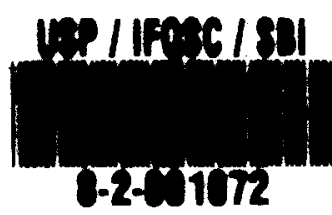

Dissertação apresentada ao Instituto de Física e Química de São Carlos, USP, para obtenção do Título de Mestre em Ciências - Física Básica

Orientador: Prof. Dr. Sylvio Goulart Rosa Jr.

Departamento de Física e Ciência dos Materiais

SÃo CarLos

1994 
IFSC Universidade de Sáo Paulo

Instituto de Física de São Carlos

Fone(0162) 72-6222

Fax (0162) 74-9151

Av. Dr. Cartos Botelho. 1465

Caixa Postal 369

CEP $13560-970$ - São Carlos - SP

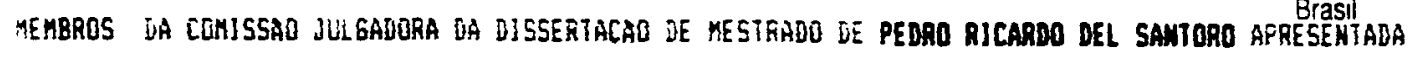

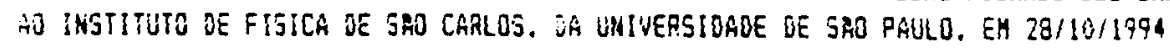

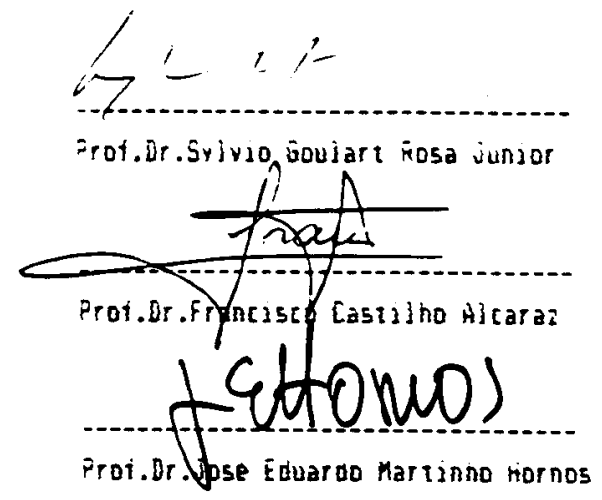


A Cida, por estar sempre a meu lado, e à Memória de Milica e Giba, meus mestres. 


\section{Agradecimentos}

Ao prof. Sylvio pela orientação segura, e pelo apoio durante todos esses anos.

Ao prof. Constantino Tsallis pelo esclarecimento de diversas dúvidas.

Aos professores e funcionários do IFQSC.

Ao IFGW-Unicamp por me proporcionar o ambiente para a conclusão desta dissertação.

Aos meus amigos e colegas: Miled, "os corticeiros" Virgilio, Bichinho e Leo. Ao Zezinho, Wilson, Javier, Paulão, Nagib, Braz, Gandhi, Alexandre, Andreas, Ed Wong, Cabra, Malmonge,Paulinho Utopia, Lobinho, Chico Bosco, Julio, Jean, Marcos, Gleise, Mary e tantos outros, que direta ou indiretamente contri buiram na preparação deste trabalho. 


\section{Conteúdo}

\section{RESUMO}

ABSTRACT

1 INTRODUÇÃO 1

2 ESTATÍSTICA GENERALIZADA 3

2.1 ENTROPIA DE ORDEM $q \ldots \ldots \ldots \ldots \ldots \ldots \ldots$

2.2 CARACTERÍSTICAS DA FUNÇÃO $S_{q} \ldots \ldots \ldots \ldots \ldots \ldots$

2.2 .1 A) ADITIVIDADE .................. 6

2.2 .2 B) CONVEXIDADE. . . . . . . . . . . . . . 7

2.3 FORMALISMO TERMODINÂMICO NA ESTATÍSTICA DE ORDEM $q .9$

3 FUNCIONAL DE ENERGIA LIVRE DE ORDEM $q$ E RELAÇÃO

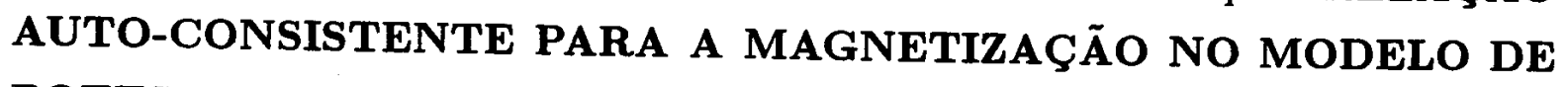
POTTS.

3.1 MODELO DE POTTS: APROXIMAÇÃO DE CAMPO MÉDIO. . . . . . 15

3.2 HAMILTONIANA E ENERGIA LIVRE DE ORDEM $q . \ldots \ldots \ldots$

3.3 RELAÇÃO AUTO-CONSISTENTE PARA A MAGNETIZAÇÃO . . . . . . 21

4 MAGNETIZAÇÃO ESPONTÂNEA E EQUILÍBRIO MACROSCÓPICO. 26

4.1 RELAÇÃO AUTO-CONSISTENTE COMO UM SISTEMA DINÂMICO . 26

4.2 DETERMINÇÃO NUMÉRICA DA MAGNETIZAÇÃO ESPONTÂNEA. . 32

4.3 DINÂMICA DO MAPA E ESTABILIDADE MACROSCÓPICA . . . . . 35 
5 TRANSIÇÃO DE FASE $\quad \mathbf{4 8}$

5.1 ENERGIA LIVRE DE ORDEM $q$ E TRANSIÇÃO DE FASE . . . . . . 48

5.2 INFLUÊNCIA DO PARÂMETRO $q$ SOBRE A TEMPERATURA CRÍTICA 57

6 CONCLUSÃO $\quad 68$

7 APÊNDICE I: Tangente Hiperbólica de Odem $p \quad 70$

8 APÊNDICE II: Biliográfica Atualizada $\quad 71$ 


\section{RESUMO}

Neste trabalho estudamos as consequências da introdução do parâmetro $q$, pela estatística generalizada de Tsallis, sobre o comportamento termodinâmico de um sistema de spins de Potts na aproximação de campo médio.

A abordagem do problema foi feita derivando-se um funcional de energia livre de ordem $q$, e por seu intermédio, uma relação auto-consistente envolvendo a magnetização, campo externo, e temperatura. Pela aplicação da teoria dos sistemas dinâmicos discretos à relação auto-consistente obteve-se curvas de magnetização espontânea e a influência sobre estas do parâmetro $q$. Determinou-se também a dependência da temperatura crítica do sistema com respeito ao parâmetro $q$. 


\section{ABSTRACT}

In this work we studied the consequences brought about by the $q$ parameter, introduced by Tsallis generalized statistics, to the termodynamic behaviour of a Potts spin system in the mean field approximation.

The approach to the problem was made by deriving a functional to the $q$ order free energy, and through this one, a self-consistent relation involving the magnetization, external field, and temperature. By the application of the discrete dynamical system theory, espontaneous magnetization curves as a function of temperature, and the influence over these of $q$ parameter were obtained. It was also determined the dependence of the system critical temperature on $q$ parameter. 


\section{Capítulo 1}

\section{INTRODUÇÃO}

Após o desenvolvimento da geometria dos fractais, por Mandelbrot[20], onde os conceitos de transformação de escala e dimensão fracionária têm papel fundamental, uma intensa pesquisa foi realizada, ao longo da década de 80 , visando aplicar estas idéias a vários ramos da física [26]. Outra vertente, trabalhando em sentido contrário, empregou métodos da física estatística ao estudo de objetos fractais. Exemplos ilustrativos disso são, o artigo de Halsey, Jansem, Kadanoff e Procaccia [13] que introduziu uma função análoga à função de partição, e o de Fujisaka e Inoue [12], que utiliza o conceito de entropia na caracterização desses objetos.

Nesses trabalhos, investigou-se através de transformações de escala as propriedades das grandezas $P_{i}^{q}\left(\epsilon_{i}\right), \operatorname{com} P_{i}\left(\epsilon_{i}\right)$ representam a distribuição de "matéria" no interior um conjuto de "esferas", de volume $\epsilon_{i}$, que recobrem um objeto fractal, e onde $q \in \Re$.

Inspirado neste formalismo, Tsallis[37] propôs uma entropia de ordem $q$, generalizando a estatística de Boltzmann-Gibbs. Posteriormente, em trabalho conjunto com Curado [9], estudou as consequências que esta generalização acarreta à estrutura formal da termodinâmica do equilíbrio, levando à redefinição de grandezas tais como energia interna e energia livre.

Desde então, uma série de trabalhos têm sido publicados sobre esta generalização, tanto em seus aspectos formais, quanto de aplicação a modelos da física estatística, astrofísica, vide apêndice II.

O objetivo deste dissertação é estudar a estatística generalizada de Tsallis aplicada a um sistema de spins de Potts na aproximação de campo médio, e investigar a influência do parâmetro $q$ sobre seu comportamento termodinâmico. 
A definição de entropia de ordem $q$, suas principais propriedades, e as consequências que esta acarreta à estrutura formal da termodinâmica do equilíbrio e física estatística, são expostas no capítulo 2.

No capítulo 3 seguindo o procedimento utilizado por Wu [38] na obtenção da hamiltoniana de Husimi [14], deriva-se uma expressão, análoga a esta, para a energia interna de ordem $q$, e um funcional para a energia livre de ordem $q$, para o sistema. Deste último, e das condições impostas a um sistema em equilíbrio térmico com o meio exterior, obtém-se uma relação auto-consistente para a magnetização do sistema dependente da temperatura e do campo externo.

No capítulo 4, aplicando-se elementos da teoria dos sistemas dinâmicos discretos à relação autoconsistente do capítulo anterior, obtém-se numericamente as curvas da magnetização espontânea do sistema em função da temperatura, e discute-se a influência do parâmetro $q$ sobre esta, e a estabilidade macroscópica do sistema.

No capítulo 5 analisa-se como a transição de fase do sistema é afetada no âmbito da estatítica de Tsallis, e utilizando a mesma técnica do capítulo 4, faz-se o cálculo numérico da variação da temperatura crítica do sistema em função do parâmetro $q$.

O capítulo 6 é reservado para a análise dos resultados obtidos e as conclusões. 


\section{Capítulo 2}

\section{ESTATÍSTICA GENERALIZADA}

\subsection{ENTROPIA DE ORDEM $q$.}

$\mathrm{Na}$ primeira metade do século XIX a ciência da termodinâmica conheceu um rápido desenvolvimento como consequência do interesse na melhoria do rendimento das máquinas a vapor. São dessa época os trabalhos de Carnot sobre máquinas cíclicas reversiveis, e a descoberta da primeira lei da termodinâmica, independentemente, pelo médico alemão Julius Robert von Mayer, baseado em observações da circulação sanguínea, e Joule pela determinação experimental do equivalente mecânico do calor. Com a introdução do conceito de entropia por Clausius e a formulação por este e Kelvin da segunda lei, a termodinâmica adquire sua forma definitiva. Faltava ainda uma teoria que fizesse a ligação entre o comportamento macroscópico da matéria, ditado pelas leis da termodinâmica, e sua constituição microscópica, regida pela mecânica, ligação que viria a ser feita pela física estatística.

As principais dificuldades para a construção dessa teoria eram: obter uma interpretação microscópica conveniente para a entropia, e o caráter irreversível dos processos termodinâmicos em contraposição às leis da mecânica.

$O$ primeiro a contornar essas dificuldades e atribuir um caráter estatístico a segunda lei foi Boltzmann, que introduziu a distinção entre o estado macroscópico de um sistema termodinâmico e o conjunto de estados micróscpicos compatíveis com este. Boltzmann postulou que a evolução espontânea de um sistema termodinâmico isolado para um estado macroscópico de entropia máxima, como prevê a segunda lei, é equivalente a evolução deste para um conjunto de micro-estados mais prováveis.

Partindo da aditividade da entropia, Boltzmann fez a suposição que a relação entre 
esta e o número de microestados $W$ acessiveis ao sistema, quando este é isolado, é dada, por sua, agora famosa fórmula:

$$
S=K_{B} \ln (W)
$$

onde $K_{B}$ é uma constante com dimensão de entropia. Esta suposição permitiu deduzir-se a distribuição de velocidades para as moléculas de um gás ideal monoatômico, obtida por Maxwell algum tempo antes. A relação de Boltzmann, eq. 2.1, levou a atribuir-se a entropia um caráter de medida da "desordem de um sistema" - compreendida esta como nossa incerteza a respeito do micro-estado em que este se encontra - uma vez que $S$ é crescente com $W[4,21]$.

Reformulada de maneira mais geral, isto é, sem impor a restrição que o sistema esteja isolado, a relação de Boltzmann, toma a forma:

$$
S=-K_{B} \sum_{i=1}^{W} P_{i} \ln \left(P_{i}\right)
$$

onde $P \equiv\left\{P_{1}, P_{2}, \ldots, P_{w}\right\}$, é a distribuição de probabilidade associada ao conjunto de $W$ micro-estados acessiveis do sistema. Esta formulaçào, conhecida como entropia de Boltzmann-Gibbs, reduz-se à relação de Boltzmann no ensemble microcanônico, isto é, quando impomos a condiçào de que o sistema encontra-se isolado.

O sucesso desta abordagem a diversos modelos clássicos, e posteriormente a quânticos [30], levou a aplicação do conceito de entropia a áreas do conhecimento não diretamente relacionadas com a termodinâmica, como a teoria da informação, por Hartley e Shannon [32], e em sentido mais abstrato à teoria das probabilidades por Kinchin [18]e Rényi [31].

Em trabalho recente, Tsallis [37] propôs uma generalização da estatística de Boltzmann-Gibbs postulando uma entropia de ordem $q$ para um sistema, definida como:

$$
S_{q}=\frac{K_{B}}{q-1}\left\{1-\sum_{i=1}^{W} P_{i}^{q}\right\}
$$

onde q é um parâmetro pertencente ao conjunto dos números reais.

Na próxima seção deste capítulo expôem-se as principais propriedades desta definição de entropia de ordem $q$, e na terceira, discutimos suas implicações no formalismo termodinâmico. 


\subsection{CARACTERÍSTICAS DA FUNÇÃO $S_{q}$}

A primeira questão levantada pela definição de Tsallis para entropia de ordem $q$, é sua relação com a expressão para a entropia na estatística de Boltzmann-Gibbs, eq. 2.2. Para esta verificação reescrevemos $S_{q}$, com a ajuda da condição de normalização $\sum P_{i}=1$, na forma:

$$
S_{q}=\frac{K_{B}}{q-1} \sum_{i=1}^{W} P_{i}\left[1-\exp \left\{(q-1) \ln \left(P_{i}\right)\right\}\right] .
$$

Expandindo-se os termos $P_{i}^{q-1}$ em uma série de potências temos:

$$
S_{q}=-\frac{K_{B}}{q-1} \sum_{i=1}^{W} P_{i}\left[\sum_{n=1}^{\infty} \frac{(q-1)^{n}}{n !} \ln ^{n}\left(P_{i}\right)\right]
$$

ou,

$$
S_{q}=-K_{B} \sum_{i=1}^{W} P_{i} \sum_{n=1}^{\infty} \frac{(q-1)^{n-1}}{n !} \ln ^{n}\left(P_{i}\right) .
$$

É fácil verificar que no limite $q \rightarrow 1$, todos os termos da somatória sobre o índice $n$, exceto aqueles com $n=1$, serão nulos. Assim,

$$
\lim _{q \rightarrow 1} S_{q}=S_{1}=S
$$

Este último resultado mostra a entropia de Boltzmann-Gibbs como o caso particular da entropia de Tsallis quando $q=1$. Deste modo todos os resultados derivados dentro do contexto da estatística generalizada de Tsallis devem no limite $q \rightarrow 1$ reproduzir aqueles da estatística de Boltzmann-Gibbs. Isto fornece um método para a verificação da consistência dos resultados que forem obtidos posteriormente. Para isso, faz-se $q \rightarrow 1 \mathrm{e}$ compara-se com aqueles da estatística de Boltzmann-Gibbs.

Outro resultado que pode ser mostrado com facilidade [37], é que $S_{q}$ tem um máximo para a distribuição de probabilidade uniforme, quando o sistema não esta sujeito a nenhuma outra condição alem de que a distribuição de probabilidade seja normalizada.

$\mathrm{Na}$ estatística de Boltzmann-Gibbs, as propriedades mais importantes da entropia são: a aditividade, e a concavidade em relação a energia interna [17]. Analisamos agora como estas são afetadas no âmbito da estatística generalizada de Tsallis. 


\subsubsection{A) ADITIVIDADE}

Sejam dois sistemas $A$ e $B$ não correlacionados, isto é, que não interagem entre si, obedecendo respectivamente às distribuições de probabilidade $P(A) \equiv\left\{P_{1}(A), \ldots, P_{W_{A}}(A)\right\}$ e $P(B) \equiv\left\{P_{1}(B), \ldots, P_{W_{B}}(B)\right\}$; pode-se definir um sistema $A \cup B$ formado pela união de $A$ e $B$, e que obedece à distribuição $P(A \cup B) \equiv\left\{P_{1,1}(A \cup B), \ldots, P_{W_{A}, W_{B}}(A \cup B)\right\}$ onde:

$$
P_{i, j}(A \cup U)=P_{i}(A) \cdot P_{j}(B)
$$

Pela eq. 2.3, a entropia de ordem $q$ para $A \cup B$ é dada por:

$$
S_{q}(A \cup B)=\frac{K_{B}}{q-1}\left\{1-\sum_{i, j=1}^{W_{A}, W_{B}} P_{i, j}^{q}(A \cup B)\right\} .
$$

Substituindo-se na equação acima a eq. 2.8 tem-se:

$$
S_{q}(A \cup B)=\frac{K_{B}}{q-1}\left\{1-\sum_{i,=1}^{W_{A}} P_{i}^{q}(A) \cdot \sum_{j=1}^{W_{B}} P_{j}^{q}(B)\right\},
$$

que junto com a definição da entropia de Tsallis, reescrita na forma,

$$
1-(q-1) \frac{S_{q}}{K_{B}}=\sum_{i=1}^{W} P_{i}^{q}
$$

leva a:

$$
S_{q}(A \cup B)=\frac{K_{B}}{q-1}\left\{1-\left[1-(q-1) \frac{S_{q}(A)}{K_{B}}\right] \cdot\left[1-(q-1) \frac{S_{q}(B)}{K_{B}}\right]\right\},
$$

ou de maneira mais simétrica,

$$
\left[1-(q-1) \frac{S_{q}(A \cup B)}{K_{B}}\right]=\left[1-(q-1) \frac{S_{q}(A)}{K_{B}}\right] \cdot\left[1-(q-1) \frac{S_{q}(B)}{K_{B}}\right] .
$$

Multiplicando-se por $K_{B}$, tomando-se o logarítmo em ambos os lados desta última expressão, e definindo,

$$
S_{q}^{R}=\frac{K_{b}}{1-q} \ln \left[1-(q-1) \frac{S_{q}}{K_{B}}\right]
$$

ou,

$$
S_{q}^{R}=\frac{K_{b}}{1-q} \ln \left(\sum_{i=1}^{W} P_{i}^{q}\right)
$$


tem-se:

$$
S_{q}^{R}(A \cup B)=S_{q}^{R}(A)+S_{q}^{R}(B) .
$$

Este resultado mostra a perda de aditividade da entropia no contexto de uma estatítica de Tsallis. Para que esta propriedade seja recuperada, é necessário a introdução de $S_{q}^{R}$. Esta grandeza, conhecida como entropia de Rényi [31] é definida pela eq. 2.15, que se relaciona com $S_{q}$ pela eq. 2.14, foi proposta como a medida de informação de ordem $q$, para uma distribuição de probabilidade incompleta, isto é, onde a condição de normalização usual é substituida por:

$$
\sum_{i=1}^{W} P_{i} \leq 1
$$

De maneira análoga aquela usada para obter o limite de $S_{q}$ quando $q \rightarrow 1$, podemos mostrar que:

$$
\lim _{q \rightarrow 1} S_{q}^{R}=-K_{B} \sum_{i=1}^{W} P_{i} \ln \left(P_{i}\right)=S,
$$

recuperando assim a entropia de Boltzmann-Gibbs.

\subsubsection{B) CONVEXIDADE.}

Uma função real $f(X)$, com $X \in \Re$, é dita côncava entre os pontos $X_{0}$ e $X_{1}$ de seu domínio, se:

$$
(1-\lambda) f\left(X_{0}+\lambda X_{1}\right)+\lambda f\left(X_{1}\right) \leq f\left((1-\lambda) X_{0}+\lambda X_{1}\right),
$$

para $0 \leq \lambda \leq 1$, e convexa quando esta desigualdade for obedecida[17].

Dadas duas distribuições de probabilidade, $P \equiv\left\{P_{1}, \ldots, P_{W}\right\}$ e $P^{\prime} \equiv\left\{P_{1}, \ldots, P_{W}\right\}$, pode-se definir uma terceira, $P^{\prime \prime} \equiv\left\{P_{1^{\prime \prime}}, \ldots, P_{W}\right\}$ com,

$$
P_{i}^{\prime \prime}=(1-\lambda) P_{i}^{\prime}+\lambda P_{i},
$$

e a quantidade,

$$
\Delta_{q}=S_{q}\left(P^{\prime \prime}\right)-(1-\lambda) S_{q}\left(P^{\prime}\right)-\lambda S_{q}(P),
$$

que serve como indicador para a convexidade da entropia de Tsallis.

Calculando-se explicitamente $\Delta_{q}$,

$$
\Delta_{q}=\frac{K_{B}}{q-1}\left\{1-\left[\sum_{i=1}^{W} P_{i}^{,, q}-(1-\lambda) \sum_{i=1}^{W} P_{i}^{q}-\lambda \sum_{i=1}^{W} P_{i}^{q}\right]\right\},
$$




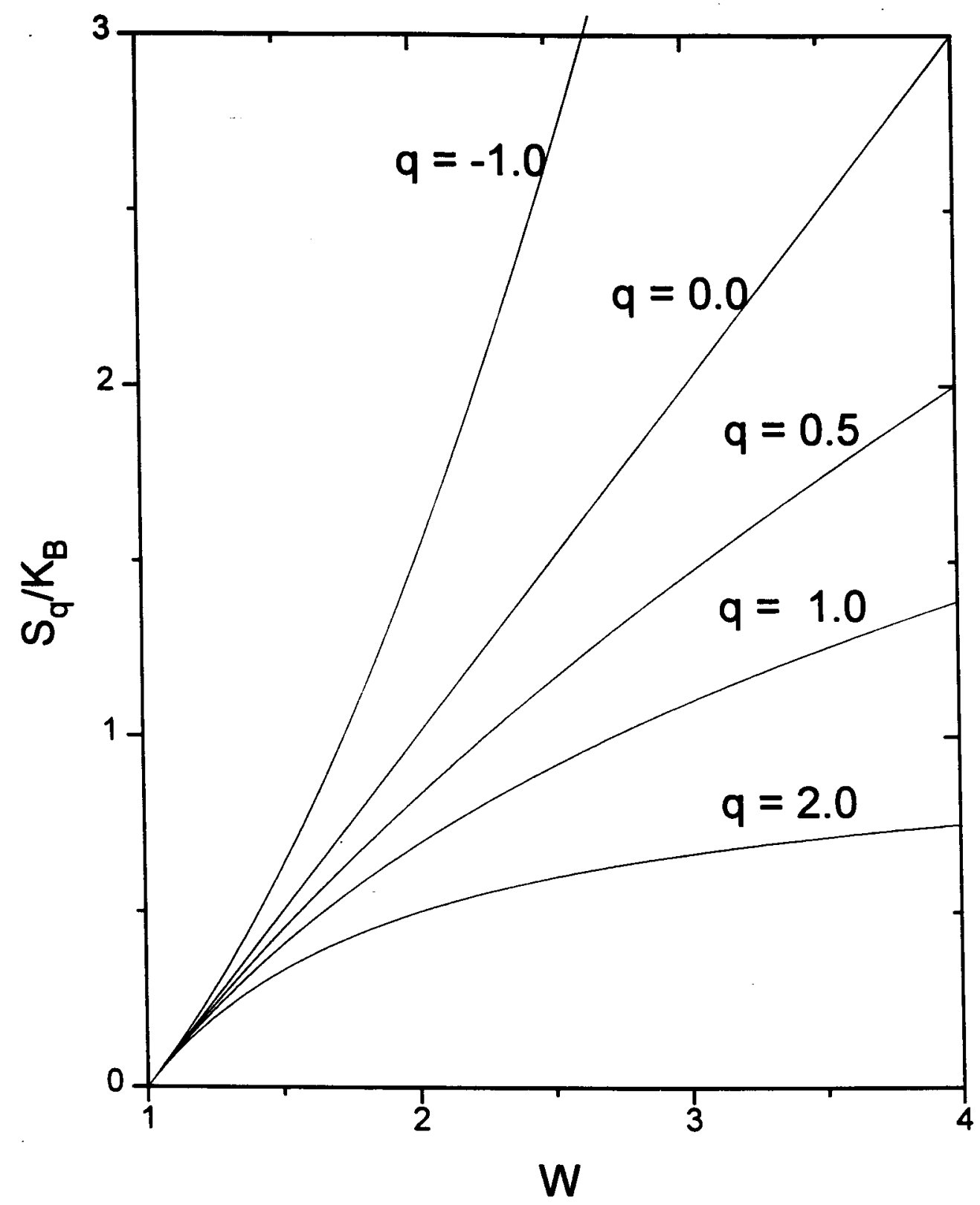

Figura 2.1: Convexidade da função $S_{q}$ em relação ao parâmetro $q$ para um sistema com $W$ estados no ensemble microcânonico, quando a distribuição de probabilidade é uniforme.

ou,

$$
\Delta_{q}=\frac{K_{B}}{q-1}\left\{1-\left[\sum_{i=1}^{W}\left((1-\lambda) P_{i}^{\prime}+\lambda P_{i}\right)^{q}-(1-\lambda) \sum_{i=1}^{W} P_{i}^{q q}-\lambda \sum_{i=1}^{W} P_{i}^{q}\right]\right\}
$$

É fácil notar que a funçào $X^{q}=\exp \{q \ln (X)\}, \operatorname{com} q>0$, é convexa, e assim:

$$
\Delta_{q} \equiv \begin{cases}>0 & \text { para } q>0 \\ >0 & \text { para } q>0\end{cases}
$$

Ou seja, $S_{q}$ é concava para $q>0$ e convexa para $q<0$, como mostra a figura 2.1 .

É importante notar que as condiçōes de estabilidade de um sistema termodinâmico, exigem a concavidade da entropia, com relação a energia interna, pois o contrário per- 
mitiria a existência de estados meta-estáveis, com, por exemplo, calor específico negativo que levaria a violação da segunda lei da termodinâmica.

\subsection{FORMALISMO TERMODINÂMICO NA ESTATÍSTICA DE ORDEM $q$}

Antes de aplicar-se o conceito de entropia generalizada de Tsallis, a um sistema físico particular, faz-se necessária a investigação das consequências que esta acarreta a estrutura formal da termodinâmica.

A hipótese básica da termodinâmica do equilíbrio $[8,36]$ é a existência da função energia interna,

$$
U=U\left(S, X_{1}, X_{2}, \ldots, X_{N}\right)
$$

dependente da entropia $S$, e de um conjunto de variáveis extensivas $\left\{X_{1}, X_{2}, \ldots, X_{N}\right\}$, que determina univocamente o estado macroscópico do sistema. Esta função é chamada relação fundamental da termodinâmica.

Para cada uma das variáveis extensivas $X_{i}$, é associada uma variável intensiva $Y_{i}$, que é definida como:

$$
Y_{i}=\left(\frac{\partial U}{\partial X_{i}}\right)_{S, X_{1}, \ldots, X_{i-1}, X_{i+1} \ldots, X_{N}} .
$$

Em especial aquela que define a temperatura,

$$
T=\left(\frac{\partial U}{\partial S}\right)_{X_{1}, X_{2}, \ldots, X_{N}} .
$$

A preservação desta estrutura formal, no âmbito de uma estatística de Tsallis depende da determinação de uma nova relação fundamental de ordem $q$,

$$
U_{q}=U_{q}\left(S_{q}, X_{1}, \ldots, X_{N}\right)
$$

a ser definida de maneira que, analogamente à eq.2.27, a temperatura do sistema seja dada por:

$$
T=\left(\frac{\partial U_{q}}{\partial S_{q}}\right)_{X_{1}, \ldots, X_{N}}
$$


Esse trabalho foi feito por Andrade e Tsallis [1] usando a suposição que a energia média de ordem $q$ de um sistema tem a forma:

$$
U_{q}=\sum_{i=1}^{W} P_{i}^{q} \epsilon_{i}
$$

onde $\epsilon \equiv\left\{\epsilon_{1}, \epsilon_{2}, \ldots, \epsilon_{W}\right\}$ é o conjunto de níveis de energia do sistema que tem $W$ estados acessíveis, e $P \equiv\left\{P_{1}, P_{2}, \ldots, P_{W}\right\}$ a distribuição de probabilidade associada aos mesmos.

É trivial verificar-se que no limite $q \rightarrow 1$ a eq. 2.30 reduz-se a forma usual da energia média, mas a demonstração de sua consistência com a eq. 2.29 exige determinação da distribuição de probabilidade $P$ no ensemble canônico.

Para isto usa-se o princípio de entropia máxima [36] que supõe-se válido em uma estatística de ordem $q$ e a técnica dos multiplicadores de Lagrange[2], onde procura-se a distribuição de probabilidade que maximiza a função $\overline{S_{q}}$ definida como:

$$
\overline{S_{q}}=\frac{S_{q}}{K_{B}}+\beta U_{q}+\lambda \sum_{i=1}^{W} P_{i},
$$

onde $\beta$ e $\lambda$ são coeficientes a serem determinados.

A exigência de que $\overline{S_{q}}$ seja máxima quando o sistema está em equílibrio térmico com o meio, implica que para qualquer variação infinitesimal arbitrária $\left\{\delta P_{1}, \ldots, \delta P_{N}\right\}$ da distribuição de probabilidade tenhamos,

$$
\delta \overline{S_{q}}=0
$$

ou, em função da variação de $P$,

$$
\delta \overline{S_{q}}=\sum_{i=1}^{W} \frac{\partial \overline{S_{q}}}{\partial P_{i}} \delta P_{i}=0 .
$$

Como as variações $\delta P_{i}$ são independentes entre si, a condição expressa pela equação acima reduz-se a:

$$
\frac{\partial \overline{S_{q}}}{\partial P_{i}}=0
$$

Que calculada explicitamente a partir das expressões para a entropia e energia média de ordem $q$ tem-se:

$$
-\frac{q}{q-1} P_{i}^{q-1}+q \beta P_{i}^{q-1}+\lambda=0
$$


ou,

$$
P_{i} \propto\left[1-(q-1) \beta \epsilon_{i}\right]^{\frac{1}{1-q}} .
$$

Desta última equação e da condição de normalização para $P$, chega-se a distribuição desejada,

$$
P_{i}=\frac{\left[1-(q-1) \beta \epsilon_{i}\right]^{\frac{1}{1-q}}}{Z_{q}}
$$

Onde

$$
Z_{q}=\sum_{i=1}^{W}\left[1-(q-1) \beta \epsilon_{i}\right]^{\frac{1}{1-q}},
$$

é a correspondente formal na estatística de Tsallis da função de partição na estatística de Boltzmann-Gibbs.

Para evidenciar esta correspondência, determina-se primeiro o valor de $Z_{q}$ quando $q \rightarrow 1$. Para isso reescrevemos $Z_{q}$ na forma,

$$
Z_{q}=\sum_{i=1}^{W} \exp \left\{\frac{1}{1-q} \ln \left[1-(q-1) \beta \epsilon_{i}\right]\right\},
$$

e expandindo-se esta em uma série de Taylor,

$$
Z_{q}=\sum_{i=1}^{W} \exp \left\{\sum_{n=1}^{\infty} \frac{(-1)^{n+1}(q-1)^{n-1}}{n}\left(\beta \epsilon_{i}\right)^{n}\right\} .
$$

No limite $q \rightarrow 1$, todos os termos entre chaves desta série anulam-se, com exceção daquele com $n=1$. Assim temos:

$$
Z_{1}(\beta)=\lim _{q \rightarrow 1}\left[Z_{q}(\beta)\right]=\sum_{i=1}^{W} \exp \left[-\beta \epsilon_{i}\right],
$$

recobrando a expresão formal da função de partição, na estatística de Boltzman-Gibbs.

Nesta última, as relações entre função de partição, energia livre de Helmoltz, a e a energia média são expressas respectivamente por:

$$
F(\beta)=-\frac{1}{\beta} \ln \left[Z_{1}(\beta)\right],
$$

$\mathrm{e}$

$\operatorname{com} \beta=1 / K b T$.

$$
U(S)=-\frac{\partial}{\partial \beta} \ln \left[Z_{1}(\beta)\right],
$$


O fato de $Z_{q}$ ser uma soma de termos elevados a potência $1 /(1-q)$ e o resultado utilizado no método da réplica,

$$
\lim _{x \rightarrow x_{0}} \frac{1}{x-x_{0}}\left\{1-g(x)^{x-x_{0}}\right\}=-\ln \left\{g\left(x_{0}\right)\right\},
$$

onde $g(x)$ é uma função arbitrária, sugerem que a função,

$$
f_{q}(\beta)=\frac{1}{1-q}\left[Z_{q}^{(1-q)}(\beta)-1\right],
$$

que no limite $q \rightarrow 1$ tende ao logarítmo de $Z_{1}(\beta)$, desempenha formalmente, em uma estatística de Tsallis, o mesmo papel do logarítmo da função de partição na estatística de Boltzmann-Gibbs.

Para estabelecer esta correspondencia formal de modo mais rigoroso, primeiro calculase a derivada de $f_{q}(\beta)$ em relação a $\beta$.

$\mathrm{Da}$ eq. 2.45 obtém-se:

$$
\frac{\partial f_{q}(\beta)}{\partial \beta}=-Z_{q}^{-q} \frac{\partial Z_{q}(\beta)}{\partial \beta},
$$

e da eq.2.38,

$$
\frac{\partial Z_{q}(\beta)}{\partial \beta}=\sum_{i=1}^{W} \epsilon_{i}\left[1-(q-1) \beta \epsilon_{i}\right]^{\frac{q}{1-q}}
$$

Assim,

$$
\frac{\partial f_{q}(\beta)}{\partial \beta}=-Z_{q}^{-q} \sum_{i=1}^{W} \epsilon_{i}\left[1-(q-1) \beta \epsilon_{i}\right]^{\frac{q}{1-q}}
$$

que pode ser reescrita como:

$$
\frac{\partial f_{q}(\beta)}{\partial \beta}=-\sum_{i=1}^{W}\left\{\frac{\left[1-(q-1) \beta \epsilon_{i}\right]^{\frac{1}{q-1}}}{Z_{q}}\right\}^{q} \epsilon_{i} .
$$

O termo entre chaves na equação acima é identificado, via eq.2.37, com a probabildade $P_{i}$ associada ao nivel de energia $\epsilon_{i}$, o que nos leva a:

$$
\frac{\partial f_{q}(\beta)}{\partial \beta}=-\sum_{i=1}^{W} P_{i}^{q} \epsilon_{i}
$$

ou

$$
U_{q}=-\frac{\partial f_{q}(\beta)}{\partial \beta}
$$


A relação expressa pela eq.2.51 permite o cálculo da transformação de Legendre de $f_{q}(\beta)$, em função de $U_{q}$, isto é:

$$
\overline{f_{q}}\left(U_{q}\right)=f_{q}(\beta)-\beta \frac{\partial f_{q}(\beta)}{\partial \beta},
$$

ou

$$
\overline{f_{q}}\left(U_{q}\right)=f_{q}(\beta)+\beta U_{q} .
$$

Estando implícito que $\beta$, no lado direito das eqs.2.52 e 2.53, é uma função de $U_{q}$.

Substituindo-se explicitamente na equação acima as eqs.2.30 e 2.38 que definem respectivamente, $U_{q}$ e $Z_{q}$, chega-se a:

$$
\overline{f_{q}}\left(U_{q}\right)=\frac{1}{1-q} \sum_{i=1}^{W}\left\{\frac{\left[1-(q-1) \beta \epsilon_{i}\right]^{\frac{1}{1-q}}}{Z_{q}^{q}}-1+(q-1) \beta \epsilon_{i} P_{i}^{q}\right\} .
$$

Fatorando-se o primeiro termo à esquerda dos termos entre chaves na última expressão, tem-se:

$$
\overline{f_{q}}\left(U_{q}\right)=\frac{1}{1-q} \sum_{i=1}^{W}\left\{\left[1-(q-1) \beta \epsilon_{i}\right]^{\frac{1}{q-1}} \times\left[\frac{\left[1-(q-1) \beta \epsilon_{i}\right]^{\frac{1}{q-1}}}{Z_{q}}\right]-1+(q-1) \beta \epsilon_{i} P_{i}^{q}\right\},
$$

que através da eq.2.37, que define $P_{i}$ chega-se a:

$$
\overline{f_{q}}\left(U_{q}\right)=\frac{S_{q}}{K_{B}} .
$$

Uma vez que $K_{B} f_{q}\left(U_{q}\right)$ é idêntica a entropia $S_{q}$, a eq.2.52 toma a forma:

$$
S_{q}=K_{B} f_{q}\left(U_{q}\right)+K_{B} \beta U_{q},
$$

E pela propriedade da derivada da transformação de Legendre ser igual ao argumento da função original, temos:

$$
\left(\frac{\partial S_{q}}{\partial U_{q}}\right)=K_{B} \beta
$$

ou, lembrando que $\beta=1 / K_{B} T$ :

$$
\left(\frac{\partial U_{q}}{\partial S_{q}}\right)=T
$$

que verifica a consistência da definição de energia interna média de ordem q com a eq.2.29. 
Com base nas duas últimas equações define-se uma energia livre de ordem $q$, de maneira formalmente análoga aquela usada para definir a energia livre de Helmoltz, como a transformação de Legendre da função $U_{q}$ em relação à $\beta$ :

$$
F_{q}(\beta)=U_{q}(\beta)-T S_{q}(\beta)
$$

Comparando-se a definição acima com a eq.2.56 chega-se a:

$$
F_{q}(\beta)=-\frac{1}{\beta} f_{q}(\beta)
$$

ou escrevendo-se $f_{q}(\beta)$ explicitamente em função de partição $Z_{q}$,

$$
F_{q}(\beta)=\frac{1}{\beta} \frac{1}{1-q}\left\{Z_{q}^{q-1}(\beta)-1\right\} .
$$

Esta equação e a de número 2.51 que relacionam a função $f_{q}(\beta)$, repectivamente à energia livre e a energia média de ordem $q$, são formalmente análogas às eqs.2.42 e 2.43 que relacionam o logarítmo da função de partição, na estatística de Boltzmann-Gibbs, com a energia livre de Helmoltz e energia média. Isso confirma a hipótese feita acima que a função $f_{q}(\beta)$ desempenha, em uma estatística de Tsallis, o mesmo papel do logarítmo da função de partição em uma estatística de Boltzmann-Gibbs.

Com as relações obtidas nesta seção podemos afirmar agora a existência de uma completa simetria formal entre as estatísticas de Tsallis e Boltzmann-Gibbs. Havendo para cada relação nesta última, uma equivalente de ordem $q$ na primeira, sendo o limite $q \rightarrow 1$, $o$ ponto de contato entre ambas. 


\section{Capítulo 3}

\section{FUNCIONAL DE ENERGIA LIVRE DE ORDEM $q$ E RELAÇÃO AUTO-CONSISTENTE PARA A MAGNETIZAÇÃO NO MODELO DE POTTS.}

\subsection{MODELO DE POTTS: APROXIMAÇÃO DE CAMPO MÉDIO.}

O modelo de Potts [27] foi proposto em 1951 como uma generalização do modelo de Ising [15] . Neste modelo, em cada um dos $N$ sítios de uma rede, cujas localizaçóes são especificadas pelo indice $i$, existe um spin ao qual associa-se uma variável $\sigma_{i}$, que pode assumir $p$ valores inteiros distintos, isto é, $\sigma_{i}=0,1, \ldots, p-1$. Sua hamiltoniana é dada, na presença de campo externo $B$, pela expressão:

$$
H=-\frac{J}{2} \sum_{\langle i, j\rangle} \delta\left(\sigma_{i}, \sigma_{j}\right)-B \sum_{i=0}^{N-1} \delta\left(\sigma_{i}, \sigma_{0}\right) .
$$

A primeira somatória do lado direito desta expressão representa a interação entre os spins da rede. O símbolo $\langle i, j\rangle$ indica que a somatória é efetuada apenas entre os vizinhos mais próximos do sítio $i$, sendo $J$ a constante de acoplamento ferromagnética entre cada um dos pares de spins, e onde o fator $1 / 2$ é introduzido para evitar que um par de spins seja contado duas vezes.

A somatória mais a direita da eq. 3.1, mostra que a interação campo externo e um spin contribui para a Hamiltoniana apenas quando este último e um spin em um sítio cuja localização na rede é escolhida arbitrariamente como $i=0$ estão "alinhados", isto é, a variável de Potts de ambos tem o mesmo valor.

Para os casos particulares: $p=1, p=2$, e $p=4$, pode-se mostrar[6] que o modelo de Potts recupera respectivamente, o modelo da percolação, o modelo de Ising, e o modelo 
de Ashkin-Teller [3].

A solução exata, isto é, a obtenção da energia livre de Helmoltz a partir do cálculo da função de partição, desse e de outros modelos da mecânica estística, quando existem envolvem cálculos bastante complexos, que dependem fortemente da dimensão e topologia da rede. Como exemplo disso tem-se a solução do modelo de Ising para uma rede bidimensional, obtida por Onsager[22] apenas em 1944, e para uma rede tridimensional não obtida até hoje. Essas dificuldades compelem ao emprego de métodos aproximativos quando pretende-se ter alguma informação a respeito do comportamento termodinâmico desses modelos.

Em 1954 Husimi [14] estudou pela primeira vez a aproximação de campo médio para o modelo de Potts. Nessa aproximação é abandonada a restrição de que a interação ocorra apenas entre o spin em um sítio e os seus vizinhos mais próximos, e introduzindo uma nova constante de acoplamento:

$$
\bar{J}=\frac{\gamma J}{N},
$$

onde $\gamma$ é o número de coordenação, e $N$ o número total de spins $n$ da rede. Assim, a eq. 3.1 toma a forma:

$$
H \simeq-\frac{\bar{J}}{2} \sum_{i, j=0}^{N-1} \delta\left(\sigma_{i}, \sigma_{j}\right)-B \sum_{i=0}^{N} \delta\left(\sigma_{i}, \sigma_{0}\right)
$$

ou

$$
H_{C M}=-\frac{\gamma J}{2 N} \sum_{i, j=0}^{N-1} \delta\left(\sigma_{i}, \sigma_{j}\right)-B \sum_{i=0}^{N-1} \delta\left(\sigma_{i}, \sigma_{0}\right)
$$

Uma vez que as somatórias sobre os índices $i$ e $j$, tornam-se independentes entre si, a hamiltoniana de campo médio pode ser vista como :

$$
H_{C M}=\sum_{i=0}^{N-1} H_{\sigma_{i}}
$$

Onde a quantidade

$$
H_{\sigma_{i}}=-\frac{\gamma J}{2 N} \sum_{j=0}^{N-1} \delta\left(\sigma_{i}, \sigma_{j}\right)-B \delta\left(\sigma_{i}, \sigma_{0}\right)
$$

é interpretada como a energia com que o spin no sítio $i$ contribui para a energia total do sistema. 
Nesta última equação cada termo da somatória $\sum \delta\left(\sigma_{i}, \sigma_{j}\right)$, efetuada sobre o índice $j$, adicionará uma unidade sempre que cada $\sigma_{i}=\sigma_{j}$, o que leva a:

$$
\sum_{j=0}^{N-1} \delta\left(\sigma_{i}, \sigma_{j}\right)=N_{\sigma_{i}}
$$

Onde $N_{\sigma_{i}}$ é o número de spins na rede que estão no mesmo estado de Potts que o spin do sítio $i$, isto é, o número de ocupação do estado de Potts $\sigma_{i}$. Dessa maneira a energia com que o spin no sítio $i$ contribui para a energia total será dada por:

$$
H_{\sigma_{i}}=-\frac{\gamma J}{2 N} N_{\sigma_{i}}-B \delta\left(\sigma_{i}, \sigma_{0}\right)
$$

Como a variável de Potts pode assumir $p$ valores distintos, haverá apenas $p$ valores possíveis para a grandeza $N_{\sigma_{i}}$, para uma dada configuração dos $N$ spins na rede, e por conseguinte $p$ valores de energia por sítio $H_{\sigma_{i}}$, dadas pela última equação.

Cada um dos possíveis conjuntos de números de ocupação $\left\{N_{0}, N_{1}, \ldots, N_{p-1}\right\}$, que obedecem à condição de normalização $\sum N_{\sigma}=N$, representa uma distribuição dos spins da rede pelos estados de Potts e define um estado macroscópico do sistema.

A somatória na equação 3.3 contém $N$ termos, com cada um dos $p$ valores de $H_{\sigma_{i}}$ sendo contados $N_{\sigma_{i}}$. Assim a somatória sobre o indice $i$ variando de 0 até $N-1$, pode ser substituída por outra, sobre o índice $\sigma_{i}$ variando de 0 até $p-1$, com cada um dos valores $H_{\sigma_{i}}$ sendo ponderado por $N_{\sigma_{i}}$, isto é,

$$
H_{C M}=\sum_{\sigma_{i=0}}^{p-1} N_{\sigma_{i}} H_{\sigma_{i}}
$$

Abandonando-se agora o índice $i$, que agora torna-se irrelevante, e fazendo-se por conveniência $\sigma_{0}=0$, temos:

com

$$
H_{C M}=\sum_{\sigma=0}^{p-1} N_{\sigma} H_{\sigma}
$$

$$
H_{\sigma}=-\frac{\gamma J}{2 N} N_{\sigma}-B \delta(\sigma, 0)
$$

A partir dos conjuntos de números de ocupação, definidos no parágrafo anterior, definem-se os conjuntos de frações de ocupação dos estados de Potts $\left\{X_{0}, X_{1}, \ldots, X_{p-1}\right\}$, 
onde $X_{\sigma}=N_{\sigma} / N$, sujeitos à condição de normalização $\sum X_{\sigma}=1$. Com isso a eq. 3.10 toma a forma:

$$
H_{\sigma}=-\frac{\gamma J}{2} X_{\sigma}-B \delta(\sigma, 0)
$$

Cujo conjunto de valores define um espectro de energia com $p$ niveis, para um spin de Potts na aproximação de campo médio.

Dividindo-se a energia total do sistema, dada pela eq. 3.8 , pelo número total de sítios na rede, tem-se a energia interna por sítio:

$$
U=\frac{1}{N} \sum_{\sigma=0}^{p-1} N_{\sigma} H_{\sigma}
$$

ou,

$$
U=\sum_{\sigma=0}^{p-1} X_{\sigma} H_{\sigma}
$$

Esta última expressão nada mais é que a forma usual para a energia interna por partícula para um sistema físico genérico, isto é, a somatória da energia de cada um dos níveis multiplicada por sua fração de ocupação.

Substituindo-se a eq. 3.11 na eq. 3.13 , obtemos de imediato a forma quadrática:

$$
U=-\frac{\gamma J}{2} \sum_{\sigma=0}^{p-1} X_{\sigma}^{2}-B \sum_{\sigma=0}^{p-1} X_{\sigma} \delta(\sigma, 0)
$$

que é a Hamiltoniana de Hussimi.

Este resultado mostra a coerência das interpretaçoes das grandezas definidas acima. Em especial a eq. 3.11 que define o conjunto de valores $H_{\sigma}$ como um espectro de energia, que terá importância fundamental na aplicação, na próxima seção, da definição de energia interna de ordem $q$ do sistema, e como consequência a determinação do funcional de energia livre de ordem $q$.

\subsection{HAMILTONIANA E ENERGIA LIVRE DE ORDEM $q$.}

O caminho direto para a aplicação da estatística generalizada de Tsallis, a um sistema de spins de Potts na aproximação de campo médio, seria o cálculo da função de partição $Z_{q}(\beta)$, a partir dos valores da hamiltoniana de campo medio do sistema 
$H_{C M}\left(N_{0}, N_{1}, \ldots, N_{p-1}\right)$, dados pela eq. 3.8, levando-se em conta cada um dos possíveis conjuntos de números de ocupação dos níveis de Potts $\left\{N_{0}, N_{1}, \ldots, N_{p-1}\right\}$, sujeitos à condição $\sum N_{\sigma}=N$. Ou seja seria necessário o cálculo de:

$$
Z_{q}(\beta)=\sum_{\sum N_{\sigma}=N}\left[1-\beta(q-1) U_{q}\left(N_{0}, N_{1}, \ldots, N_{p-1}\right)\right]^{\frac{1}{-q}}
$$

e uma vez feito este cálculo obteria-se, via eq. 2.61 , a função energia livre $F_{q}(\beta)$ a qual determinaria todo o comportamento termodinâmico do sistema.

O fato de $Z_{q}(\beta)$ ser expressa por uma somatória de termos elevados à potência $1 / 1-q$, torna o computo desta muito mais complexo do que o cálculo da função de partição na estatítistica de Boltzmmann-Gibbs, mesmo no caso dos modelos mais simples da mecânica estatística, como o calor específico de uma partícula livre [35], ou para uma cadeia linear de spins de Ising[1].

Para contornar essa dificuldade, usou-se como procedimento alternativo a determinação de um funcional $F_{q}\left(T, X_{0}, \ldots, X_{p-1}\right)$, para a energia livre de ordem $q$ por spin do sistema dependente da temperatura e do conjunto de frações de ocupação dos niveis. As frações de ocupação $X_{\sigma}$ são funções da temperatura $\mathrm{T}$, e de um parâmetro de ordem M que será posteriormente identificado como a magnetização espontânea do sistema.

Isto foi feito colocando-se a eq. 2.59 , que define $F_{q}(T)$, na forma:

$$
F_{q}\left(T, X_{0}, \ldots, X_{p-1}\right)=U_{q}\left(T, X_{0}, \ldots, X_{p-1}\right)-T S_{q}\left(T, X_{0}, \ldots, X_{p-1}\right),
$$

que é a composição dos funcionais $U_{q}\left(T, X_{0}, \ldots, X_{p-1}\right)$ e $S_{q}\left(T, X_{0}, \ldots, X_{p-1}\right)$, que representam respectivamente a energia interna e entropia de ordem $q$ por sítio do sistema.

O funcional de energia interna de ordem $U_{q}$, é determinado substituindo-se na eq. 2.30 o conjunto de valores $H_{\sigma}$, eq. 3.10, definido como o espectro de energia para um spin de Potts na aproximação de campo médio. Dessa maneira obtém-se:

$$
U_{q}=\sum_{\sigma=0}^{p-1} P_{\sigma}^{q} H_{\sigma}
$$

onde o conjunto $P=\left\{P_{0}, \ldots, P_{p-1}\right\}$ é a distribuição de probabilidades associada ao espectro de energia de um spin de Potts na aproximação de campo médio.

Cada um dos elementos da distribuição de probabilidade $P_{\sigma}$ pode ser identificado com a respectiva fração de ocupação $X_{\sigma}$, uma vez que, no limite termodinâmico, escolhendo-se 
aleatoriamente um sítio $i$ da rede, a probabilidade do spin nesse sítio estar em um dado estado $\sigma$ será igual a razão entre o número total de spins nesse estado $N_{\sigma}$ e o número total de spins na rede $N$, isto é:

$$
P_{\sigma}=\lim _{N \rightarrow \infty} \frac{N_{\sigma}}{N}=X_{\sigma} .
$$

Com esta identificação entre $P_{\sigma}$ e $X_{\sigma}$ a eq. 3.17 toma a forma:

$$
U_{q}=\sum_{\sigma=0}^{p-1} X_{\sigma}^{q} H_{\sigma}
$$

Substituindo-se explicitamette $H_{\sigma}$ como função das fraçōes de ocupação $X_{\sigma}$, já consideradas como dependentes da temperatura e parâmetro de ordem, chega-se a:

$$
U_{q}(T, M)=-\frac{\gamma J}{2} \sum_{\sigma=0}^{p-1} X_{\sigma}^{q+1}(T, M)-B \sum_{\sigma=0}^{p-1} X_{\sigma}^{q}(T, M) \delta(\sigma, 0) .
$$

Esta expressão é a generalização no âmbito de uma estatística de ordem $q$ da hamiltoniana de Hussimi, que é recuperada de maneira imediata quando $q=1$, como era esperado tendo em vista a necessidade de todos os resultados em uma estatística de ordem $q$ convergirem para os resultados da estatística de Boltzmann-Gibbs quando $q \rightarrow 1$.

O funcional para a entropia de ordem $q$ por sítio é obtido simplesmente pela substituição, na definição de $S_{q}$, da distribuição de probabilidade $P$, pelo conjunto das fraçōes de ocupação, isto é:

$$
S_{q}(T, M,)=\frac{K_{B}}{q-1}\left[1-\sum_{\sigma=0}^{p-1} X_{\sigma}^{q}(T, M,)\right]
$$

Substituindo-se as duas últimas equaçòes na eq. 3.16, chega-se ao funcional $F_{q}(T, M)$ na forma:

$F_{q}(T, M)=-\frac{\gamma J}{2} \sum_{\sigma=0}^{p-1} X_{\sigma}^{q+1}(T, M)-B \sum_{\sigma=0}^{p-1} X_{\sigma}^{q}(T, M) \delta(\sigma, 0)+\frac{T K_{B}}{1-q}\left[1-\sum_{\sigma=0}^{p-1} X_{\sigma}^{q}(T, M)\right]$.

Ou fazendo-se a escolha das unidades de energia, temperatura, e campo externo de modo a tornar $F_{q}(T, M)$ adimensional, tem-se:

$$
F_{q}(T, M)=-\operatorname{sum}_{\sigma=0}^{p-1} X_{\sigma}^{q+1}(T, M)-B \sum_{\sigma=0}^{p-1} X_{\sigma}^{q}(T, M) \delta(\sigma, 0)+\frac{T}{1-q}\left[1-\sum_{\sigma=0}^{p-1} X_{\sigma}^{q}(T, M)\right] .
$$


Embora este funcional por si mesmo não traga nenhuma informação sobre o comportamento do sistema, o fato das frações de ocupação $X_{\sigma}$ dependerem de $T$ e $M$, que são variaveis de estado, permitirá que, na próxima seção, sejam aplicadas as condições gerais de equilíbrio para sistemas termodinâmicos ao funcional $F_{q}(T, M)$, e a partir daí a obtenção de uma relação autoconsitentes envolvendo as variáveis $M, T$, e $B$.

\subsection{RELAÇÃO AUTO-CONSISTENTE PARA A MAGNE- TIZAÇÃO}

Uma condição geral, imposta pela termodinâmica do equilíbrio [8], é que a uma temperatura constante, a variação da energia livre de Helmoltz de um sistema é nula como consequência de uma variação infinitesimal das variáveis extensivas que a define, isto é, $F(T, M)$ é mínima quando o sistema está em equilíbrio.

Extendendo-se esta condição a sistemas magnéticos sujeitos a uma estatística de ordem $q$, e em especial ao sistema de spins de Potts na aproximação de campo médio, dada uma variação infinitesimal do parâmetro de ordem $M$ tem-se que,

$$
\delta F_{q}(T, M)=0,
$$

ou explicitando a dependência do funcional $F_{q}(T, M)$ em relação às frações de ocupação:

$$
\sum_{\sigma=0}^{p-1} \frac{\partial F_{q}}{\partial X_{\sigma}} \frac{\partial X_{\sigma}}{\partial M} \delta M=0,
$$

que leva à forma diferencial da condição de equilíbrio:

$$
\sum_{\sigma=0}^{p-1} \frac{\partial F_{q}}{\partial X_{\sigma}} \frac{\partial X_{\sigma}}{\partial M}=0
$$

uma vez que $\delta M$ é não nula.

Para que esta condição de equilibrio forneça alguma informação a respeito do comportamento desse sistema é necessária a determinação da relação entre as frações de ocupação e as variáveis $M$ e $T$. Isto implica em fazer algumas hipóteses sobre o comportamento do sistema nas temperaturas assintóticas: $T=0$ e $T \rightarrow \infty$. 
Quando $T=0$ o único termo não nulo da eq. 3.16 será $U_{q}$, com este identificando-se com $F_{q}$. Nessa situação o conjunto de fraçoes de ocupação $X_{\sigma}(T, M)$ que minimiza $U_{q}$, e por conseguinte $F_{q}$, será:

$$
X_{\sigma}(T, M)= \begin{cases}1 & \text { para } \sigma=0 \\ 0 & \text { para } \sigma \neq 0\end{cases}
$$

uma vez que os termos $\sum X_{\sigma}^{q+1}(T, M)$ e $\sum X_{\sigma}^{q}(T, M) \delta(\sigma, 0)$ da eq. 3.22 , que estão relacionados respectivamente com a interação dos spins entre si e a interação dos spins com o campo externo, serão menores que a unidade para qualquer outro conjunto de frações de ocupação, ou em outras palavras, a $T=0$ todos os spins estarão no estado de mais baixa energia, com $\sigma=0$ que é aquele em que existe interaçăo deste com o campo externo.

No limite $T \rightarrow \infty$ o termo dominante no funcional energia livre será aquele que envolve a entropia $S_{q}$, o qual é mínimo quando $S_{q}$ é máximo. Como foi visto na sec. 2.2 a distribuição de probabilidades que maximiza a entropia de ordem $q$, é a distribuição uniforme. Assim as frações de ocupação dos niveis de Potts serão todas idênticas, estando os estados igualmente populados, ou seja:

$$
\lim _{T \rightarrow \infty} X_{\sigma}(T, M)=\frac{1}{p}
$$

Para obter-se o comportamento das frações de ocupação entre esses dois limites, supõese um processo quase-estático em que temperatura seja aumentada a partir de $T=0$. Inicialmente todos os spins estarão no estado fundamental, e a medida que a temperatura é elevada um certo número deles irá popular os estados com $\sigma \neq 0$, com suas fraçòes de ocupação sujeitas à condição:

$$
\left.\sum_{\sigma \neq 0}^{p-1} X_{\sigma}(T, M)\right)=1-X_{0}(T, M)=c t e
$$

uma vez que para uma dada temperatura, o número de spins no estado fundamental será constante.

A cada passo do processo, isto é, para cada valor de $T$, o sistema estará em equilíbrio, sendo portanto aplicável o princípio de entropia máxima. Este princípio obriga que a variação da quantidade $S_{q}\left(X_{1}, \ldots, X_{p-1}\right)$ definida como:

$$
S_{q}\left(X_{1}, \ldots, X_{p-1}\right)=S_{q}\left(X_{0}, X_{1}, \ldots, X_{p-1}\right)-S_{q}\left(X_{0}\right)=\frac{K_{B}}{q-1}\left[1-\sum_{\sigma \neq 0}^{p-1} X_{\sigma}^{q}\right],
$$


que nada mais é que a contribuição para $S_{q}$ dos spins que estão fora do estado fundamental, seja nula para uma variação arbitrária do conjunto de frações de ocupação incompleto $\left\{X_{1}, \ldots, X_{p-1}\right\}$, obedecendo a condição 3.29. É evidente que como no caso de $S_{q}$ para uma distribuição completa $\left\{X_{0}, X_{1}, \ldots, X_{p-1}\right\}$, a entropia para a distribuição incompleta será máxima quando:

$$
X_{1}(T, M)=X_{2}(T, M)=\ldots=X_{p-1}(T, M)=X(T, M) .
$$

Isto é, no equilíbrio todos os estados com $\sigma \neq 0$ estarão igualmente populados para qualquer temperatura. $\mathrm{E}$ assim a condição de normalizaçăo para o conjunto de frações de ocupação reduz-se a:

$$
\sum_{\sigma=0}^{p-1} X_{\sigma}(T, M)=X_{0}(T, M)+(p-1) X(T, M)=1 .
$$

Com o aumento da temperatura crescerá o número de spins que deixarão o estado fundamental e irão popular de maneira uniforme os níveis $\operatorname{com} \sigma \neq 0$, até uma temperatura em que $X_{0}(T, M)=X(T, M)$ quando todos os estados estarão igualmente populados, além da qual não haverá mudança nas frações de ocupação. Comportamento este que antecipa a existência de uma transição de fase do sistema.

Fazendo-se a suposição de que as frações de ocupação não dependem explicitamente da temperatura, isto é, $X_{\sigma}(T, M)=X_{\sigma}(M)$, com $M=M(T)$ tal que:

$$
\lim _{T \rightarrow \infty} M(T)=0 .
$$

Tem-se que a forma linear mais simples para a relação entre as frações de ocupação e o parâmetro de ordem, que obedece a condição 3.32 , é dada por:

$$
X_{\sigma}= \begin{cases}X_{0}=\frac{1+(p-1) M(T)}{p} & \text { para } \sigma=0 \\ X=\frac{1-M(T)}{p} & \text { para } \sigma \neq 0 .\end{cases}
$$

Esta relação entre as frações de ocupação e o parâmetro de ordem leva a uma identificação deste com a magnetização de maneira quase imediata, uma vez que esta é a variável termodinamicamente conjugada ao campo externo, e derivando-se o funcional de energia livre de ordem $q$ em relação a $B$, obtém-se $X_{0}$. Assim o parâmetro de ordem $M$ pode ser interpretado como uma forma normalizada da magnetização. 
A existência de apenas dois valores distintos para as frações de ocupação, leva a reescrever-se a condição de equilíbrio, eq. 3.26 como:

$$
\frac{\partial F_{q}}{\partial X_{0}} \frac{\partial X_{0}}{\partial M}+\frac{\partial F_{q}}{\partial X} \frac{\partial X}{\partial M}=0
$$

e usando a expressão 3.34 para o cálculo das derivadas de $X_{0}$ e $X$ em relação a $M$, a condição de equilíbrio torna-se:

$$
(p-1) \frac{\partial F_{q}}{\partial X_{0}}-\frac{\partial F_{q}}{\partial X}=0 .
$$

Uma vez que o funcional $F_{q}$ depende de $B$ e $T$, e as frações de ocupação $X_{0}$ e $X$ dependem de $M$, a eq. 3.36 é em última análise a equação de estado do sistema pois, em princípio, poderia ser solucionada para qualquer uma destas três variáveis em função das outras duas.

Escrevendo-se $F_{q}$ em relação a $X_{0}$ e $X$ têm-se,

$$
F_{q}(T, M)=-\left[X_{0}^{q+1}+(p-1) X^{q+1}\right]-B X_{0}^{q}+\frac{T}{1-q}\left[1-X_{0}^{q}-(p-1) X^{q}\right],
$$

e substituindo-se esta na condição 3.36 ,

$$
-(q+1)\left[X_{0}^{q}-X^{q}\right]-q B X_{0}^{q-1}+\frac{q T}{1-q}\left[X_{0}^{q-1}-X^{q-1}\right]=0,
$$

que pode ser rearranjada na forma:

$$
\left(\frac{X_{0}}{X}\right)^{q-1}=1+\frac{\left(q^{2}-1\right)}{q T} X\left[\left(\frac{X_{0}}{X}\right)^{q}-1\right]+\frac{(q-1)}{q T} B\left(\frac{X_{0}}{X}\right)^{q-1} .
$$

Colocando-se o termo a esquerda desta última equação explicitamente em funcão de $M$, tomando-se o logarítmo em ambos os lados, e dividindo-se por 2, chega-se à relação:

$$
\frac{1}{2} \ln \left[\frac{1+(p-1) M}{1-M}\right]=\frac{1}{2(q-1)} \ln \left\{1+\frac{\left(q^{2}-1\right)}{q T} X\left[\left(\frac{X_{0}}{X}\right)^{q}-1\right]+\frac{(q-1)}{q T} B\left(\frac{X_{0}}{X}\right)^{q-1}\right\}
$$

É fácil verificar que o lado esquerdo desta equação reduz-se a expressão usual para a função arcotangente hiperbólica de $M$ no caso de um sistema de spins de Ising, onde 
$p=2$. E da definição de arcotangente hiperbólica de ordem $p$, vide apêndice I, segue que,

$$
\operatorname{arctanhp}(M)=A_{q}(M, B, T),
$$

ou invertendo-se a função $\operatorname{arctanh}(M)$,

$$
M=\operatorname{tanhp}\left[A_{q}(M, B, T)\right],
$$

onde $A_{q}(M, B, T)$ foi definida como:

$$
A_{q}(M, B, T)=\frac{1}{2(q-1)} \ln \left\{1+\frac{\left(q^{2}-1\right)}{q T} X\left[\left(\frac{X_{0}}{X}\right)^{q}-1\right]+\frac{(q-1)}{q T} B\left(\frac{X_{0}}{X}\right)^{q-1}\right\} .
$$

Estas duas últimas expressòes fornecem a relação auto-consistente para a magnetização que é o principal resultado deste capítulo. Para evidenciar sua coerência com a estatística de Boltzmann-Gibbs é necessário o cálculo de seu limite quando $q \rightarrow 1$. Notando que a relação 3.42 depende de $q$ apenas através da função $A_{q}(M, T, B)$, expande-se o logarítmo contido nesta, em uma série de potências em torno de $\ln (1)$, e chega-se a:

$$
A_{q}(M, T, B)=\left\{\frac{(q+1)}{2 q T} X\left[\left(\frac{X_{0}}{X}\right)^{q}-1\right]+\frac{1}{2 q T} B\left(\frac{X_{0}}{X}\right)^{q-1}+\theta^{2}(q-1)\right\} .
$$

É trivial mostrar que fazendo-se $q \rightarrow 1$, todos os termos desta série proporcionais a ordem superior a dois em $(q-1)$ tendem a zero, restando apenas o primeiro termo. Assim,

$$
\lim _{q \rightarrow 1} A_{q}(M, T, B)=\frac{1}{T}\left\{\left[X_{0}-X\right] X+B\right\}=\frac{1}{T}(M+B) .
$$

Recobrando a relação auto-consistente para o modelo de Potts na aproximação de campo médio, na estatística de Boltzmann-Gibbs:

$$
M=\tanh p\left[\frac{1}{T}\left(M+\frac{B}{2}\right)\right],
$$

e em especial no caso $p=2$, modelo de Ising, quando a tangente hiperbólica de ordem $p$ reduz-se à tangente hiperbólica usual. 


\section{Capítulo 4}

\section{MAGNETIZAÇÃO ESPONTÂNEA E EQUILÍBRIO MACROSCÓPICO.}

\subsection{RELAÇÃO AUTO-CONSISTENTE COMO UM SISTE- MA DINÂMICO}

Como foi mencionado no capítulo anterior, a solução da relação auto-consistente para a magnetização, eq. 3.42, para uma das variáveis em relação as outras duas levaria à obtenção da equação de estado do sistema e a partir desta à completa determinação do seu comportamento termodinâmico. Contudo sua complexidade, cujo lado direito envolve várias funções transcendentais, faz necessária a utilização de métodos numéricos para sua resolução, entende-se por soluções desta os pontos em que a reta com inclinação de $45^{0}$ intercepta a função tanhp $\left[A_{q}(M, B, T)\right]$ para um dado par de valores de $B$ e $T$, como é mostrado na fig. 4.1 .

O algorítmo utilizado na obtenção de tais soluções foi baseado em resultados elementares da teoria dos sistemas dinâmicos discretos [10]. Para aplicar-se esses resultados, a relação auto-consistente foi colocada na forma de um mapa, ou aplicação, do domínio em que $M$ está definido $D=[-1 /(p-1), 1]$, sobre si mesmo. Este mapa é dado pela relação auto-consistente colocada na forma de uma relação de recorrência que define um sistema dinâmico discreto:

$$
M_{n+1}=\operatorname{tanhp}\left[A_{q}\left(M_{n}, B, T\right)\right] .
$$

Onde dado um valor inicial $M_{0} \in D$ fica definido, através do mapa 4.1, um conjunto de pontos $\left\{M_{0}, M_{1}, \ldots, M_{\infty}\right\}$ denominado órbita do ponto $M_{0}$.

Uma classe especial de pontos pertencentes a $D$, são aqueles invariantes em relação ao 


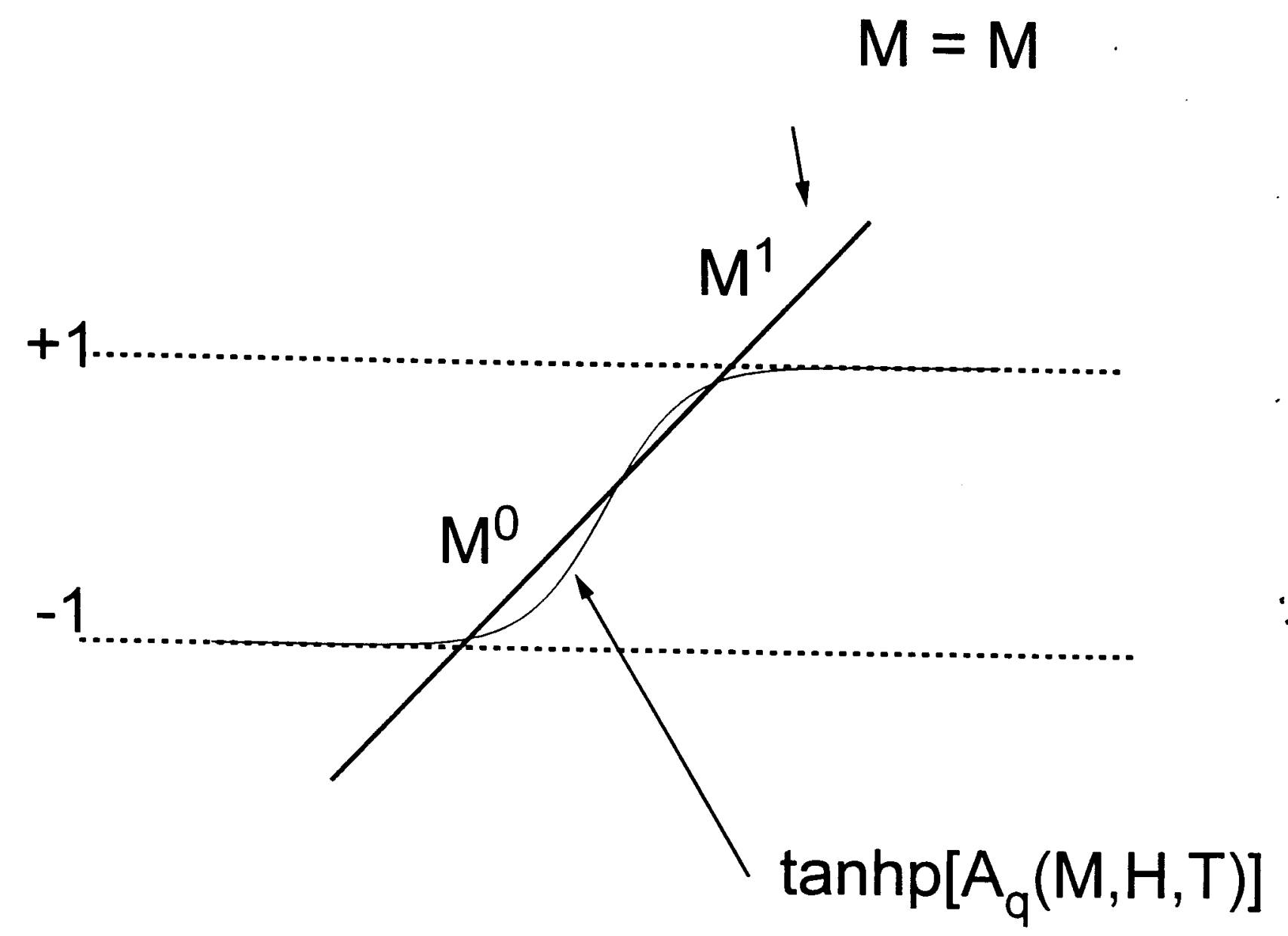

Figura 4.1: $M^{0}$ e $M^{1}$ são soluções para a relação auto-consistente obtidas pela interseção da funçào tanhp $\left[A_{q}(M, B, T)\right] \operatorname{com}$ a reta $M=M$. Para $p=2.0, q=1$, e $T=0.7$ 
mapa 4.1, isto é, seja $M^{*}$ um desses pontos tem-se:

$$
M^{*}=\tanh \left[A_{q}\left(M^{*}, B, T\right)\right] .
$$

Estes pontos, denominados pontos fixos do mapa, representam as soluções desejadas para a relação de auto-consistente. Assim o problema da obtenção da magnetização, para um determinado par de valores de $B$ e $T$, reduz-se a determinação'dos pontos fixos do mapa 4.1.

A classificação de um ponto fixo em estável ou instável é feita através da análise da dinâmica do mapa nas vizinhanças do mesmo.

Expandindo-se o mapa em uma série de Taylor, nas vizinhanças de um ponto fixo $M^{*}$, tem-se:

$M_{n+1}=\operatorname{tanhp}\left[A_{q}\left(M^{*}, B, T\right)\right]+\frac{\partial}{\partial M}\left\{\operatorname{tanhp}\left[A_{q}(M, B, T)\right]\right\}_{M=M^{*}}\left(M_{n}-M^{*}\right)+\theta^{2}\left(M_{n}-M^{*}\right)$

Notando-se que pela definição de ponto fixo o primeiro termo desta série é idêntico a $M^{*}$, desprezando-se os termos de ordem superior a dois, e tomando-se o módulo em ambos os lados da equação chega-se a:

$$
\frac{\left|\left(M_{n+1}-M^{*}\right)\right|}{\left|\left(M_{n}-M^{*}\right)\right|} \simeq \Lambda
$$

onde,

$$
\Lambda=\left|\frac{\partial}{\partial M}\left\{\operatorname{tanhp}\left[A_{q}(M, B, T)\right]\right\}_{M=M^{*}}\right|
$$

Para classificarmos o ponto fixo $M^{*}$ tem-se que analisar duas hipóteses para o fator $\Lambda$.

I ) $\Lambda>1$.

Neste caso é facil observar-se que, $\left|\left(M_{n+1}-M^{*}\right)\right|>\left|\left(M_{n}-M^{*}\right)\right|$, isto é, dado um ponto $M_{n}$ nas vizinhanças de $M^{*}$ sua órbita tenderá a afastar-se de $M^{*}$, fig. $4.2(\mathrm{a})$, e será classificado como um repulsor ou ponto fixo instável.

II ) $\Lambda<1$. 


\section{$M_{n} \quad M_{n+1} M^{*} M_{n+1} M_{n}$}

(a)

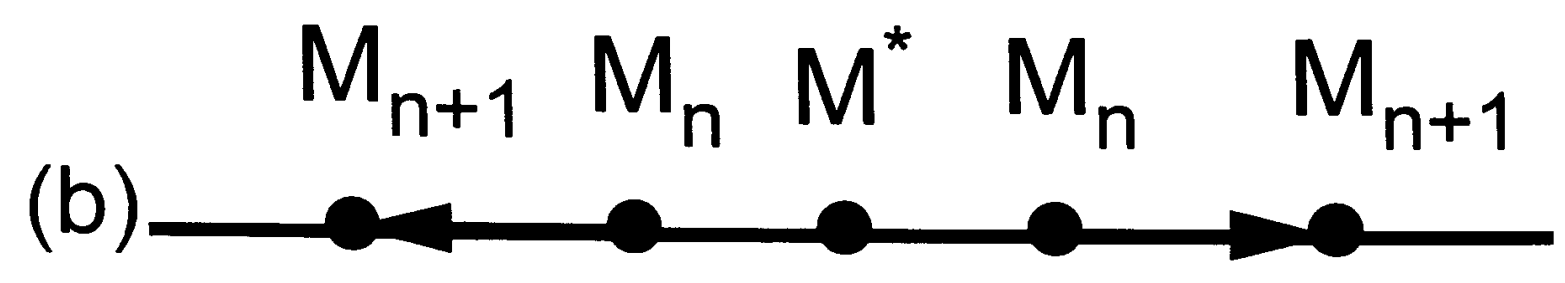

Figura 4.2: Dinâmica do mapa nas vizinhanças de um ponto fixo $M^{*}$. (a) $M^{*}$ é um ponto fixo instável ou repulsor. (b) $M^{*}$ é um ponto fixo estável ou atrator.

Neste caso $\left|\left(M_{n+1}-M^{*}\right)\right|<\left|\left(M_{n}-M^{*}\right)\right|$, que implica que a órbita de um ponto nas vizinhanças do ponto $M^{*}$, fig. 4.2 (b), tenderá a aproximar-se deste, que será classificado como um atrator ou ponto fixo estável.

Outro conceito importante na teoria dos sistemas dinâmicos discretos, é o de bacia de atraçào para um ponto fixo estavél $M^{*}$. Esta é definida como o subconjunto do domínio do mapa, cujas órbitas no limite $n \rightarrow \infty$ tendem a $M^{*}$. A determinação destes conjuntos, que são abertos e cujos fechos são denominados conjuntos de Julia, é uma tarefa que está longe de ser trivial para a maioria dos mapas não-lineares, uma vez que têm uma estrutura topológica extremamente rica, sendo na maioria das vezes multifractais [26, 7].

Os métodos iterativos usuais do cálculo numérico para a solução de equações [11], como o método de Newton-Raphson, consistem basicamente em associar-se a equação em questão um mapa $X_{n+1}=X_{n+1}\left(X_{n}\right)$, cujos pontos fixos são as soluções procuradas. Tomando-se um valor inicial arbitrário $X_{0}$ suposto pertencente a bacia de atração de uma ponto fixo estável $X^{*}$, observa-se a órbita do mesmo, até que a quantidade $\left|X_{n+1}-X_{n}\right|$ 
seja menor que a precisão desejada.

A principal razão porque não utilizou-se aqui estes métodos é que estes fornecem apenas os ponto fixos estáveis [33] e, como será visto na terceira seção deste capítulo, a estabilidade ou não de um ponto fixo estará ligada à estabilidade macroscópica do sistema.

$\mathrm{O}$ algoritmo destinado a determinar os pontos fixos do mapa 4.1, e indicar a estabilidade dos mesmos, para um determinado par de valores de $B$ e $T$, foi construído a partir da análise da dinâmica dos pontos extremos de um sub-intervalo fechado $\left[M_{i}^{0}, M_{i}^{1}\right]$, com $\left|M_{i}^{1}-M_{i}^{0}\right|<<1$, pertencente ao domínio da magnetização $D$. O primeiro passo dessa análise é a definição, utilizando-se as primeira interaçõe dos pontos $M_{i}^{0}$ e $M_{i}^{1}$ denominadas respectivamente $M_{i+1}^{0}$ e $M_{i+1}^{1}$, as quantidades:

$$
\left\{\begin{array}{l}
\Delta^{0}=M_{i+1}^{0}-M_{i}^{0} \\
\Delta^{1}=M_{i+1}^{1}-M_{i}^{1}
\end{array} .\right.
$$

Que medem o deslocamento das órbitas de $M_{i}^{0}$ e $M_{i}^{1}$ através da primeira iteração do mapa 4.1. Com respeito aos sinais de $\Delta^{0}$ e $\Delta^{1}$ existem quatro possibilidades, uma vez descartada a hipótese de $M_{i}^{0}$ e $M_{i}^{1}$ serem pontos fixos.

As duas primeiras são: $\Delta^{0}<0$ e $\Delta^{1}<0$, ou, $\Delta^{0}>0$ e $\Delta^{1}>0$, e equivalem a afirmação de que as órbitas de $M_{i}^{0}$ e $M_{i}^{1}$ estão deslocando-se no mesmo sentido ao longo do intervalo $D$, aproximando-se de um mesmo atrator $M^{*}$, a esquerda de $M_{i}^{0}$ no primeiro caso, ou a direita de $M_{i}^{1}$ no segundo, como mostra a fig. 4.3 (a) e (b). Isto leva a concluir pela inexistência de um ponto fixo no intervalo $\left[M_{i}^{0}, M_{i}^{1}\right]$. As outras duas possibilidades devem ser analisadas separadamente, uma vez que levarão à distinção entre a existência de um ponto fixo estável ou instável no intervalo $\left[M_{i}^{0}, M_{i}^{1}\right]$.

No caso $\Delta^{0}<0$ e $\Delta^{1}>0$, as órbitas de $M_{i}^{0}$ e $M_{i}^{1}$ estão evoluindo em sentidos opostos, com a órbita de $M_{i}^{0}$ caminhando para a esquerda e a de $M_{i}^{1}$ caminhando para a direita, fig. 4.3 (c). Esta dinâmica leva à conclusão de que as órbitas de $M_{n}^{0}$ e $M_{i}^{1}$ estão afastandose de um repulsor $M^{*}$ que existe entre esses pontos. Portanto podemos concluir que há um ponto fixo instável no intervalo $\left[M_{i}^{0}, M_{i}^{1}\right]$.

Analogamente ao caso anterior, quando $\Delta^{0}>0$ e $\Delta^{1}<0$ as órbitas de $M_{i}^{0}$ e $M_{i}^{1}$ evoluem em sentidos opostos, mas com a órbita de $M_{i}^{0}$ caminhando para a direita, e a de $M_{i}^{1}$ caminhado para a esquerda. Que significa a existência de um atrator, ou ponto fixo estável no intervalo $\left[M_{i}^{0}, M_{i}^{1}\right]$, fig. 4.3 (d). 


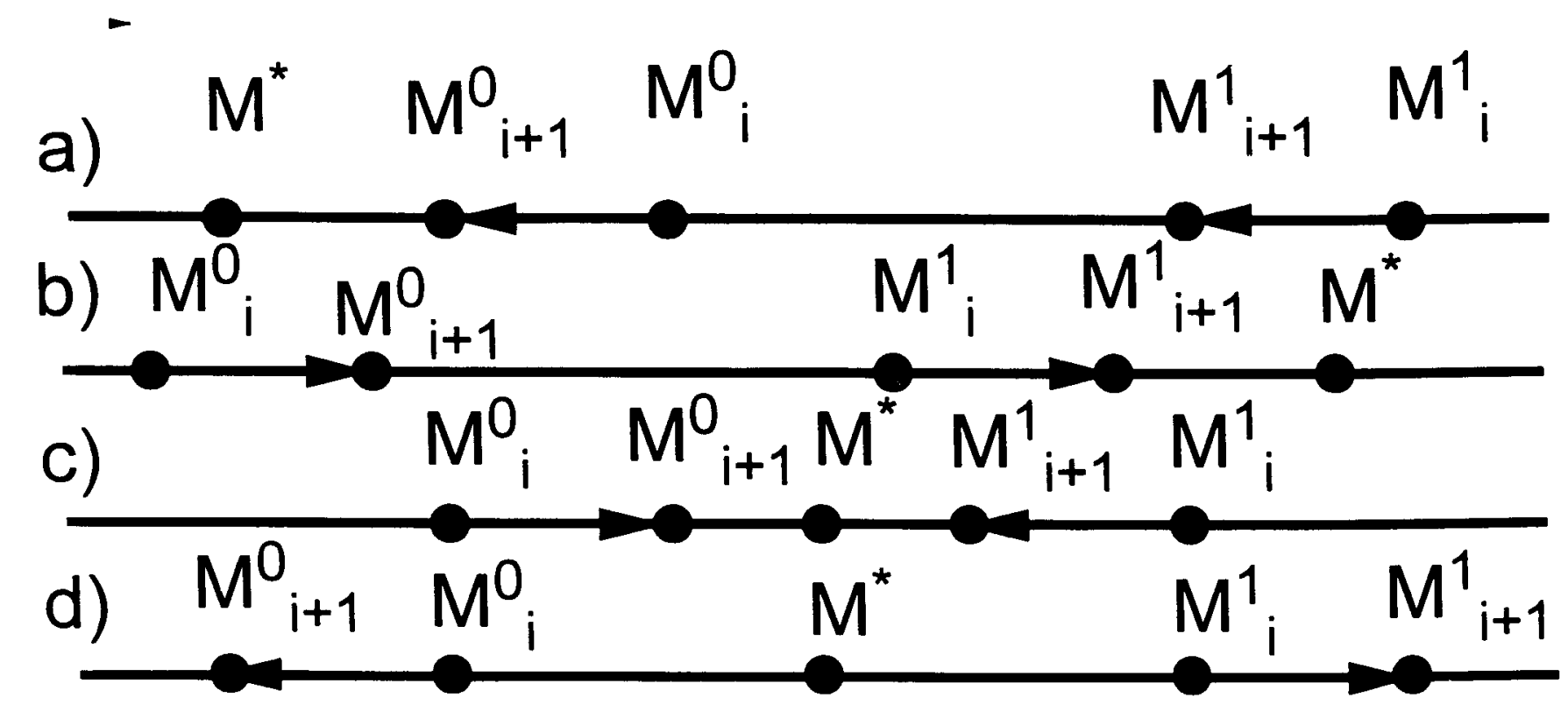

Figura 4.3: Dinâmica dos extremos do intervalo $D_{i}=\left[M_{i}^{0}, M_{i}^{1}\right]$ na vizinhança de um ponto fixo. Onde $\Delta^{0}=\left(M_{i+1}^{0}-M_{i}^{0}\right)$ e $\Delta^{1}=\left(M_{i+1}^{1}-M_{i}^{1}\right)$ (a) $\Delta^{0}<0$ e $\Delta^{1}<0: M^{*}$ esta a esquerda de $D$ (b) $\Delta^{0}>0$ e $\Delta^{1}>0: M^{*}$ esta a direita de $D$ (c) $\Delta^{0}>0$ e $\Delta^{1}<0$ : $M^{*} \in D$ e é estável (d) $\Delta^{0}<0$ e $\Delta^{1}>0: M^{*} \in D$ e é instável 
Dividindo-se o domínio da magnetização em um número $N$ de intervalos $\left[M_{i}^{0}, M_{i}^{1}\right]$ de comprimento $\Delta=(p-2) / N(p-1)$, onde $M_{i}^{0}=\Delta \times i-1 /(p-1)$, e $M_{i+i}^{1}=\Delta \times(i+1)-$ $1 /(p-1)$, com $i=0,1,2, \ldots N-1$, e aplicando-se em cada um destes intervalos, o processo descrito nos parágrafos anteriores, a existência ou não de pontos fixos e sua estabilidade, vide o fluxograma na fig. 4.4, teremos computado todos os pontos fixos do mapa, para uma determinada temperatura e campo, com uma precisão, que cresce inversamente ao número de sub-intervalos $N$ em que o domínio da magnetização for subdividido.

\subsection{DETERMINÇÃO NUMÉRICA DA MAGNETIZAÇÃO ESPONTÂNEA.}

Uma das características mais importantes de um sistema magnético é a variação da magnetização com a temperatura. Dentro da metodologia utilizada aqui determinar-se esta variação é essencial, uma vez que sustituindo-se esta no funcional de energia livre por spin de ordem $q$ este fica plenamente definido em função da magnetização, do campo externo, e temperatura, por seu intermédio todo o comportamento termodinâmico do sistema pode, em princípio, ser obtido. Assim este cálculo é equivalente ao cálculo direto de partição de ordem $q$.

O caso de maior interessante é o da variação da magnetização espontânea, isto é, quando $B=0$, uma vez que esta nos mostra como o sistema reagirá a flutuações das condições do campo externo, e pemitirá, o que será feito na próxima seção, verificar a relação entre a dinâmica do mapa 4.1 e a estabilidade dos estados macroscópicos do sistema.

O algorítmo descrito na seção anterior que determina os pontos fixos da relação de recorrência, e a estabilidade dos mesmos, para uma dada temperatura e campo constantes, foi utilizado no cálculo numérico das curvas de magnetização espontânea em função da temperatura, e através destas verificou-se a influência do parâmetro $q$ introduzido pela estatística de Tsallis.

O programa utilizado nesse cálculo, toma um número de pontos NPT, igualmente espaçados, no intervalo de temperatura em que se deseja investigar o comportamento da magnetização espontânea. Para cada um desses pontos determinam-se os pontos fixos 


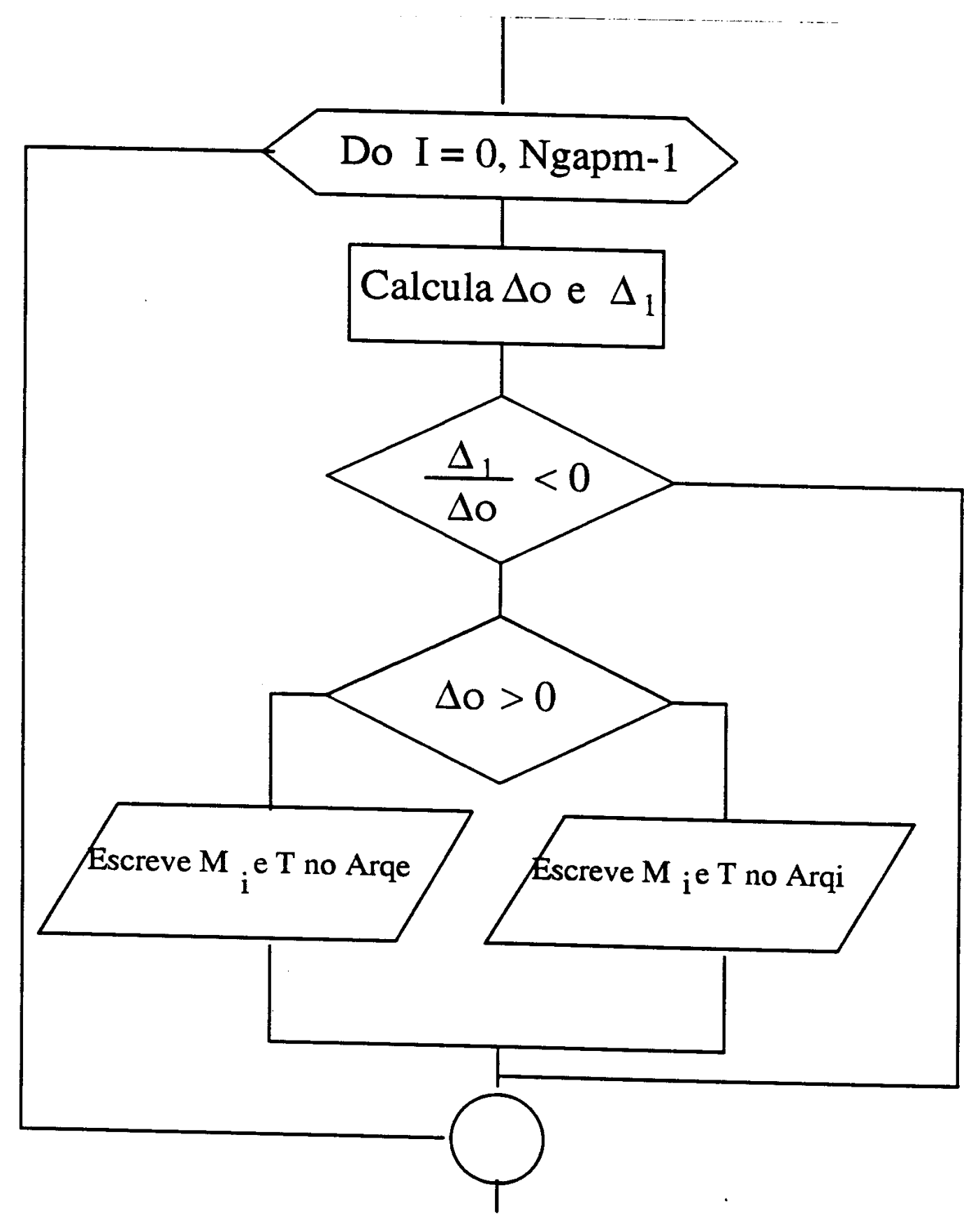

Figura 4.4: Fluxograma do algorítmo utilizado na determinação dos pontos fixos do mapa e sua estabilidade. 
da relação de recorrência, com $B=0$, dentro de um intervalo de precisão da ordem de $(p-2) /(p-1) N G A P S$, onde NGAPS é o número de subintervalos em que o domínio da magnetização é dividido, e fornece um indicador IND, igual a 1 ou 0 , comforme a estabilidade ou não de cada ponto fixo encontrado.

Em primeiro lugar foram obtidas as curvas de magnetização espontânea para diversos valôres da variável de Potts $p$, com um valor do parâmetro $q$ fixo próximo de um, tipicamente 0.99999 , pois utilizando $q=1$ haveria a ocorrência de um erro computacional quando do cálculo do valor da relação de recorrência, dado que nesta o argumento da tangente hiperbólica de ordem $p$, a função $A_{q}(M, B, T)$, depende do inverso de $(q-1)$, e juntamente com o fato de qualquer máquina real ter uma precisão finita haveria uma divergência numérica.

O conhecimento das curvas de magnetização espontânea, quando $q$ é próximo da unidade, tem importância também para ter-se um padrão de comparação com outros resultados que venham a ser obtidos em uma estatística de Tsallis, e aqueles obtidos para o mesmo sistema no contexto da estatística de Boltzmmanm-Gibbs. Posteriormente, no próximo capítulo, o comportamento do sistema quando $q \simeq 1$, será importante para a análise da variação da temperatura crítica com o parâmetro $q$.

A fig 4.5 mostra as curvas para a magnetização espontânea em função da temperatura, com a variável de Potts $p$, assumindo os valôres $1.5,1.75,2.0,3.0,4.0, \operatorname{com} q=0.9999$, e onde as linhas pontilhadas indicam a instabilidade da solução correspondente.

Estas curvas são típicas para a magnetização espontânea do modelo de Potts na aproximação de campo médio na estatística de Boltzmann-Gibbs [5], em particular a curva com $p=2$, quando o modelo de Potts reduz-se ao modelo de Ising, a qual aparece na maioria dos livros textos de mecânica estatística que tratam da aproximação de campo médio.

Em todas elas vemos que o valor $M=0$ é uma solução para a magnetização espontânea para qualquer temperatura, como poderia ser verificado facilmente substituindo-se este valor na relação de recorrência. Quanto a esta solução deve ser notado ainda, que, em todas as curvas, para altas temperaturas ela é estável e única, perdendo este caráter quando a temperatura cai abaixo de um certo valor. Outra caracteristíca, comum a todas as curvas, é o aparecimento de dois novos ramos abaixo de uma determinada temperatura de bifurcação, isto é, a existência de duas soluções diferentes de zero. 
O único caso em que a curva é simétrica em relação ao eixo $T$, e onde a temperatura de bifurcação e perda de estabilidade da solução nula coincidem, é aquele em que $p=2$, e por uma obvervação grosseira da fig. 4.5 (c), que será refinada no próximo capítulo, vemos que esta é aproximadamente igual a 1.0, como prevê a teoria de campo médio para o modelo de Ising. Sendo essa a primeira indicação da exatidão do método de cálculo utilizado.

O próximo passo é a investigação de como estas curvas são afetadas com a variação do parâmetro de $q$, isto é, como a passagem da estatística de Boltzman-Gibbs para uma estatística de Tsallis afetará o comportamento da magnetização espontânea do sistema.

Para um dado valor da variável de Potts $p$, calculamos as curvas da magnetização espontânea com o parâmetro $q$ assumindo diferentes valores. Nas figs. 4.6 a 4.10 tem-se as curvas com os valores de $p$ utilizados na fig 4.5. Em cada uma destas o parâmetro $q$ apresenta diversos valores.

$O$ resultados qualitativos mais importantes que podem ser observados em cada uma dessas séries de curvas, como efeito da variação do parâmetro $q$, são: a inexistência de alteração em suas estruturas, isto é, existência de uma temperatura de bifurcação, simetria em relação ao eixo $T$, modo como a solução $M=0$ torna-se instável a um certa temperatura, etc; e um progressivo "achatamento" das curvas em direção do eixo $M$ quando o valor de $q$ é reduzido.

\subsection{DINÂMICA DO MAPA E ESTABILIDADE MACROS- CÓPICA}

As curvas de magnetização espontânea obtidas na seção anterior são, do ponto de vista da teoria dos sistemas dinâmicos discretos, diagramas dos pontos fixos do mapa 4.1, que indicam o valor e a estabilidade dos mesmos no eixo $M$, para um determinado intervalo de temperatura quando $B=0$. Esta visão permite a determinaç o a dinâmica dos pontos pertencentes ao plano $M \times T$ com relação ao mapa 4.1, e baseado nestas fazer uma análise qualitativa do comportamento termodinâmico macroscópico do sistema.

Cada ponto do plano $M \times T$, com $B=0$, representa um estado macroscópico do sistema. Uma vez que as condições de equilíbrio termodinâmico, discutidas no capítulo 

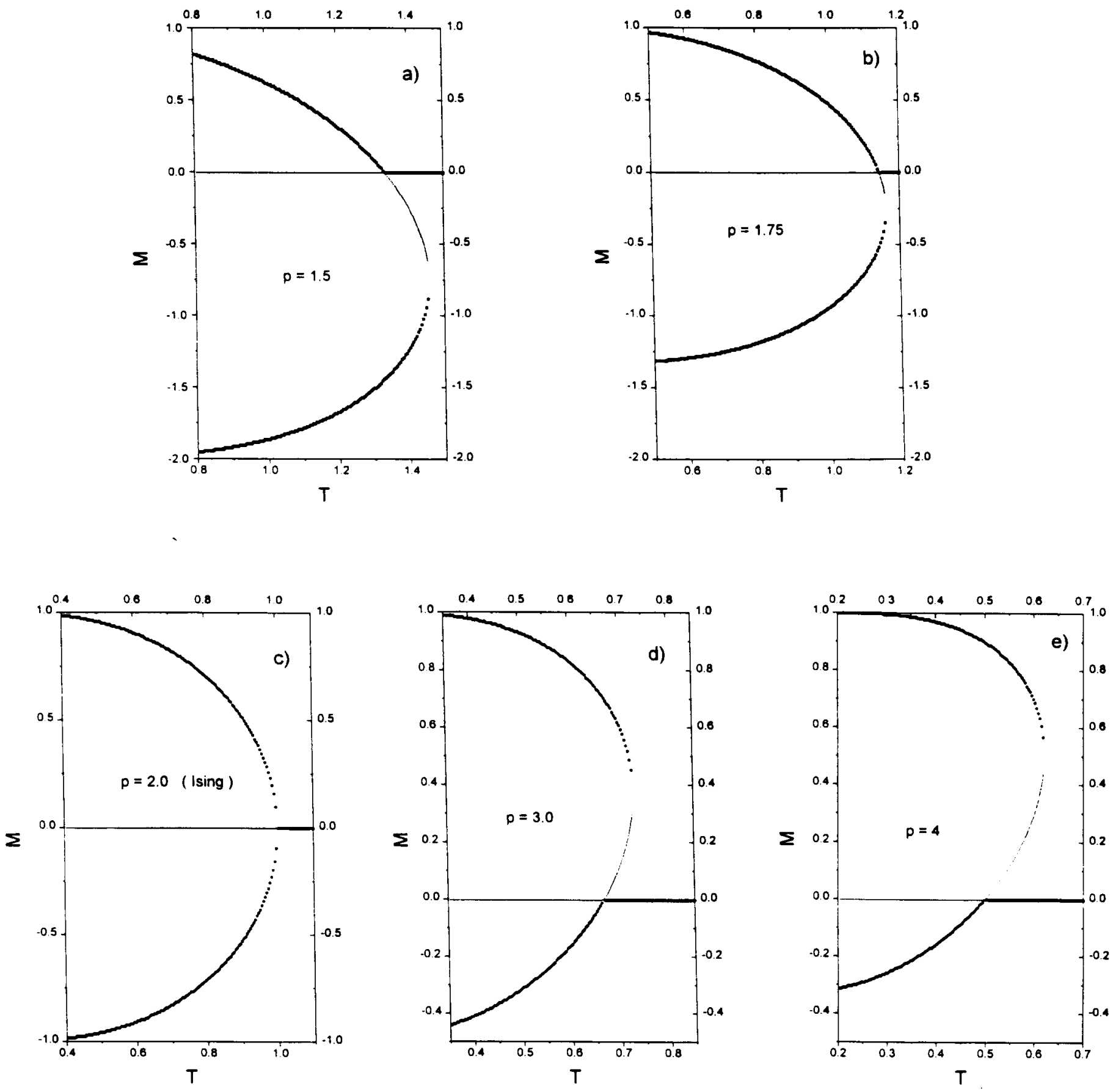

Figura 4.5: Magnetização espontânea em função da temperatura com $q \simeq 1.0$ e a variável de Potts assumindo os valores: (a) $p=1.5$, (b) $p=1.75$, (c) $p=2.0$, (d) $p=3.0$, (e) $p=4.0$. 

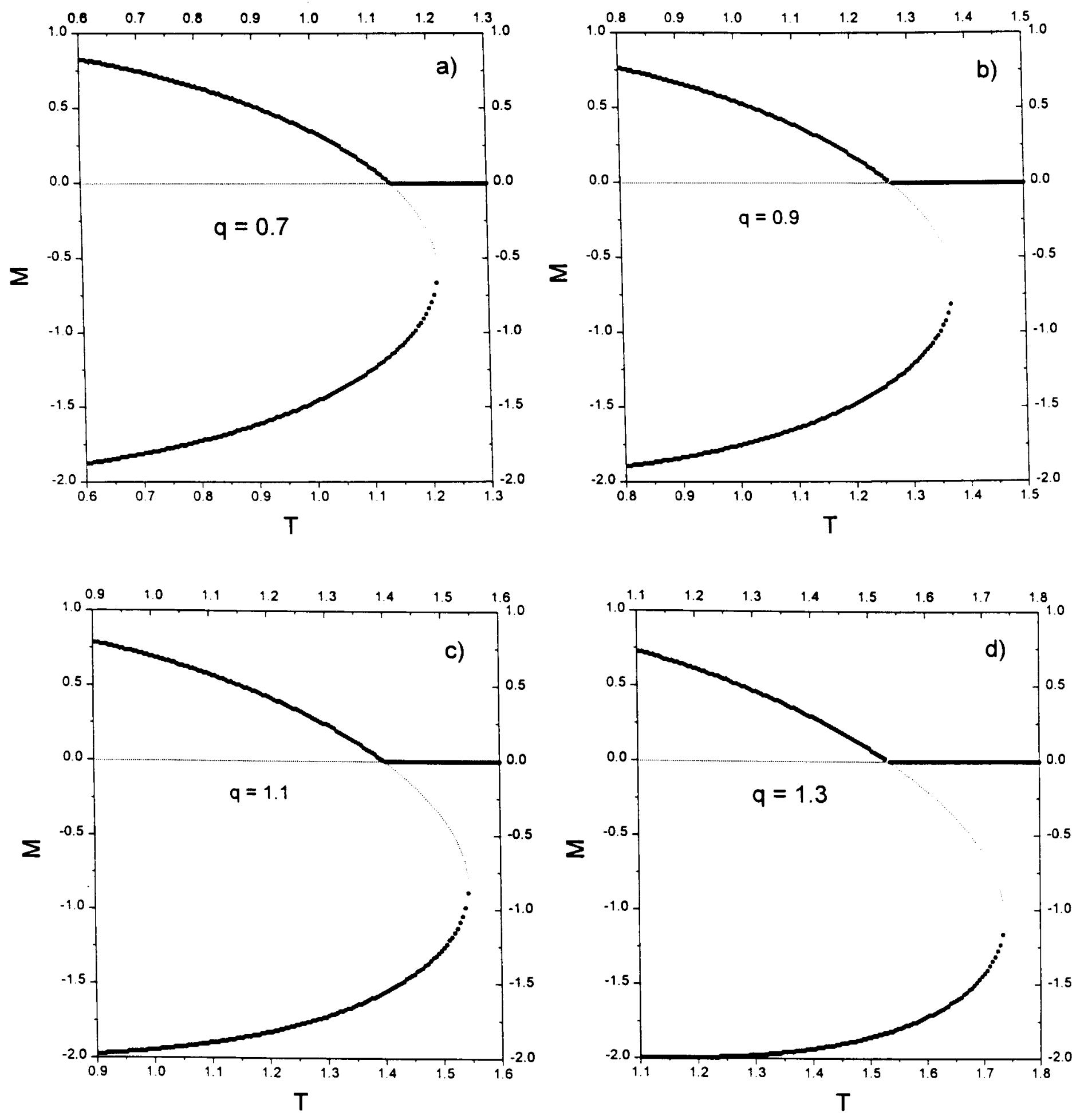

Figura 4.6: Magnetização espontânea quando a variável de Potts $p=1.5$ e o parâmetro $q$ assume os valores:(a) $q=0.7$,(b) $q=0.9$, (c) $q=1.1$, (d) $q=1.3$. 

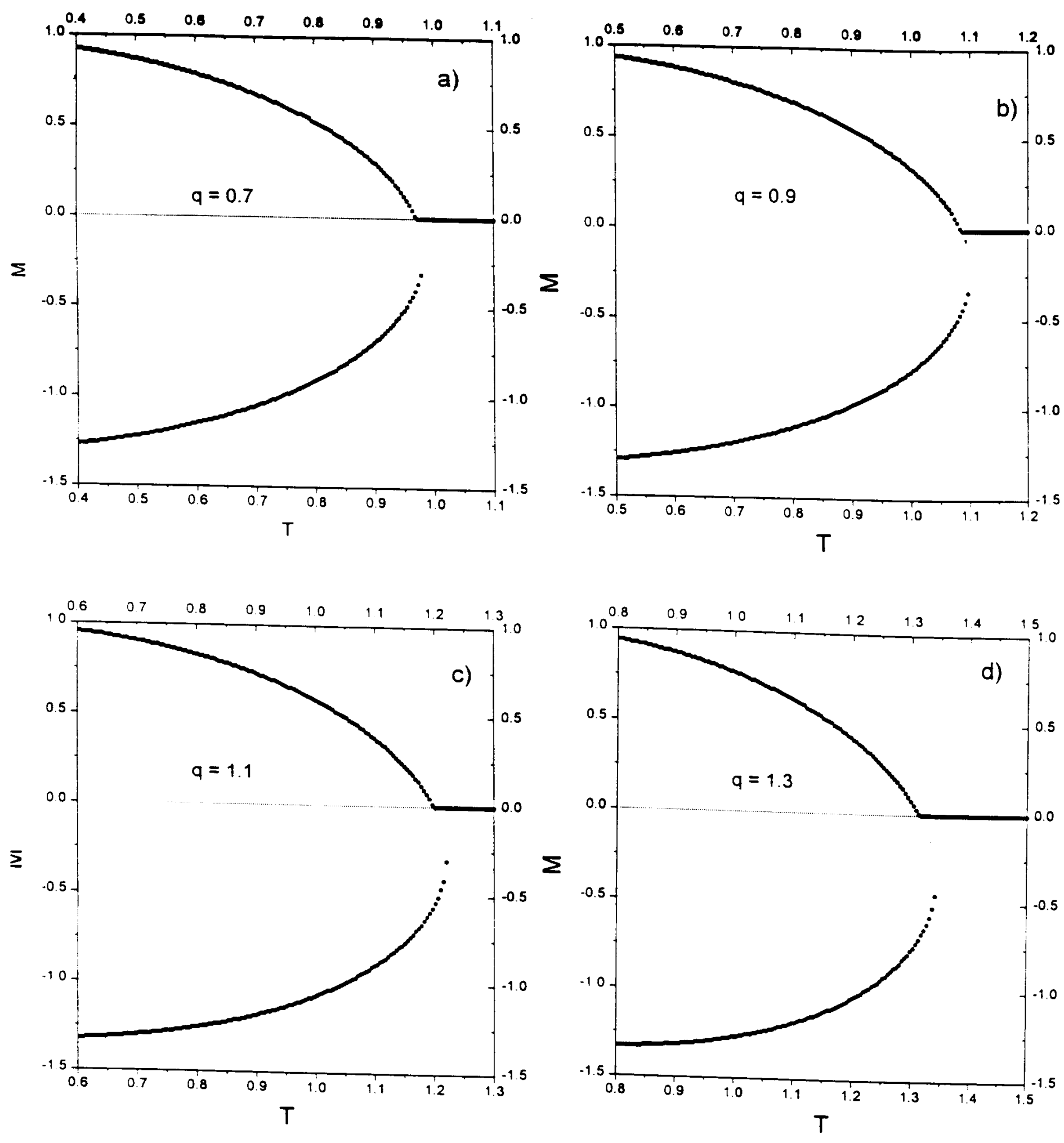

Figura 4.7: Magnetização espontânea quando a variável de Potts $p=1.75$ e o parâmetro $q$ assume os valores:(a) $q=0.7$,(b) $q=0.9$, (c) $q=1.1$,(d) $q=1.3$. 

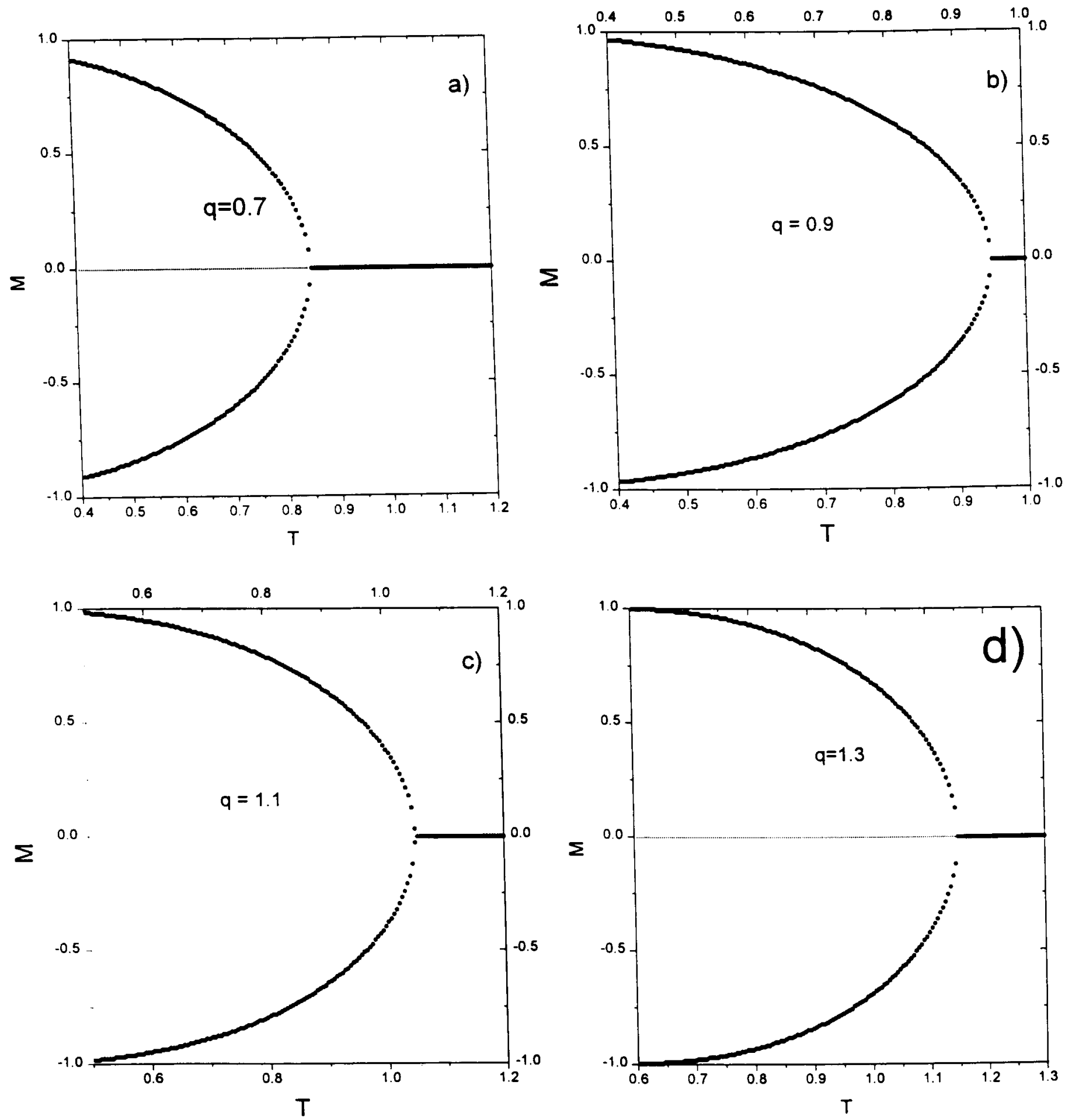

Figura 4.8: Magnetização espontânea quando a variável de Potts $p=2.0$. e o parâmetro $q$ assume os valores:(a) $q=0.7$,(b) $q=0.9$, (c) $q=1.1$,(d) $q=1.3$.

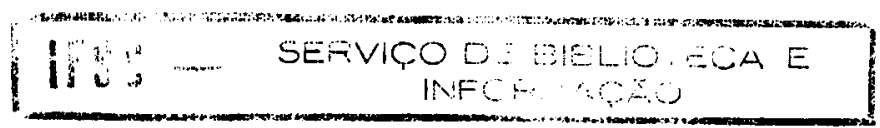



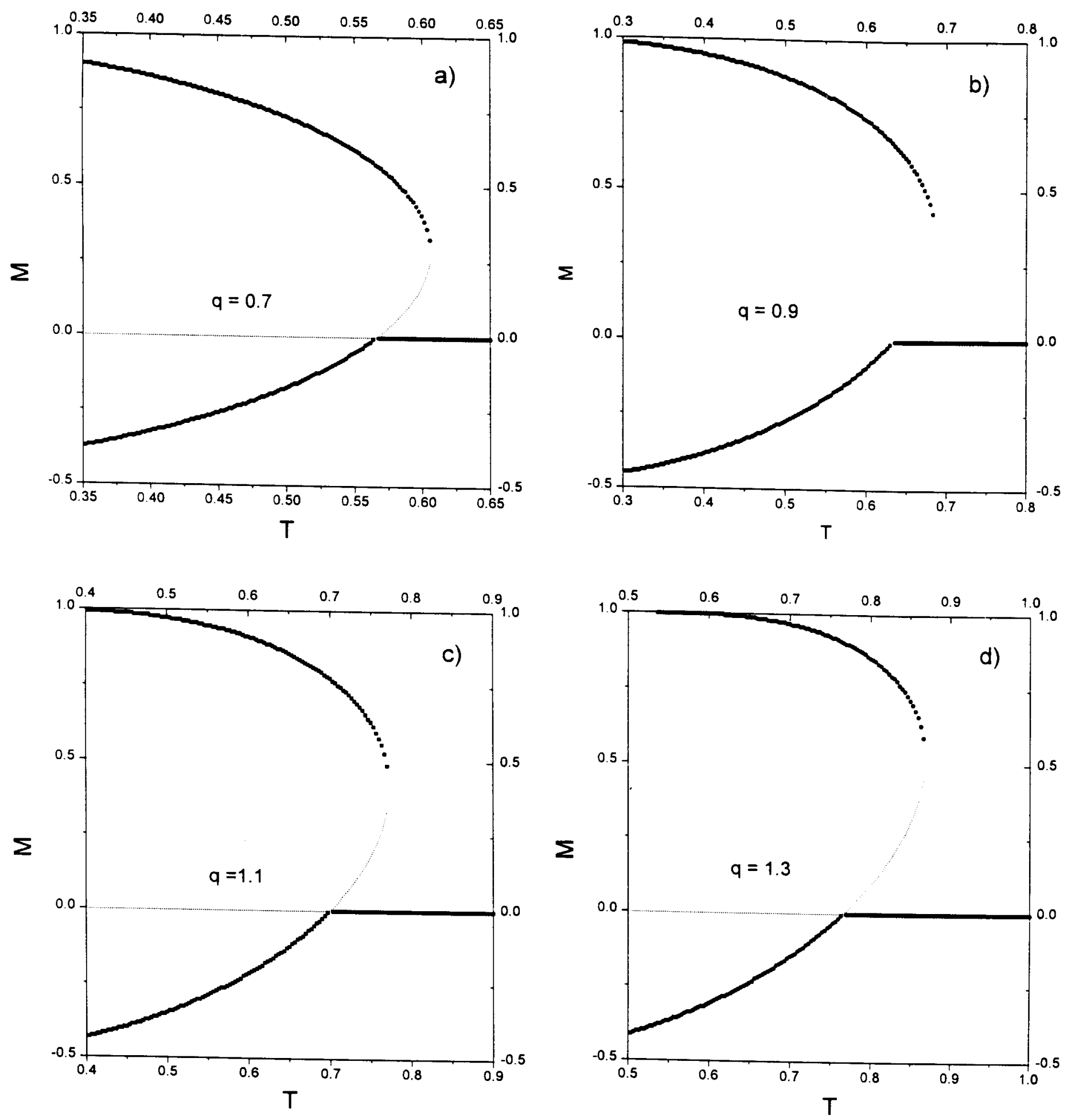

Figura 4.9: Magnetização espontânea quando a variável de Potts $p=3.0$ e o parâmetro $q$ assume os valores:(a) $q=0.7$,(b) $q=0.9$, (c) $q=1.1$, (d) $q=1.3$. 

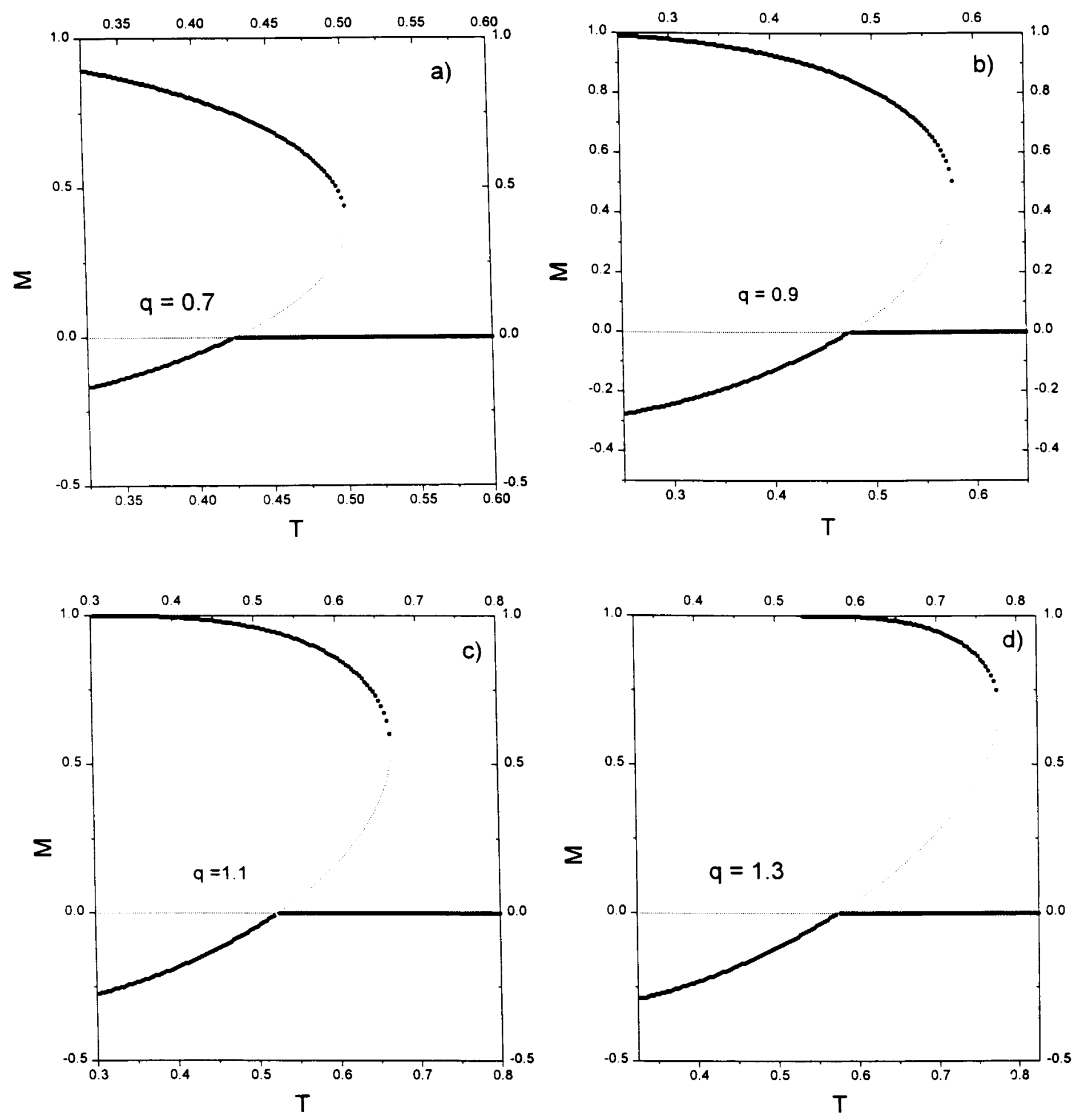

Figura 4.10: Magnetização espontânea quando a variável de Potts $p=4.0$ e o parâmetro $q$ assume os valores:(a) $q=0.7$,(b) $q=0.9$, (c) $q=1.1$,(d) $q=1.3$. 
3, impõem que a relação auto-consistente 3.42 seja satisfeita para que o sistema esteja em um estado de equilíbrio macroscópico, o ponto do plano que representa um desses estados deve pertencer a uma das curvas de magnetização espontânea, isto é, deve ser um ponto fixo do mapa 4.1 e um ponto do plano que não pertença a uma das curvas de magnetização espontânea representará um estado macroscópico de não-equilíbrio.

A correspondência entre os pontos fixos do mapa 4.1 e os estados de equilíbrio macroscópico do sistema também extende-se à estabilidade dos mesmos. Um ponto fixo estável corresponde a um estado de equilíbrio macroscópico estável, uma vez que qualquer mudança infinitesimal na magnetização espontânea, fará o do sistema ser representado por um ponto do plano $M \times T$ pertencente a bacia de atração do ponto fixo estável, e cuja órbita, seguindo da dinâmica do mapa 4.1, evoluirá na direção do mesmo, isto é, retornará ao ponto que representa o estado de equilíbrio macroscópico estável. De maneira análoga um ponto fixo instável, corresponde a um estado de equilíbrio macroscópico meta-estável, pois qualquer alteração infinitesimal da magnetização espontânea, levará o sistema a um estado representado por um ponto do plano $M \times T$ cuja órbita será repelida, isto é, fazendo o sistema afastar-se do ponto fixo que representa o estado macroscópico instável.

Um dos princípios mais gerais da termodinâmica [8] é o de que um sistema fora do equilíbrio evoluirá espontaneamente de maneira a atingir um estado de equilíbrio estável e assim, cada um dos pontos do plano $M \times T$ representando estados macroscópicos de não-equilíbrio, evoluirá até um ponto fixo estável do mapa 4.1. Essa evolução ocorrerá na direção do ponto fixo estável à cuja bacia de atração o ponto que representa o estado de não-equilíbrio pertence, uma vez que do contrário a correspondência entre pontos fixos estáveis do mapa 4.1 e os estados de equilíbrio macroscópico estáveis não seria válida.

Desse modo podemos concluir que existe uma correspondência entre a órbita de um ponto no plano $M \times T$, ditada pelo mapa, e a evolução do estado macroscópico que esse ponto representa.

O método utilizado para o cálculo das curvas de magnetização espontânea, que analisa a direção da órbita de cada um dos pontos do plano $M \times T$, permite reconhecer que esse plano é dividido em regióes bem definidas, delimitadas por retas verticais em certos intervalos de temperatura e pelos ramos das curvas de magnetização espontânea contidos nesses intervalos. A característica comum dos pontos do plano pertencentes a uma dessas 
regiões é o fato de suas órbitas, e por conseguinte os estados macroscópicos por eles representados, evoluirem todas no mesmo sentido ao longo do eixo $M$. Em uma nomenclatura matemática mais rigorosa [7] cada par destas regiões, separados pelos segmentos de um ramo estável, e que pertence ao mesmo intrevalo de temperatura, chama- se bacia de atração desse segmento e o fecho desta seu conjunto de Julia.

A dinâmica coletiva dos pontos pertencentesa dessas regiões pode ser compreendido como o fluxo de todos os pontos do plano $M \times T$, que representam estados macroscópicos fora do equilíbrio termodinâmico, em direção aos ramo estável da curva de magnetização espontânea, que representa todos os estados macroscópicos estáveis suceptíveis de serem atingidos pelo sistema quando este evolui espontaneamente a partir do não-equilíbrio.

Como exemplo dessa divisão do plano, as curvas de magnetização espontânea com a variável de Potts $p$ assumindo respectivamente os valores 2 e 3 , e com o parâmetro $q \simeq 1$, foram redesenhadas nas figs. 4.11 (a) e (b) com cada uma das diferentes regiões numeradas por algarismos romanos, e contendo uma seta que indica o ramo estável da curva de magnetização espontânea na direção do qual seus pontos evoluem. No caso $p=2$, onde a curva de magnetização espontânea é simétrica em relação ao eixo $M$, o plano é dividido em quatro regiões. Para o caso $p=3$, como em qualquer caso onde $p \neq 2$, a simetria em relação ao eixo $T$ é quebrada e o plano divide-se em dez regiões.

Em ambas as figuras, nas regiões I e II existe apenas um ramo da curva de magnetização espontânea, com $M=0$, e este é estável. Assim qualquer ponto do plano $M \times T$, que pertença a essas regiões, evoluirá para o estado de magnetização nula, e nenhuma flutuação microscópica desta poderá levá-lo deste a outro estado macroscópico. Para as outras regiões, onde as temperaturas estão abaixo da temperatura de bifurcação [33], quando surgem dois novos ramos da curva de magnetização espontânea com $M \neq 0$, este panorama muda completamente.

Na fig. 4.11 (a), na temperatura em que o ramo com $M=0$ perde a estabilidade,surjem os dois novos estáveis ramos com $M \neq 0$. Assim qualquer ponto nas regiões III e V evoluirá para o ramo da curva com $M>0$, e os pontos nas regiões IV e VI evoluirão para o ramo da curva com $M<0$. Uma vez que estes dois ramos são estáveis as flutuações microscópicas da magnetização espontânea [19], não farão o sistema evoluir para outro ponto do plano. O segmento instável do ramo $M=0$ não pertence a nenhuma das seis regiões, e uma 


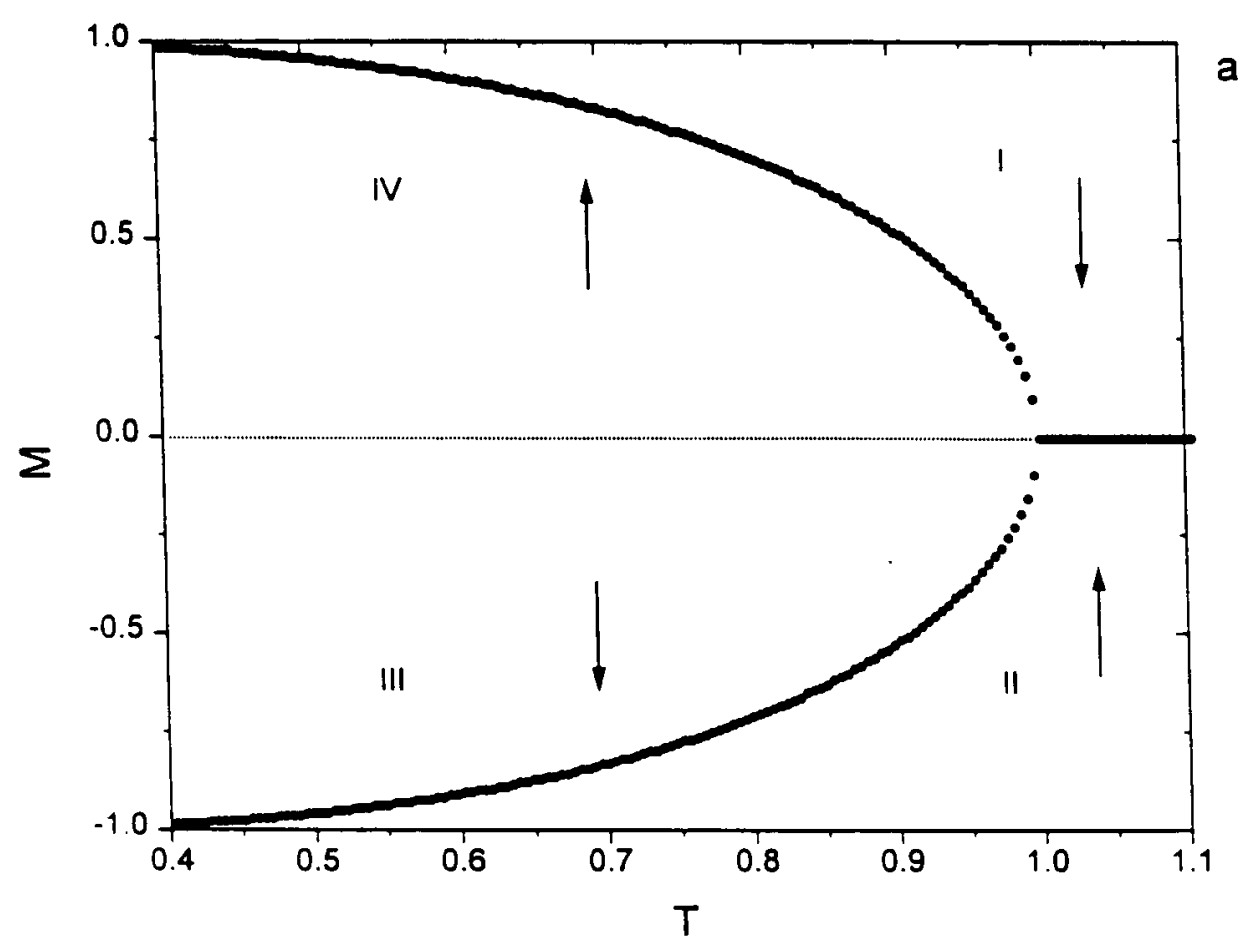

a)

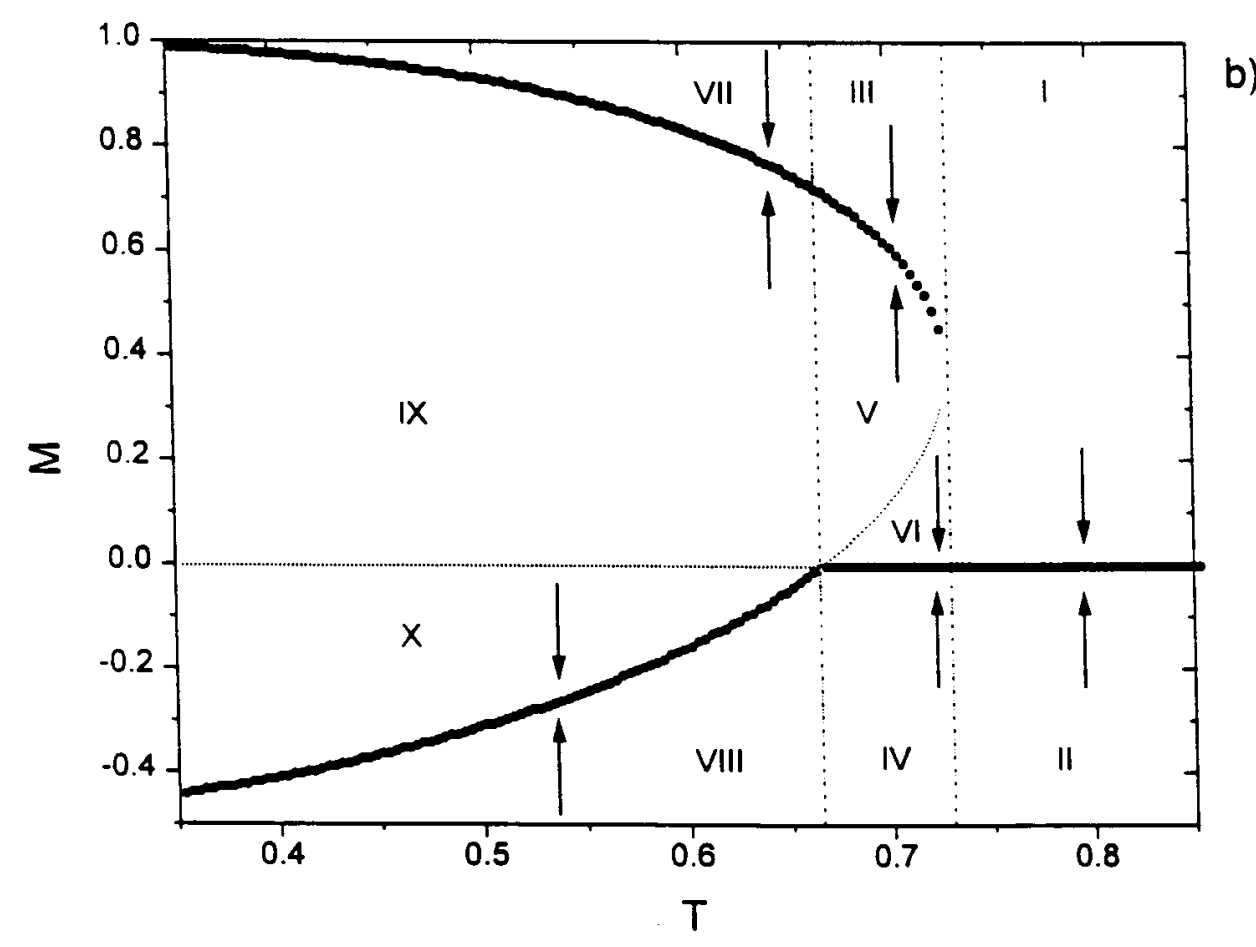

Figura 4.11: Dinâmica global do mapa 4.1 para os casos: (a) $p=2$, (b) $p=3$. As bacias de atração são distintas por algarismos romanos e o sentido da evolução de seus pontos é indicada por setas.

\section{4}

IFSC - SEFVCO DEBIBLIOTECAE 
flutuação microscópica qualquer da magnetização espontânea fará o sistema deslocar-se para um ponto nas vizinhanças desse segmento, que pertencerá a região $V$ ou VI e portanto evoluindo para um dos ramos estáveis com $M \neq 0$.

Do ponto de vista macróscopico isto significa que reduzindo-se a temperatura através de um processo quase-estático, partindo de uma temperatura maior que a temperatura de bifurcação, será impossível atingir o segmento instável do ramo $M=0$ da curva de magnetização espontânea.

Para o caso $p=3$, fig. 4.11 (b), além da assimetria em relação ao eixo $T$, deve-se notar que a temperatura de difurcação e aquela em que o ramo $M=0$ torna-se instável não coincidem.

O comportamento dos pontos pertencentes as regiões de número III a VI, é idêntico aquele dos pontos das regiões de mesmo número no caso $p=2$, mas como uma consequência do fato da temperatura de bifurcação e aquela em que o ramo $M=0$ torna-se instável não coincidirem, fez-se necessária a introdução das regiões com números VII a X.

Neste intervalo, entre a temperatura de bifurcação e a temperatura em que o ramo com $M=0$ torna-se instável, os ramos da curva para os estados de equilíbrio com $M>0$ têm a forma aproximada de uma parábola horizontal, sendo o ramo superior estável e o ramo inferior instável.

O ramo instável com $M>0$, faz com que a região IX funcione como uma "barreira ", estabilizando o ramo com $M=0$, e impedindo que os pontos nesse ramo sejam deslocados por flutuações microscópicas da magnetização espontânea, para a região X, e assim evoluirem para o ramo superior estável.

$O$ fato desse ramo instável decrescer com a temperatura até interceptar o eixo $T$, no ponto em que o ramo $\operatorname{com} M=0$ perde a estabilidade, tendo a partir daí o ramo estável com $M<0$ como sua continuação análitica, faz com que a capacidade da região IX em "barrar" o deslocamento dos pontos do ramo com $M=0$ para a região X diminua à medida em que a temperatura aproxima-se daquela em que este último ramo perde a estabilidade. Quando a temperatura for suficientemente baixa, de modo que o valor da magnetização do ramo instável seja pequeno o bastante para ser comparada às flutuações microscópicas da magnetização espontânea, e notando-se que a essa temperatura o ramo estável com $M<0$ ainda não surgiu, as flutuações microscópicas negativas farão o sistema 
deslocar-se para a região VII, fazendo-o evoluir de maneira a retornar ao ramo com $M=0$, enquanto uma flutuação microscópica positiva fará o sistema deslocar-se e evoluir até o ramo estável com $M>0$, "pulando" a "barreira" da região IX, para a região X.

Este comportamento, para os caso em que $p=3$, implica que reduzindo-se a temperatura em um processo quase-estático, o ramo com $M=0$ continua sendo preferido macroscopicamente pelo sistema, devido ao efeito de "barreira" exercido pelo ramo instável com $M>0$, abaixo da temperatura de bifurcação até a temperatura em que as flutuações microscópicas da magnetização espontânea levarão o sistema a evoluir para o ramo estável com $M>0$. A temperatuca em que isso ocorre é conhecida como temperatura crítica $T_{C}$.

Assim parte do ramo com $M>0$, no intervalo entre a temperatura de bifurcação e a temperatura crítica, e o ramo $\operatorname{com} M<0$, não são acessíveis ao sistema. O mesmo comportamento ocorre nos casos em que $p<2$, com a única diferença que o ramo que continua é acessível, quando a temperatura é menor que a temperatura de bifurcação é aquele com $M<0$, visto que nesses casos a assimetria em relação ao eixo $T$ dá-se de forma que as duas soluções que aparecem quando a curva se bifurca têm $M<0$.

Como resultado das observações acima, temos que para obtermos as curvas observadas macroscopicamente, figs. 4.12 (a) e (b) respectivamente para os casos $p=2$ e $p=3$, é necessário "cortar " os ramos com $M \neq 0$, no intervalo entre as temperaturas de bifurcação e aquela em que o ramo com $M=0$ torna-se instável, sendo esta considerada como aproximadamente igual a $T_{C}$, fato que será justificado no capítulo seguinte, e para temperaturas abaixo desta última a continuação instável do ramo com $M=0$, e o ramo com $M \neq 0$ de menor módulo. 

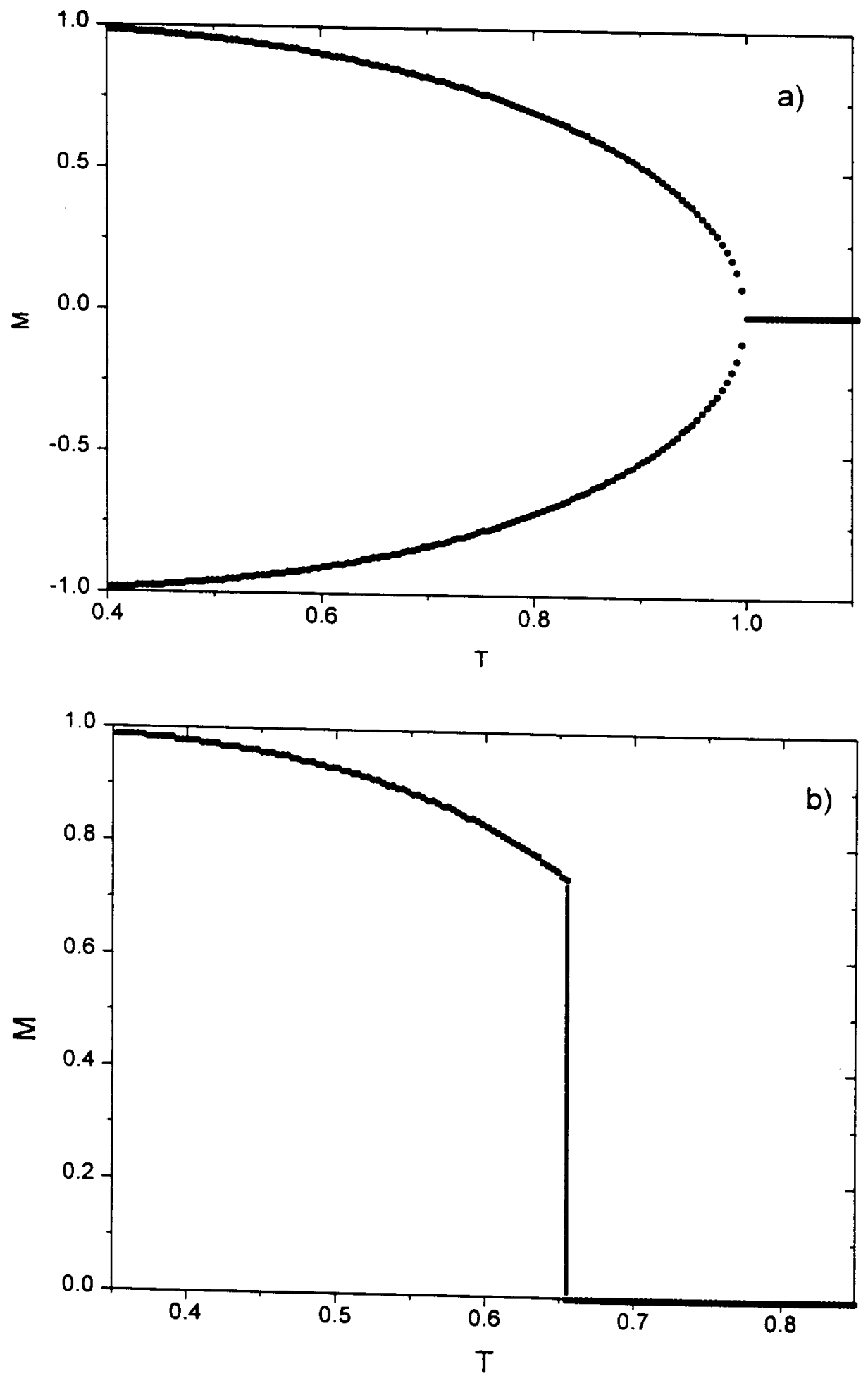

Figura 4.12: Ramos de magnetização espontanea acessiveis ao sistema por processos quasi-estáticos, nos casos:(a) $p=2$, (b) $p=3$. 


\section{Capítulo 5}

\section{TRANSIÇÃO DE FASE}

\subsection{ENERGIA LIVRE DE ORDEM $q$ E TRANSIÇÃO DE FASE}

$\mathrm{Na}$ última seção do capítulo anterior, analisando-se a dinâmica do mapa 4.1, chegouse a conclusão de que embora as curvas de magnetização espontânea apresentarem três ramos abaixo de uma determinada temperatura $T_{B}$, cada um dos quais representa um conjunto de estados de equilíbrio termodinâmico do sistema, apenas um segmento de um desses ramos representa estados acessíveis do ponto de vista macroscópico, o que provoca a existência de uma descontinuidade na magnetização espontânea em relação a temperatura, com excessão do caso $p=2.0$, quando esta é igual aquela em que o ramo com $M=0$ muda sua estabilidade.

Este comportamento mostra que o sistema sofre uma transição de uma fase paramagnética a altas temperaturas, onde o único estado macroscopicamente estável é aquele com magnetização nula, para uma fase ferromagnética a baixas temperaturas, onde os estados macroscópicos estáveis têm magnetização espontânea diferente de zero.

Transições deste tipo onde existe um parâmetro de ordem, neste caso a magnetização espontânea, que torna-se não nulo apenas abaixo de um determinado valor de uma variável intensiva, no presente caso a temperatura, são conhecidas como transições de fase descontinuas [34]. A temperatura em que isso acontece é denoninada temperatura crítica $T_{C}$, e no caso específico de sistemas magnéticos, de Curie.

Uma vez que, como vimos na última seção do capítulo anterior a partir da dinâmica do mapa 4.1, a fase ferromagnética existe apenas quando a temperatuta cai abaixo daquela em que o ramo da magnetização espontânea com $M=0$ torna-se instável, podemos 
identificar esta com a temperatua $T_{C}$.

As características típicas dese tipo de transição, em uma estística de BoltzmmanGibbs, são dadas pela variação das curvas da energia livre de Helmoltz em função da magnetização, quando a temperatura é alterada. No contexto de uma estatística de Tsallis, estas características devem ser obtidas a partir da variação das curvas do funcional de energia livre de ordem $q$.

As curvas de magnetização espontânea, do capítulo anterior, permitem fazer estimativas grosseiras das temperaturas de bifurcação $T_{\dot{B}}$ e daquela abaixo da qual ramo $M=0$ torna-se instável e que coincide com $T_{C}$.

Mantendo-se $q \simeq 1$, e com a variável $p$ assumindo respectivamente os valores $1.5,2.0, \mathrm{e}$ 3.0, foram traçadas em cada uma das figs. 5.1 a 5.3 uma série de quatro curvas de $F_{q}$ em função da magnetização, para as temperaturas: $T_{1}>T_{B}, T_{B}>T_{2}>T_{C}, T_{3} \simeq T_{C}$, e $T_{4}<T_{C}$.

Estas curvas, como esperado uma vez que $q \simeq 1$, mostram estruturas idênticas aquelas apresentadas pelo modelo de Potts na aproximação de campo médio, em uma estatística de Boltzmann-Gibbs [5].

Em todos os casos para altas temperaturas, isto é, $T>T_{B}$, as curvas $F_{q}$ têm uma forma parabolóide, sendo convexa em toda a extensão do domínio da magnetização, com apenas um mínimo no ponto $M=0$.

Quando $T_{B}>T_{2}>T_{C}$, nos casos em que $p \neq 2$, acontece $o$ aparecimento de dois novos pontos de equilíbrio, isto é, onde a derivada de $F_{q}$ em relação a $M$ é nula. Um desses pontos, o mais afastado do eixo $F_{q}$, é um mínimo local, sendo a curva convexa em suas vizinhanças. O ponto mais próximo do eixo $F_{q}$ é um máximo local, sendo a curva côncava em suas vizinhanças.

Este comportamento mostra de que maneira o ramo instável da magnetização espontânea com $M \neq 0$, funciona como uma "barreira" impedindo a transição do sistema de estados de magnetização espontânea nula, para estados onde esta é $M \neq 0$ quando a temperatura pertence ao intervalo $\left[T_{C}, T_{B}\right]$, como foi observado na última seção do capítulo anterior. Neste intervalo, a ocorrência de uma transição espontânea do sistema de um estado com $M=0$ para outro com $M \neq 0$ é extremamente improvável, uma vez que para isso seria necessária uma flutuação espontânea de $F_{q}$ maior que o valor desta no ponto 


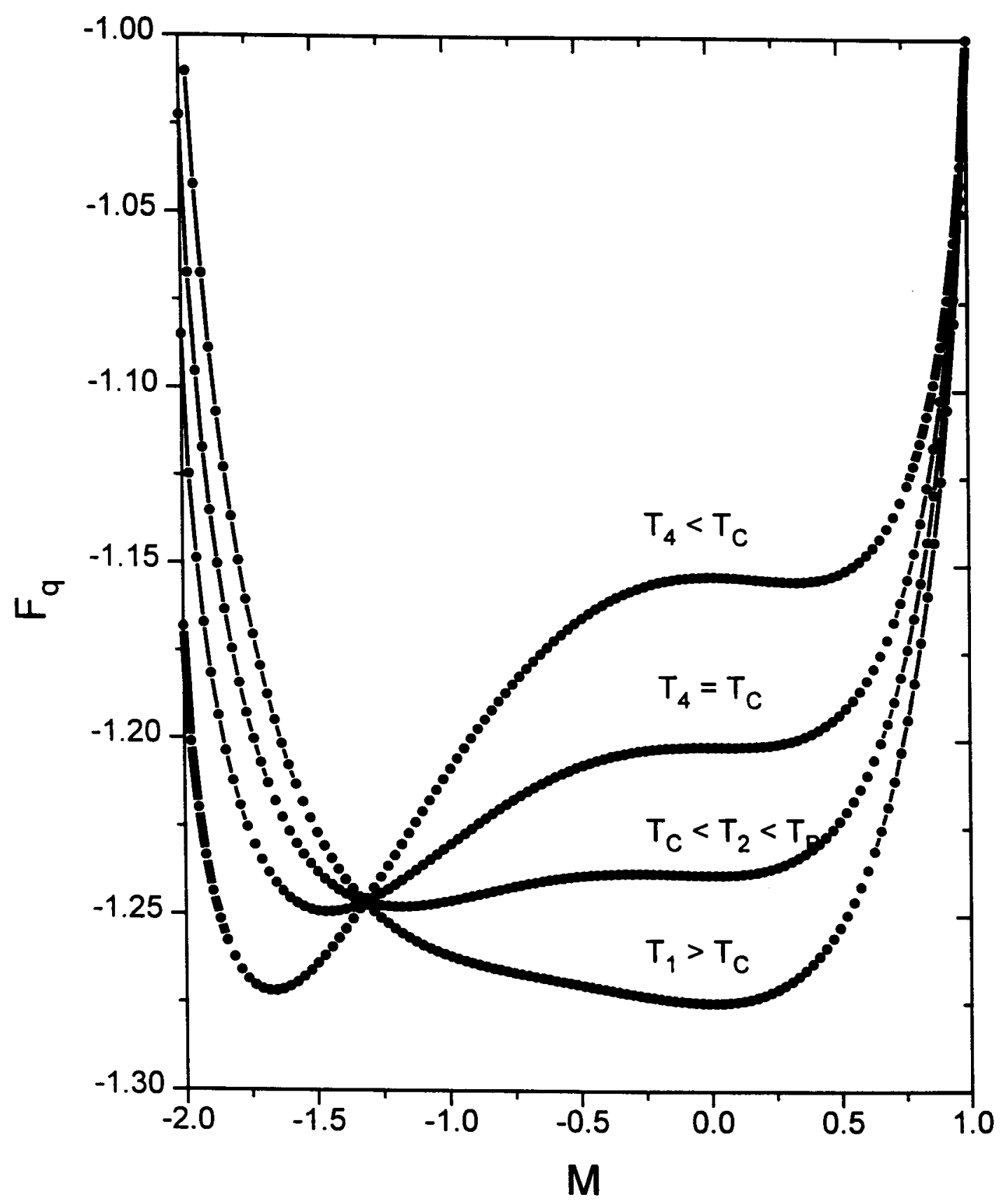

Figura 5.1: Energia livre de ordem $q$ em função da magnetização com $p=1.5$. (a) $T_{1}>T_{B}$, (b) $T_{B}>T_{2}>T_{C}$, (c) $T_{3} \simeq T_{C}$, (d) $T_{4}<T_{C}$. 


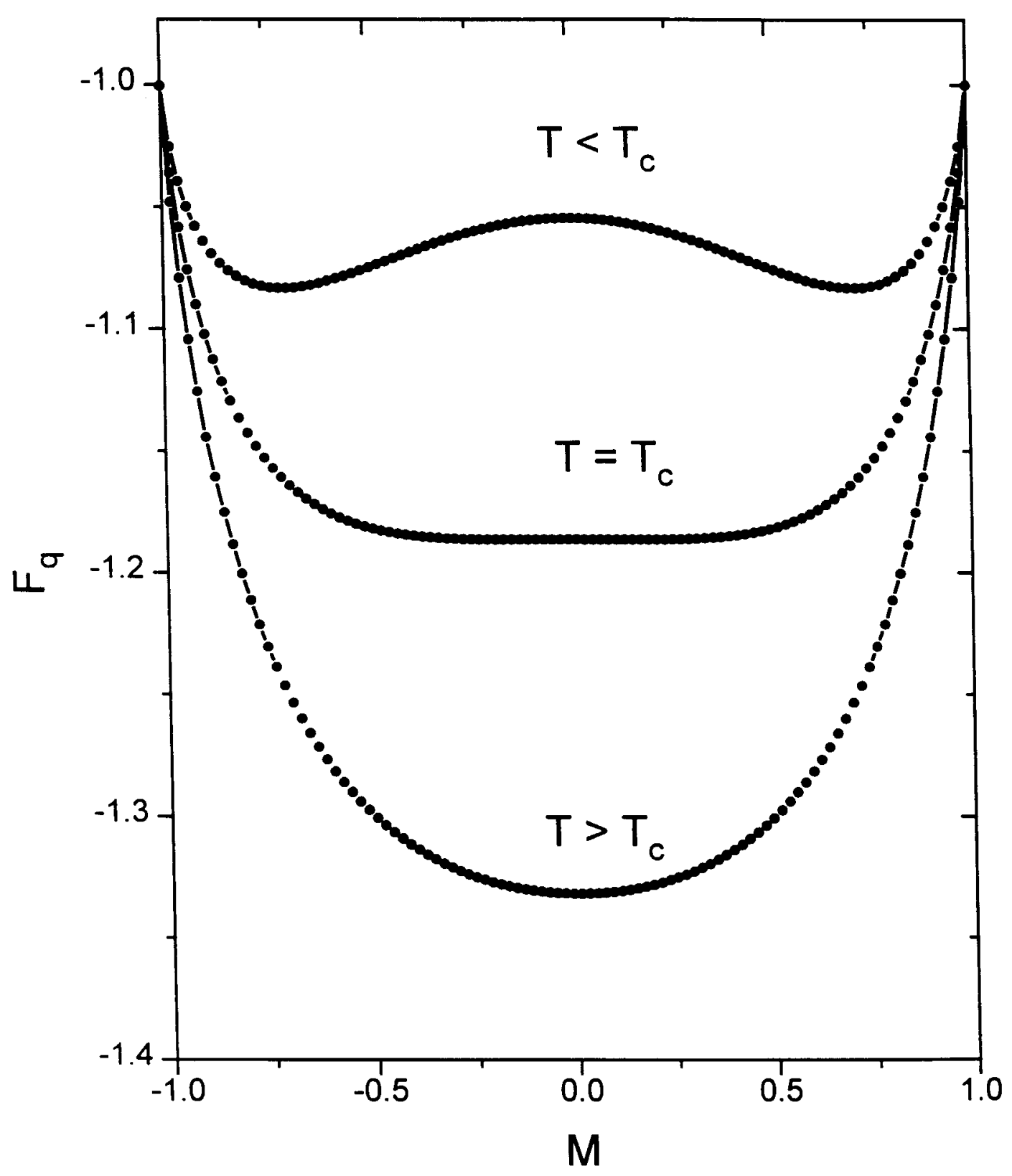

Figura 5.2: Energia livre de ordem $q$ em função da magnetização $\operatorname{com} p=2.0$. (a) $T_{1}>T_{B}$, (b) $T_{B}>T_{2}>T_{C}$, (c) $T_{3} \simeq T_{C}$, (d) $T_{4}<T_{C}$. 


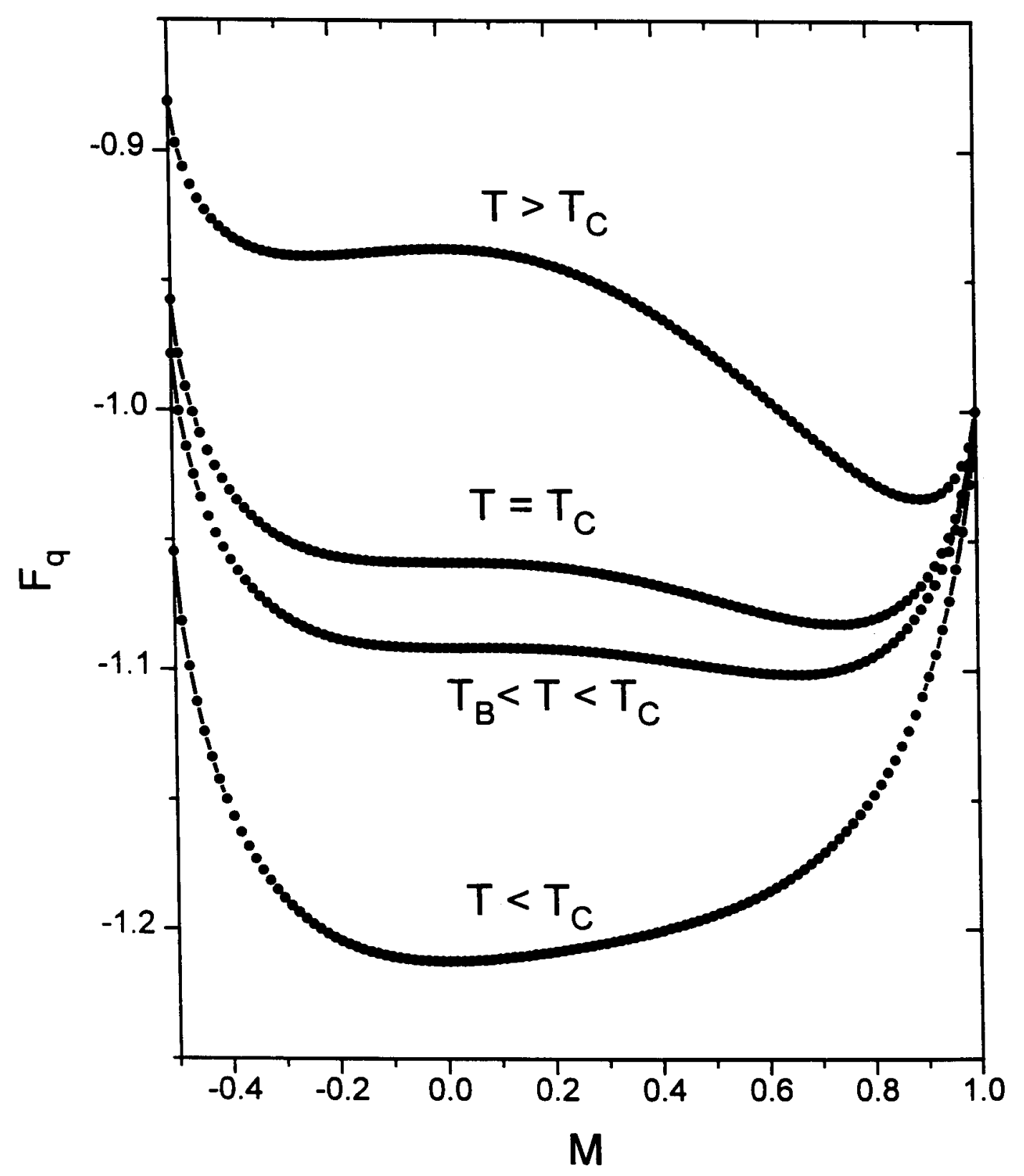

Figura 5.3: Energia livre de ordem $q$ em função da magnetização $\operatorname{com} p=3.0$. (a) $T_{1}>T_{B}$, (b) $T_{B}>T_{2}>T_{C}$, (c) $T_{3} \simeq T_{C}$, (d) $T_{4}<T_{C}$. 
em que esta tem um máximo local.

Nas curvas em que $T \simeq T_{C}$, esta diferença cai praticamente a zero, e o sistema ficará transitando, devido às flutuações microscópicas de $F_{q}$, entre os estados de mínimo com $M=0$ e $M \neq 0$. Uma analogia mecânica para este fenômeno é apresentada no livro de Callen [8].

As curvas onde $T<T_{C}$ mostram que o ponto $M=0$ torna-se um máximo local, com a convexidade das curvas sendo invertida em suas vizinhanças, e que os outros dois pontos de equilíbrio, os quais ambos são agora mínimos locais, situam-se agora em lados opostos do eixo $F_{q}$, com aquele que apresenta o maior valor absoluto de $M$ sendo o mais favorecido energeticamente.

Para poder verificar a forma com que a variação do parâmetro $q$ afeta a transiçã de fase do sistema, foram desenhadas nas figs. 5.4 a 5.6 séries das curvas de $F_{q}$ em função de $M$, com a temperatura mantida fixa e o valor do parâmetro $q$ sendo variado. Nesta sequência de figuras, como na anterior, a variável de Potts $p$ assume respectivamente os valores $1.5,2.0$, e 3.0. Em cada uma das três séries a temperatura $T$ foi escolhida de maneira que o sistema se encontre próximo à criticalidade quando $q \simeq 1$, isto é, $T \simeq T_{C}$ na estatística de Boltzmann-Gibbs.

Pode-se notar a semelhança estrutural entre cada uma destas últimas séries de curvas com aquelas das figs. 5.1 a 5.3, onde ao contrário destas últimas, o que varia é a temperatura, com o parâmetro $q$ sendo mantido constante. Essa semelhança leva à conclusão que o efeito da variação do parâmetro $q$ é uma mudança na temperatura crítica do sistema, sem afetar a ordem da mesma. Ou em outras palavras, fixado o valor da variável de Potts $p$ e da temperatura $T$, haverá um valor do parâmetro $q$ em que $T$ coincidirá com a temperatura crítica do sistema.

$\mathrm{Na}$ seção seguinte será feita a determinação numérica da dependência da temperatura crítica com o parâmetro de ordem $q$. 


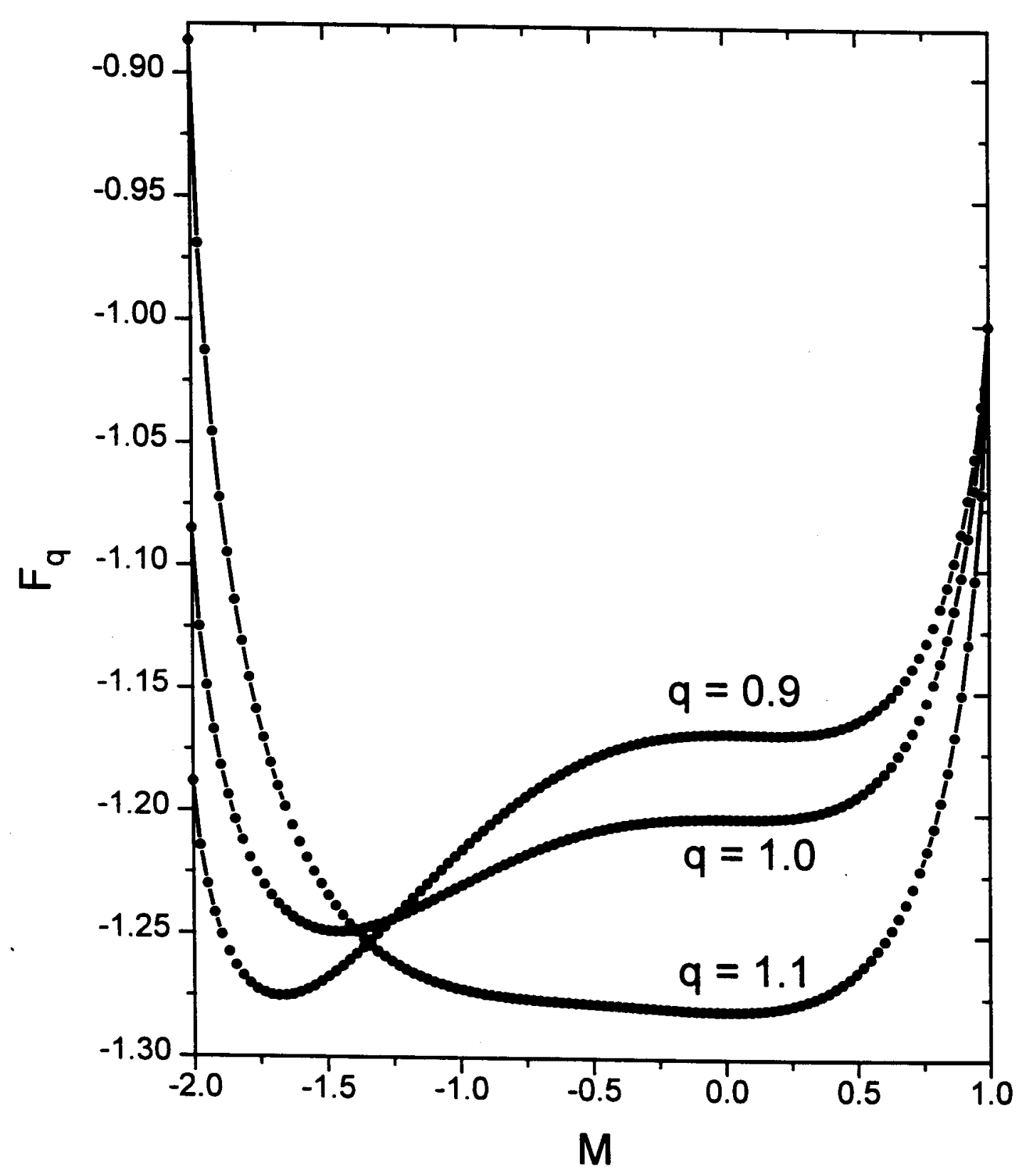

Figura 5.4: Variação da curva de energia livre de ordem $q$, com o parâmetro $q$ quando $p=1.5$. 


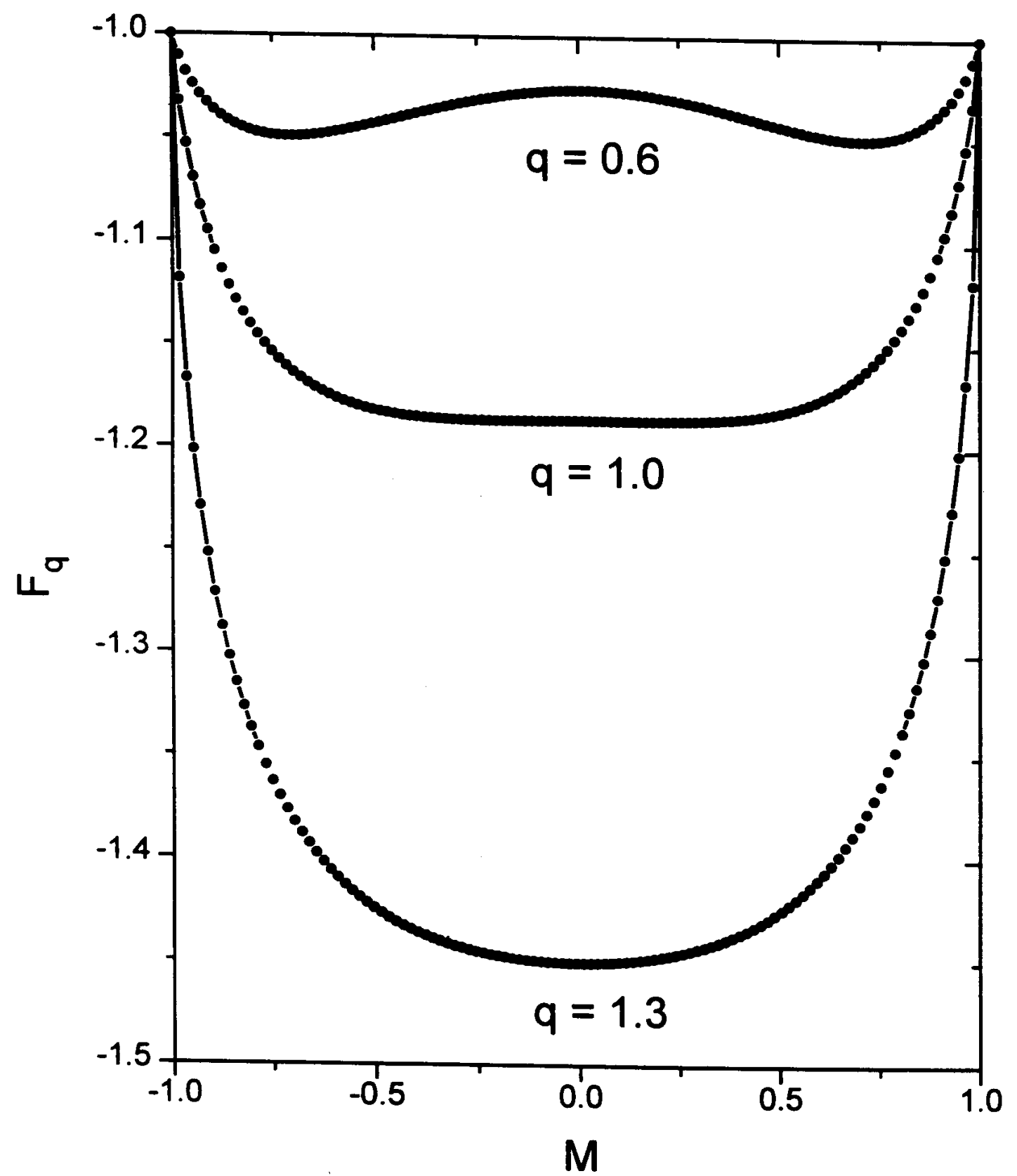
Figura 5.5: Variação da curva de energia livre de ordem $q$, com o parâmetro $q$ quando
$p=2.0$. 


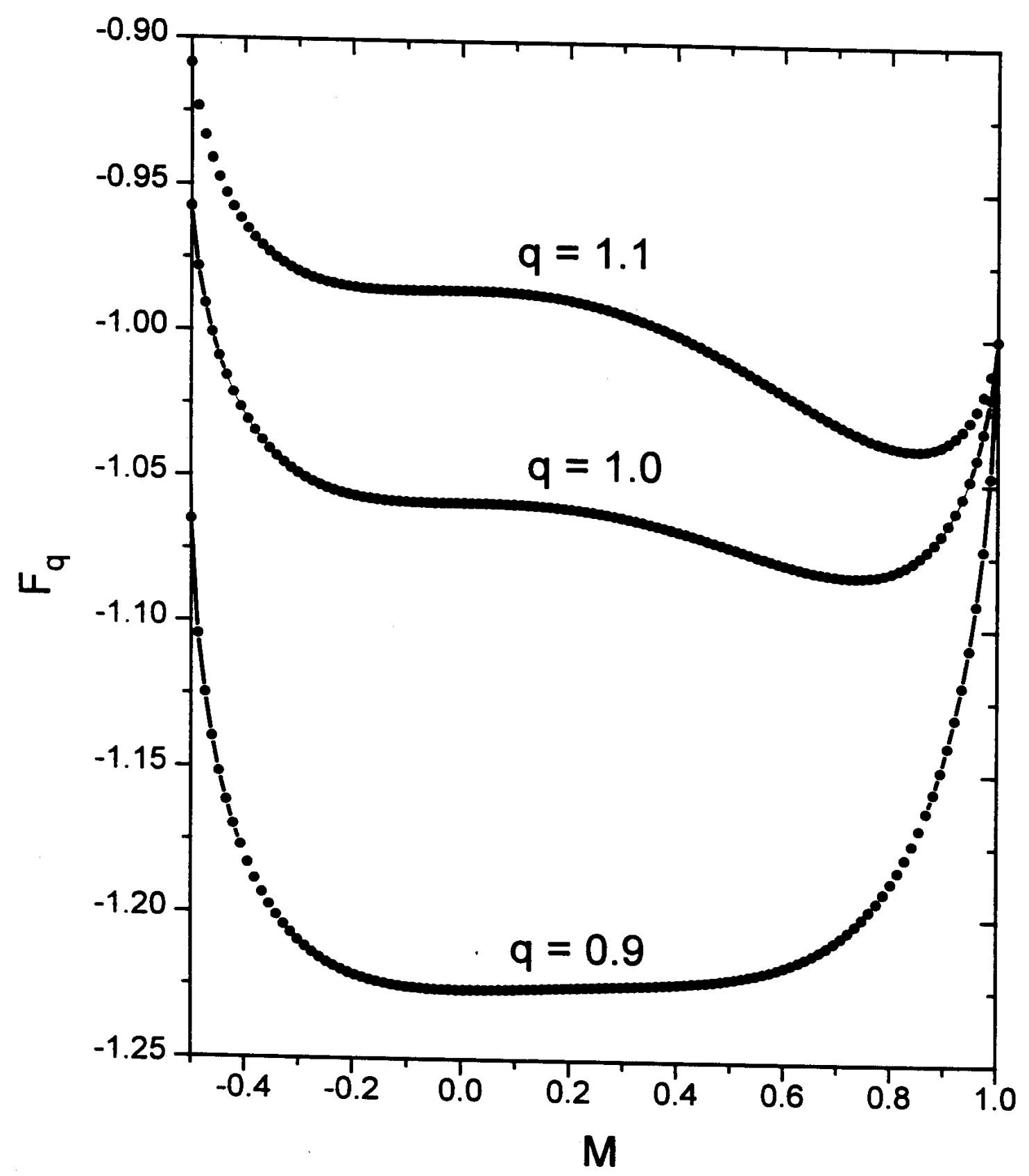

Figura 5.6: Variação da curva de energia livre de ordem $q$, com o parâmetro $q$ quando
$p=3.0$. 


\subsection{INFLUENCIA DO PARÂMETRO $q$ SOBRE A TEMPE- RATURA CRÍTICA}

A dependência da temperatura crítica em relação a variável $p$ para o modelo de Potts na aproximação de campo médio, foi derivada por Wu [38], no contexto da estatística de Boltzmann-Gibbs, a partir da hipótese do funcional de energia livre de Helmoltz ser analítico em relação a magnetização na criticalidade, isto é, impondo-se as condições:

$$
F\left(M_{c}, T_{c}\right)=F\left(0, T_{c}\right)
$$

e

$$
\left(\frac{\partial F}{\partial M}\right)_{M_{C}, T_{C}}=0,
$$

com $H=0$, e onde $M_{C}$ é a magnetização espontânea não nula para $T=T_{C}$.

$\mathrm{O}$ cálculo explícito destas duas condições, leva ao sistema de equações em $M_{c}$, e $T_{c}$ :

$$
T_{C} \ln \left[\frac{1+(p-1) M_{C}}{1-M_{C}}\right]-M_{C}=0
$$

e

$$
\frac{2 T_{C}}{(p-1)}\left\{\left[1+(p-1) M_{C}\right] \ln \left[1+(p-1) M_{C}\right]+(p-1)\left(1-M_{C}\right) \ln \left(1-M_{C}\right)\right\}-M_{C}^{2}=0 .
$$

Pode-se verificar que a solução para este sistema é dada por:

$$
T_{C}=\frac{(p-2)}{2(1-2)} \frac{1}{\ln (p-1)},
$$

e

$$
M_{C}=\frac{(p-2)}{(p-1)}
$$

Que no limite $q \rightarrow 2$ recobram o resultado do modelo de Ising: $T_{C}=0.5$ e $M_{C}=0$.

Em uma estatística de ordem $q$, a determinação de expressões análiticas para, $T_{C}$ e $M_{C}$, seria feita através da aplicação das condições de analiticidade 5.1 e 5.2 ao funcional de energia livre $F_{q}$. O sistema de equações daí resultante, em que o parâmetro $q$ também estaria envolvido, seria por demais complexo para ser manipulado algebricamente, o que fez necessária a utilização de métodos numéricos na obtenção da dependência da temperatura crítica $T_{C}$ com relação a variável $p$ e ao parâmetro $q$. 
A localização numérica da temperatura crítica em um determinado intervalo de temperatura $D T=\left[T^{<}, T^{>}\right]$quando os valores de $p$ e $q$ estão fixados, é feita por um algorítmo baseado na propriedade, discutida na seção anterior, do ramo com $M=0$ das curvas de magnetização espontânea perderem sua estabilidade quando $T=T_{C}$. Este algorítmo, testa a estabilidade do ramo $M=0$ para um conjunto de pontos, do intervalo $D T$, $\left\{T^{<}, \ldots, T_{i-1}, T_{i}, \ldots, T^{>}\right\}$, igualmente espaçados entre si. Reduzindo-se a temperatura, a partir de $T^{>}$, determina-se a estabilidade ou não dos pontos $T_{i}$. Quando ocorre a perda de estabilidade entre dois pontos consecutivos $T_{i-1}$ e $T_{i}$, isto é, o ramo com $M=0$ é estável para $T_{i}$ e instável $T_{i-1}$, tem-se que $T_{i-1}<T_{C}<T_{i}$.

$O$ teste da estabilidade da solução $M=0$, para uma dada temperatura $T_{i}$, é feito através da análise do deslocamento das órbitas dos pontos extremos de um sub-intervalo da magnetização espontânea, $d=[-\epsilon,+\epsilon] \operatorname{com} \epsilon<<$. Partindo-se da primeira iteração desses pontos através do mapa 4.1, com $H=0$,

$$
\epsilon^{+}=\operatorname{tanhp}\left\{A_{q}\left(+\epsilon, H, T_{i}\right)\right\}
$$

e

$$
\epsilon^{-}=\tanh p\left\{A_{q}\left(-\epsilon, H, T_{i}\right)\right\}
$$

obtém-se os deslocamentos:

$$
\Delta^{+}=\epsilon^{+}-\epsilon
$$

e

$$
\Delta^{-}=\epsilon^{-}-\epsilon .
$$

Aplicando o mesmo critério usado no capítulo 4, para a determinação da estabilidade de um ponto fixo do mapa contido em um intervalo pertencente ao domínio da magnetização espontânea, a partir da análise da dinâmica do extremos desse intervalo $d$, fig. 5.7, chegamos a:

$$
\frac{\Delta^{+}}{\Delta^{-}} \equiv \begin{cases}>0 \Rightarrow M=0 & \text { é estável e } T_{i}>T_{C} \\ <0 \Rightarrow M=0 & \text { é instável e } T_{i}<T_{C}\end{cases}
$$

$O$ grau de precisão com que este algorítmo fornece o valor de $T_{C}$ é dado pelo tamanho dos sub-intervalos em que o intervalo de temperatura $D T$ é subdividido, uma vez que o que fornece é que a temperatura crítica esta contida no subintervalo $\left[T_{i-1}, T_{i}\right.$. $]$. Assim 


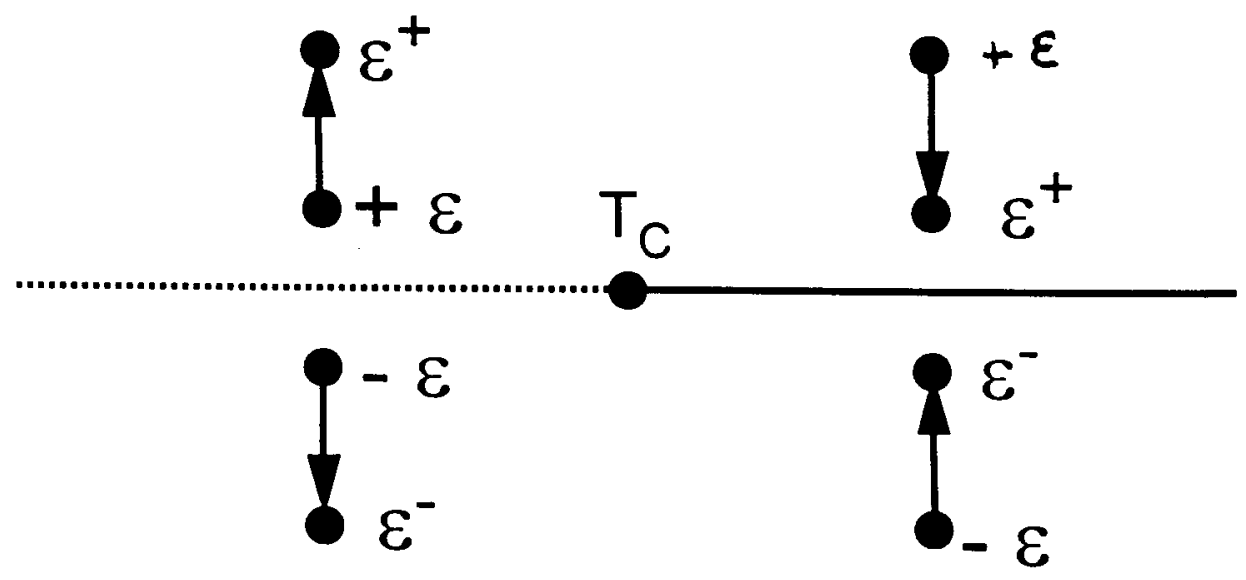

Figura 5.7: Comportamento das grandezas $\Delta^{+}$e $\Delta^{-}$nas vizinhanças de $T_{C}$. 
podemos dizer que os resuldados deveriam a rigor, ser lidos como: $T_{C .}=\left(T_{i .}+\Delta T\right) \pm \Delta T$, onde $\Delta T=\left(T_{i .}-T_{i-1}\right) / 2$.

O programa utilizando o algoritmo descrito acima, vide fig. 5.8, calcula a temperatura crítica em cada um dos NPTOS pontos, igualmente espaçados, contidos num intervalo [QMIN,QMAX] do parâmetro $q$, para um valor fixo da variável de Potts $p$.

Esse procedimento, embora simples, demanda um considerável tempo de computação, e novamente é necessário contornar-se a singularidade computacianal que aparece na relação de recorrência quando $q=1$.

Os resultados obtidos através desse programa para vários valores da variável $p$, são mostrados nas figs. 5.9 a 5.13. Essas figuras mostram claramente uma dependência linear entre a temperatura crítica $T_{C}$ e o parâmetro $q$ na forma:

$$
T_{C}=\alpha(p) q+a(p)
$$

onde $\alpha(p)$ e $a(p)$ variam com o valor de $p$.

Aplicando a técnica da regressão linear [11] a cada uma das curvas de $T_{C}$ em função de $q$, obtém-se os valores aproximados para $\alpha(p)$ e $a(p)$ apresentados na tabela A.

Com o objetivo de verificar a consistência destes resultados, é necessário comparar a concordância dos valores de $T_{C}$ calculados numericamente para uma estatística de Tsallis quando $q \rightarrow 1$, com aqueles, previstos pela eq.5.3, para o mesmo sistema na estatística de Boltzmman-Gibbs. Para isso utilizou-se os valores aproximados de $\alpha(p)$ e $a(p)$, da tabela A, e fêz-se a interpolação dos valores de $T_{C}$ quando $q=1$, para cada uma das retas com valores distintos da variável de Potts.

Os valores de $T_{C}$ obtidos por interpolação para $q=1$, e aqueles dados a partir da eq. 5.5, para cada valor de $p$, e os respectivos desvios, estão na tabela B.

Nessa tabela podemos observar que as discrepâncias entre os valores interpolados de $T_{C}$ e aqueles obtidos analiticamente são da ordem de menos de 0.1 por cento. $O$ que mostra a confiabilidade na dependência linear entre a temperatura crítica e do parâmetro $q$ em uma estatística de Tsallis, e dos métodos numéricos aqui utilizados.]

break 


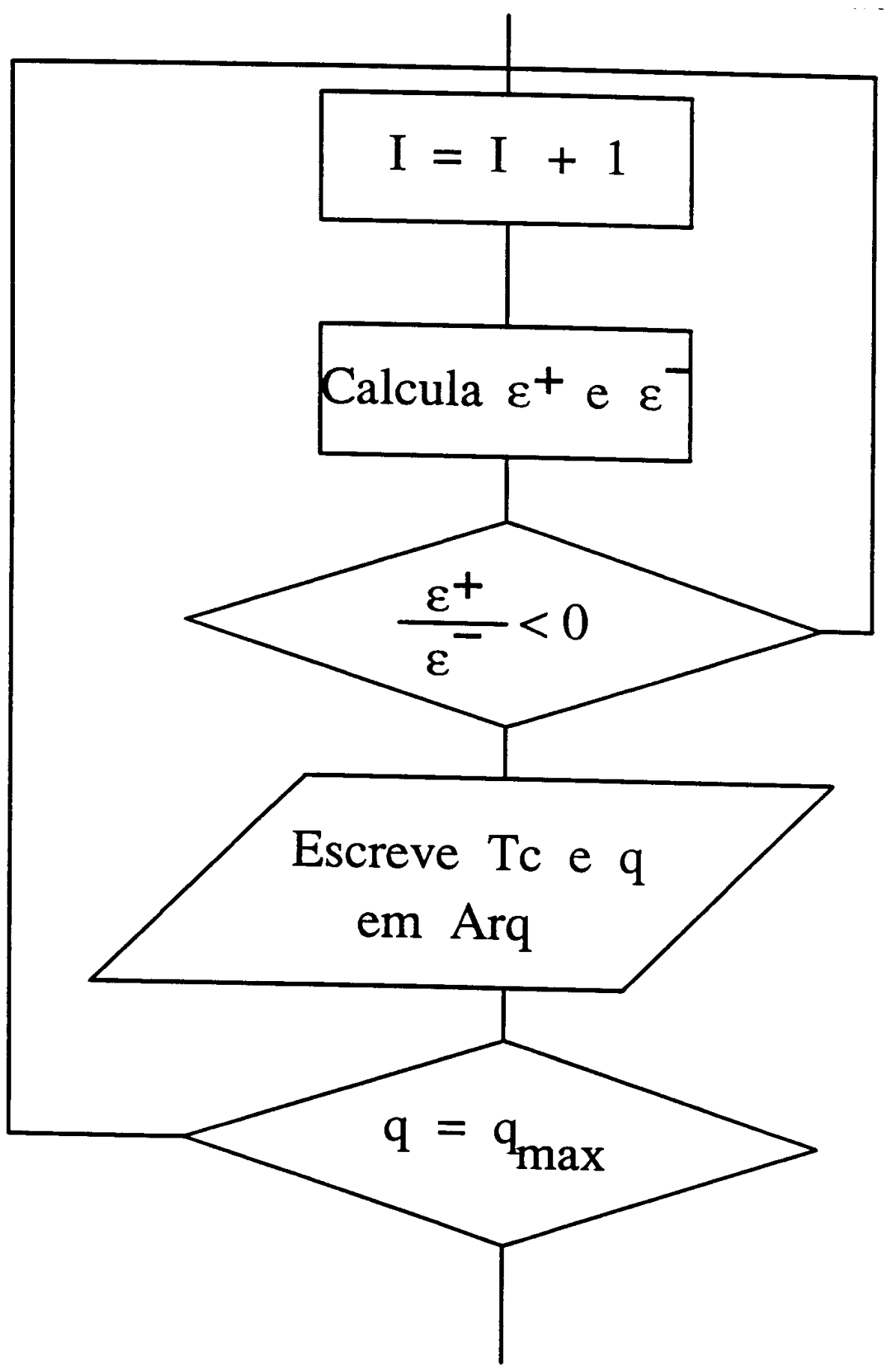

Figura 5.8: Fluxograma do algorítmo para a determinação de $T_{C}$ baseado na perda de estabilidade do ramo da magntização espontânea com $q$ fixo. 


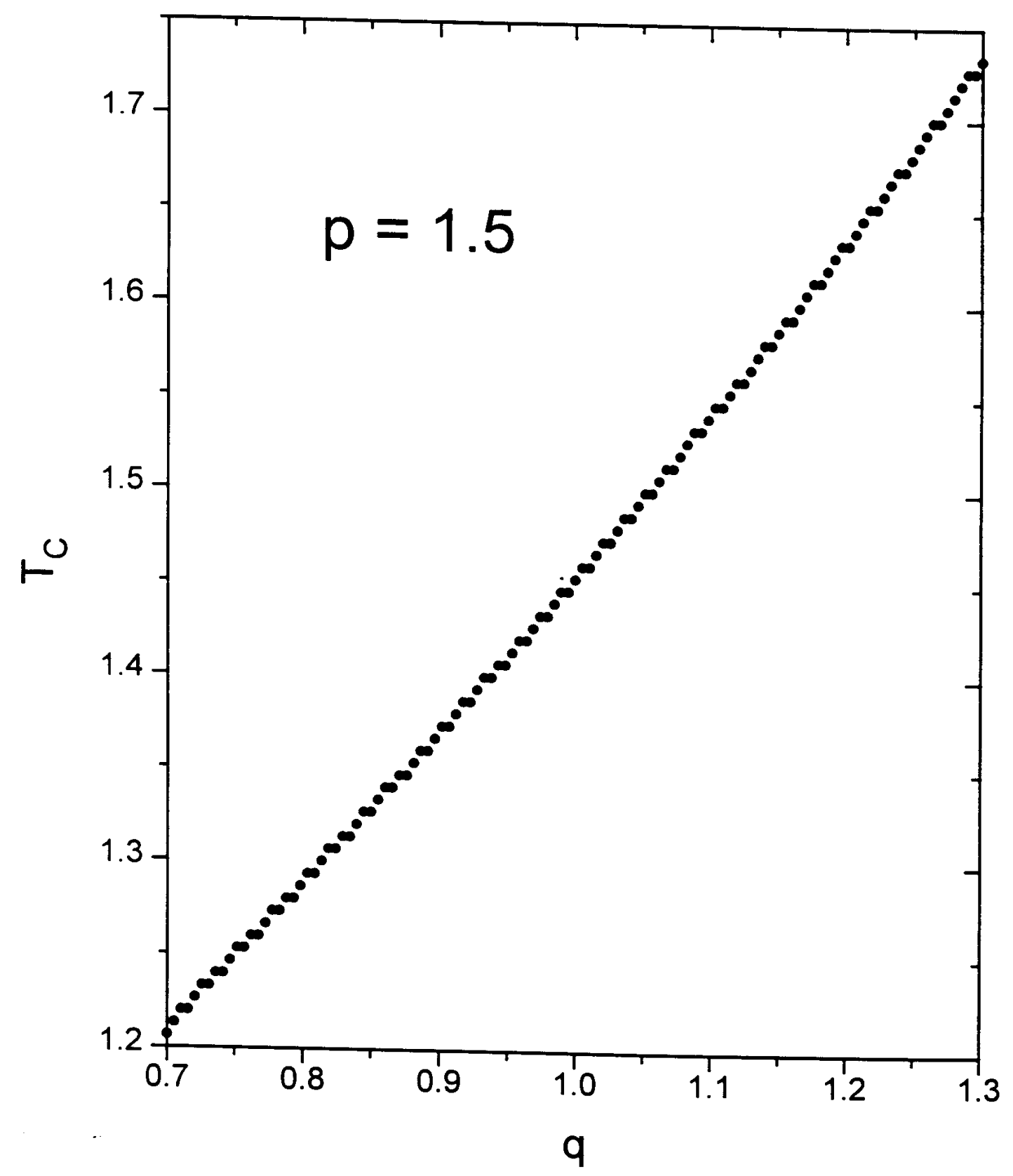




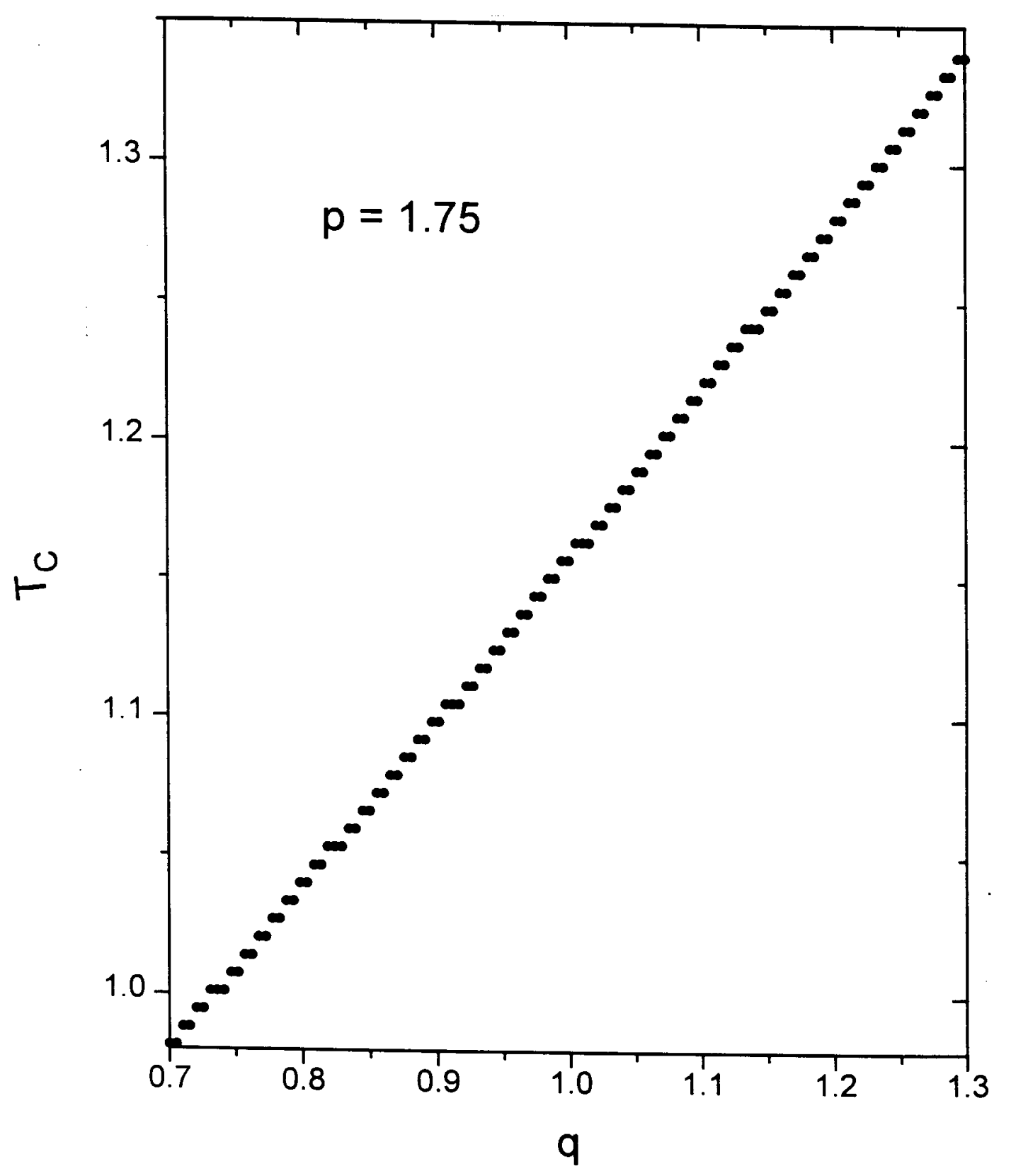

Figura 5.10: Variação de $T_{C}$ com o parâmetro $q, \operatorname{com} p=1.75$. 


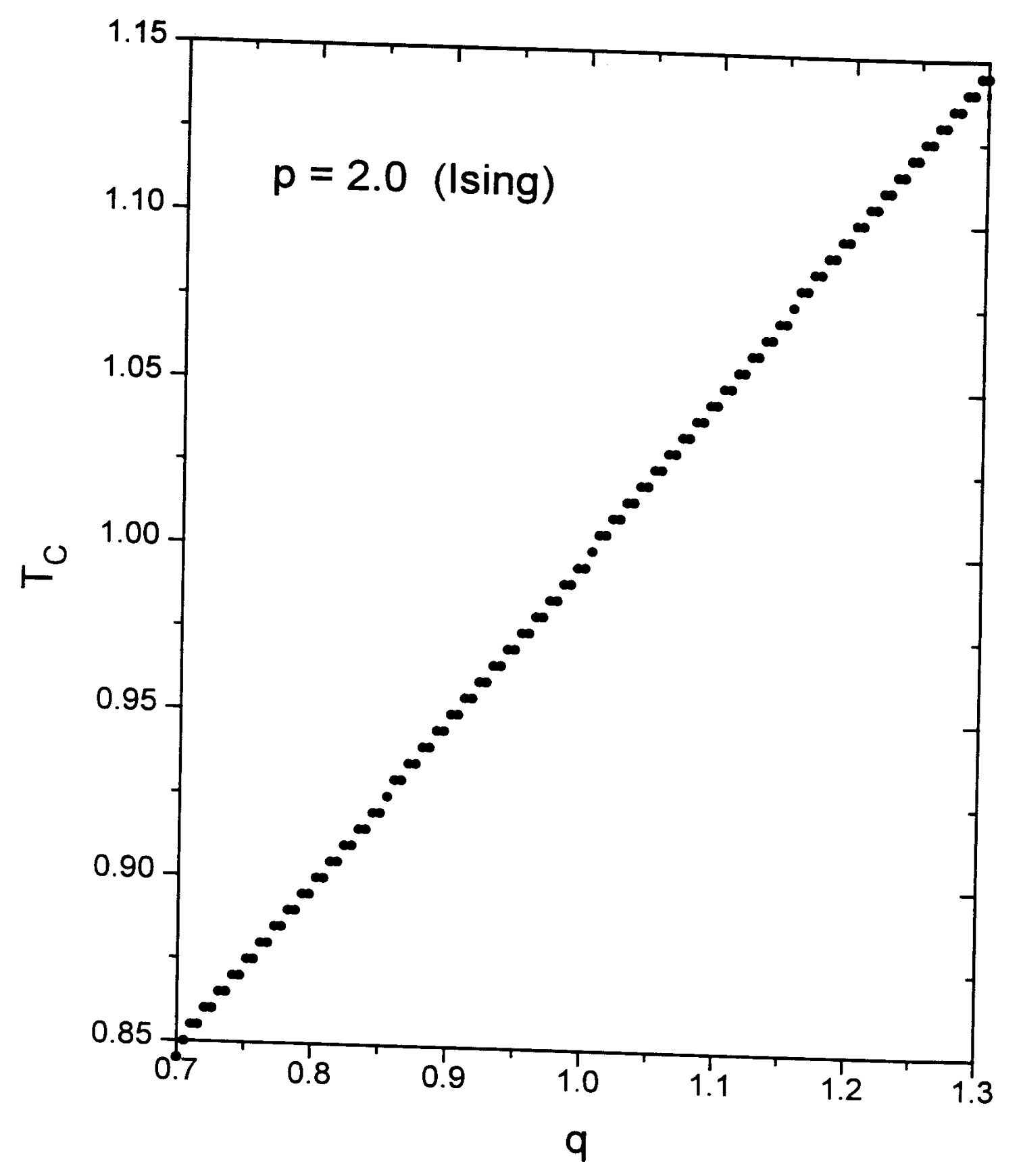

Figura 5.11: Variação de $T_{C}$ com o parâmetro $q, \operatorname{com} p=2.0$. 


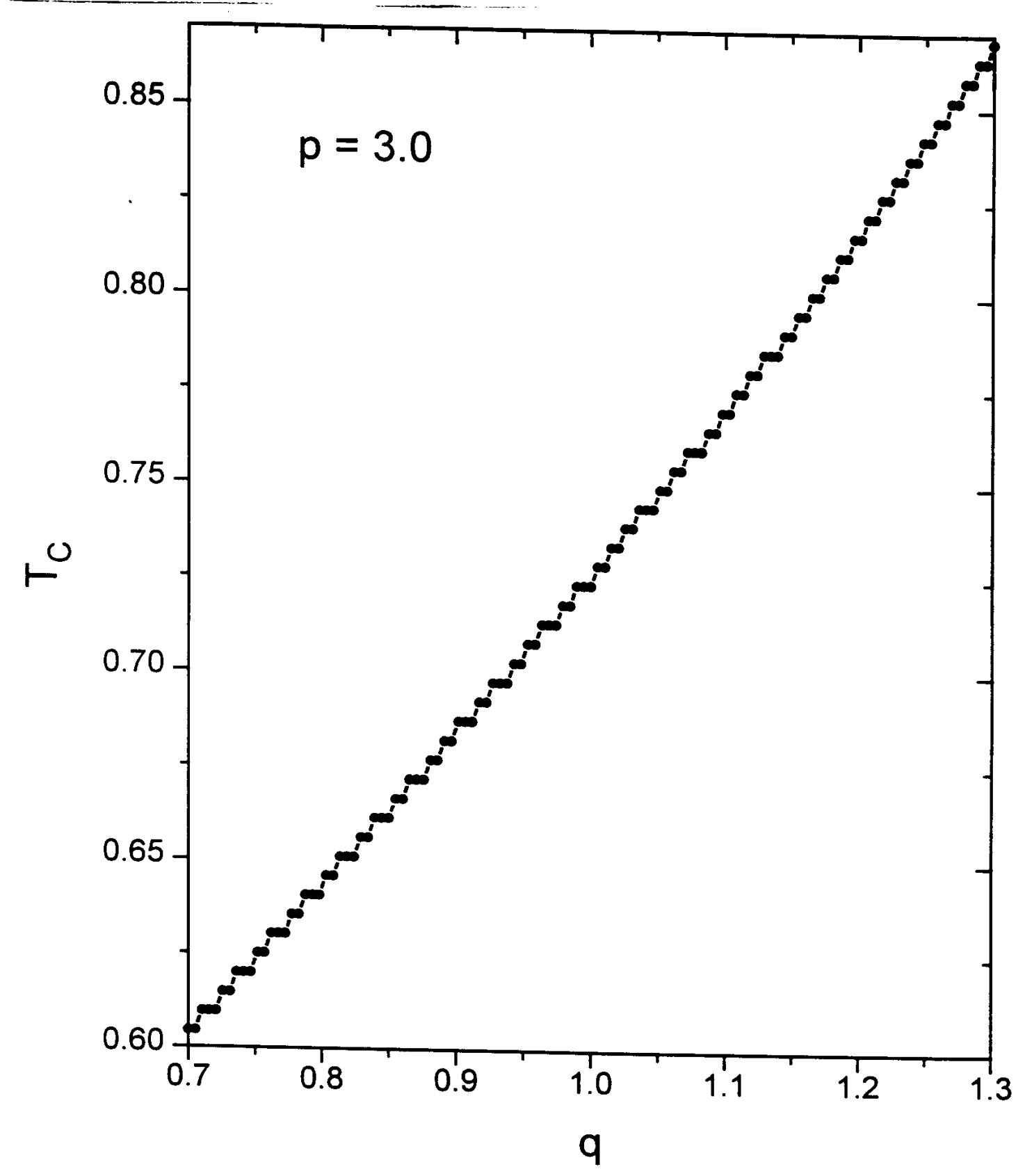

Figura 5.12: Variação de $T_{C}$ com o parâmetro $q, \operatorname{com} p=3.0$. 


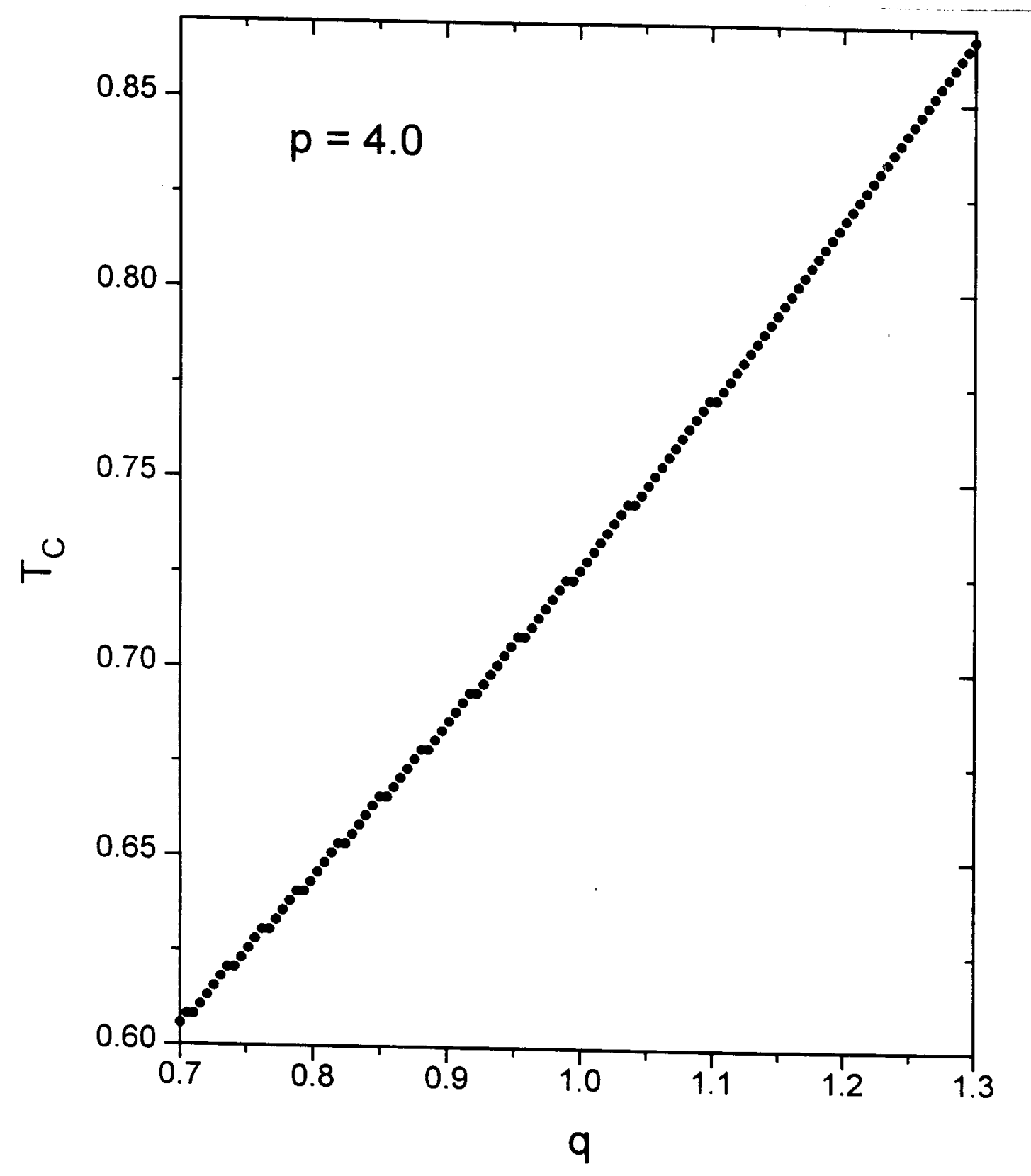

Figura 5.13: Variação de $T_{C}$ com o parâmetro $q, \operatorname{com} p=4.0$. 
TABELA A

\begin{tabular}{||c|c|c||}
\multicolumn{3}{c}{$T_{C}=\alpha(p)+a(p)$} \\
\hline \hline$p$ & $\alpha(p)$ & $a(p)$ \\
\hline \hline 1.50 & 0.86672 & 0.59276 \\
\hline 1.75 & 0.59916 & 0.55906 \\
\hline 2.00 & 0.49919 & 0.49820 \\
\hline 3.00 & 0.49919 & 0.29418 \\
\hline 4.00 & 0.43424 & 0.29612 \\
\hline \hline
\end{tabular}

TABELA B

\begin{tabular}{||c|c|c|c||}
\hline \hline$p$ & $T_{C}$ interpolado & $T_{C}$ analitico $(\mathrm{Wu})$ & Desvio \\
\hline \hline 1.50 & 1.45948 & 1.44269 & 0.0167 \\
\hline 1.75 & 1.15822 & 1.15868 & 0.0004 \\
\hline 2.00 & 0.99739 & 1.00000 & 0.0026 \\
\hline 3.00 & 0.72903 & 0.72134 & 0.0076 \\
\hline 4.00 & $0 . .73036$ & 0.73240 & 0.0020 \\
\hline \hline
\end{tabular}




\section{Capítulo 6}

\section{CONCLUSÃO}

Para a determinação da influência de uma estatística generaliza de Tsallis sobre o comportamento termodinâmico do sistema estudado neste trabalho, contrariamente ao processo encontrado na literatura citada, que parte do cálculo direto da função de ordem $q$ para modelos da física estatística, optou-se pela determinação de um funcional de energia livre de ordem $q$, e através da aplicação a este de condições de equilíbrio prescritas pela termodinâmica, uma obteve-se relação auto-consistente para a magnetização, o qual é equivalente à equação de estado do sistema.

$\mathrm{O}$ fato desta relação no limite de $q$ tendendo à unidade recuperar o resultado na estatística de Boltzmann-Gibbs, mostra a consistência desta abordagem, em especial a hipótese que diz respeito à aplicabilidade das condições de equilíbrio válidas para a estatística de Boltzmann-Gibbs, a um sistema sujeito à uma estatística de Tsallis.

A utilização da teoria dos sistemas dinâmicos discretos, aplicada à relação auto-consistente, permitiu não só a determinação numérica da magnetização espontânea como função da temperatura e sua variação com o parâmetro $q$, como também uma associação de um mapa a esta relação, e relacionar a dinâmica global deste último à evolução dos estados de equilíbrio macroscópico do sistema. Por meio desta associação foi possivel distinguirmos entre estados macroscópicos do sistema que constituem apenas soluções matemáticas para a relação auto-consistente da magnetização, isto é, estados que cumprem as condições de equilíbrio, incluídos aí soluções meta-estáveis, e ramos estáveis $\mathrm{n}$ o acessíveis macroscopicamente, daqueles que têm significado físico, isto é, que podem ser alcançados por meio de processos quase-estáticos.

As curvas de magnetização espontânea e da temperatura crítica em função do pa- 
râmetro $q$ levam à conclusão que não há, dentro da precisão numérica, e do intervalo do parâmetro $q$ aqui pesquisado, nenhuma alteração estrutural significativa no comportamento termodinâmico do sistema com a introdução de uma estatística generalizada. Com isso significando principalmente que as características das curvas de magnetização espontânea para determinado valor da variável de Potts, como: número e forma dos ramos estáveis e instáveis, ordem da transição, etc; não mudam com a variação do parâmetro q. Este comportamento, embora não seja em absoluto auto-evidente é coerente com a observação feita por Tsallis [37], no trabalho em que propôs a generalização da entropia de Boltzmann-Gibbs, a respeito da monotonicidade de $S_{q}$ em relação ao parâmetro $q$ no ensemble microcanônico.

A linearidade da relação entre a temperatura crítica do sistema e o parâmetro $q$, leva a especular sobre a existência, para cada valor de $q$, de um sistema com uma nova constante de interação $J$ que obedece à estatística de Boltzmann-Gibbs. Uma extensão natural para este trabalho seria a determinação de como seriam afetadas, por uma estatística generalizada, as funções resposta do sistema, tais como calor específico, suscetibildade magnética, e seus expoentes críticos. Estas funções, definidas através das derivadas da energia livre de ordem $q$, poderiam ser investigadas pela técnica de derivação funcional aplicada a relação auto-consistente da magnetização. Dessa maneira, embora sendo necessárias bastante extensões, expressões analíticas poderiam ser obtidas para essas grandezas como funções da magnetização, campo externo, e temperatura, o que evitaria a propagação de erros númericos, e as dificuldades inerentes ao cálculo numérico das sucessivas derivadas da energia livre de ordem $q$, em especial nas vizinhanças da criticalidade. 


\section{Capítulo 7}

\section{APENNDICE I}

Na teoria de campo médio do modelo de Potts, em uma estatística de Boltzmann-Gibbs. a partir de condições de equilíbrio termodinâmico macroscópico. temos a expressão:

$$
\ln \left\{\frac{1+(p-1) M}{1-M}\right\}=\frac{2}{T}[M+B] .
$$

O lado direito da equação acima dividida por dois. para $p=2$, reduz-se à expressão usual da funçăo arco- tangente hiperbólica de $M$. Assim é razoável usarmos esta para definirmos uma função arco-tangente hiperbólica de ordem $p$ como:

$$
\operatorname{arctanhp}(M)=\frac{1}{2} \ln \left\{\frac{1+(p-1) M}{1-M}\right\}
$$

Pode-se verificar que a função inversa desta função é:

$$
\operatorname{arctanh}(M)^{-1}=\frac{e^{M}-e^{-M}}{e^{M}+(p-1) e^{-M}},
$$

que para $p=2$ recobra a definição usual de tangente hiperbólica de $M$. Segue então que tangente hiperbólica de ordem $p$ é definida como:

$$
\operatorname{tanhp}(M)=\frac{e^{M}-e^{-M}}{e^{M}+(p-1) e^{-M}},
$$

cujos limites assintóticos são iguais a um para $M \rightarrow \infty$ e $-\frac{1}{p-1}$ para $M \rightarrow-\infty$.

$\mathrm{Na}$ figura a seguir mostram-se algumas curvas da função tangente hiperbólica de ordem $p$ para alguns valores deste parâmetro. 


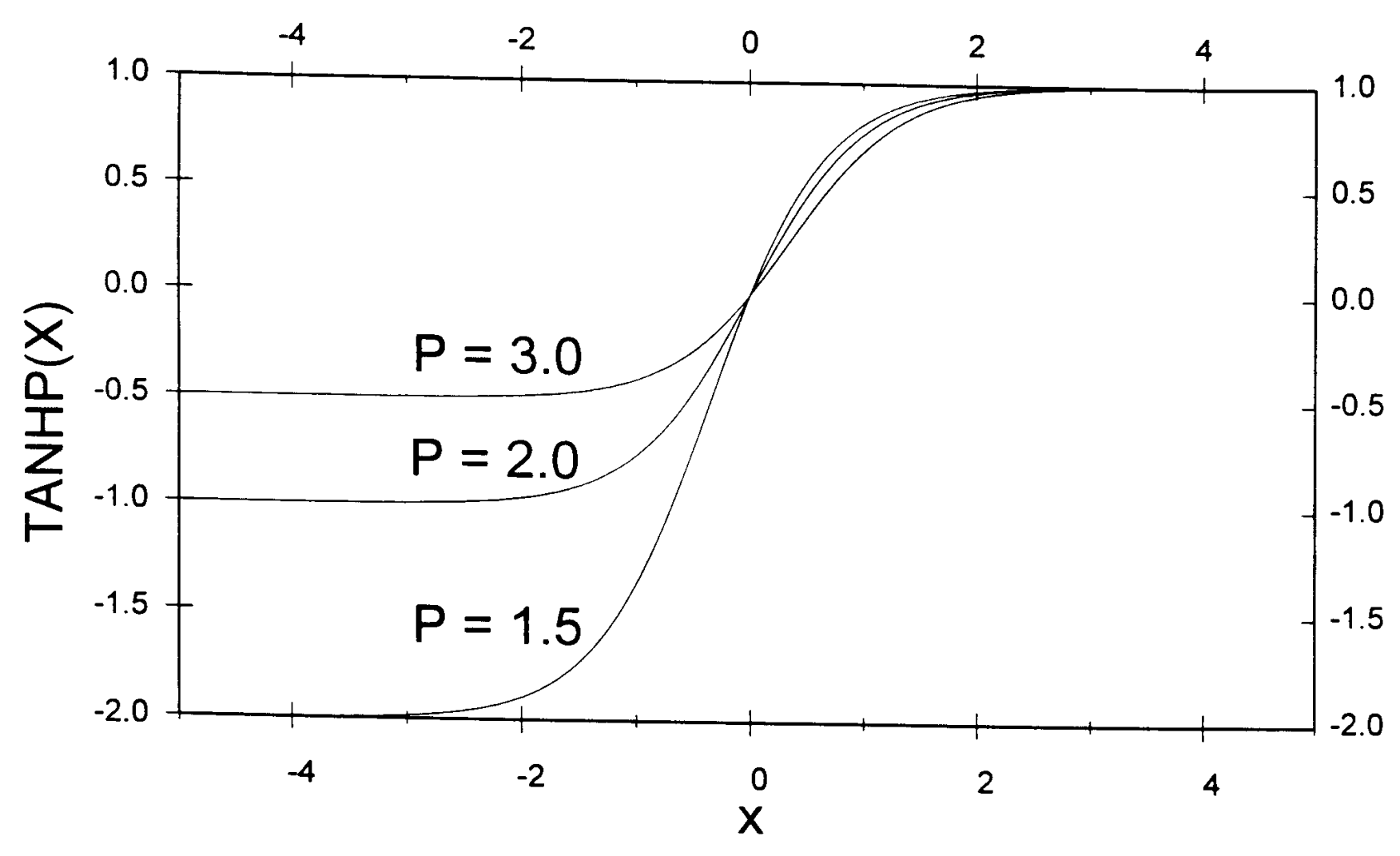




\section{Capítulo 8}

\section{APÊENDICE II: Biliográfica Atualizada}

Trabalhos publicações sobre a estatística generalizada de Tsallis em diversos ramos da fśica até Agosto de 1994.

Entropia Generalizada e Estatística do Equilíbrio

Tsallis C. J. Stat. Phys. 52, 479 (1988)

Temodinmica Generalizada, Ensenbles

Curado E. M. F. e Tsallis C., J. Phys. A 243187 (1991) e 25, 1019 (1992)

Ireversibilidade e Teorema $\mathrm{H}$ Generalizado

Mariz A. M., Phys. Lett. A 165, 409

Ramshow J. D., Phys. Lett. A 175, 169 (1993)

Ramshow J. D., Phys. Lett. A 175, 171 (1993)

Teorema de Ehrenfest Generalizado, von Neumann equation e Conexào com a Teoria da Informação de Jaynes

Plastino A. R. e Plastino A., Phys. Lett. A 177, 177 (1993)

Plastino A. R. e Plastino A., Physica A 202, 438 (1994)

Etstatísticas Generalizadas de Bose-Einsten e Fermi-Dirac 
Büyükkiliç F. e Demirhan D., Phys. Lett A 181, 24 (1993)

Método variacional Generalizado e Desigualdade de Bogolyubov

Plastino A. e Tsallis C., J.Phys. A 26 L983 (1993)

Equações de Langevin e Fokker-Planck Generalizadas

Stariolo D. A. Phys. lett. A 185, 262 (1994)

Flutuação Dissipa, ao Generalizada, Teoremas de Nyquist e Onsager

Chame A. e de Mello E. V. L. J. Phys. A 273663 (1994)

Princṕio Clássico de equipartição e Gás Ideal Generalizado

Plastino A. R., Plastino A. e Tsallis C., J. Phys. A 27, 5707 (1994)

Física Não-Extensiva; Posivessiveis Conexões com Grupos Quanticos e Fractais

Tsallis C., "New Trends in Magn. and their Applic." ed Moran-Lopez J. L. e

Sanchez J. M., p. 451, Plenum 1994

Tsallis C., "Chaos Solitons and Fractals", ed. Marshall G., Pergamon, 1994

Sistemas de Dois Niveis

Tsallis C., J. Stat. Phys. 52, 479

Ito and Tsallis C., N. Ciment. D 11, 907

Oscilador Harmônico

Ito and Tsallis C., N. Ciment., D 11, 907

Particula Livre 
Silva E. P., Tsallis C. e Curado, Physica A 203, 160 (1993)

\section{Precessão de Larmor}

Plastino A. R., Plastino A., Physica A 202, 438

\section{Ferromagneto de Ising $d=1$}

Andrade R. F. S., Physica A, 175, 285 (1991)

Andrade R. F. S., Physica A, 203, 486 (1994)

\section{Astrofśica}

Plastino A. R., Plastino A., Phys. Lett. A 174, 384 (1993)

Aly J. J. "N-Bory Problems and Gravitational Dynamics", Proceedings of Meeting held at Aussois-France, p. 19 , ed Combes F. and Athanassoula E., Publications de l'Observatorie de Paris 1993

\section{Levy Flights}

Alemany p. A. e Zanette D. H., Phys. Rev. E 49, 956 (1994)

Possivéis Usos em Biologia

Landsberg P. T., ' "On Self-Organization", Synergetics 61, 157, Springer (1994)

\section{Equação de Vaslov}

Plastino A. R., Plastino A., Phys. Lett. A 193, 251 


\section{Referências}

[1] Andrade R. F. S; Physica A; 75 (1991) 285.

[2] Arfken G., Mathematical Methods for Physicists, Academic Press, London (1971).

[3] Ashkin J., Teller E.; Phy. Rev.; 64,178, (1943).

Physica A 203

[4] Bailyn, M., A Survey on Termodynamycs, no prelo.

[5] Barrca A., Bellesi M., Levi R., Phys. Lett. A 99156 (1983).

[6] Baxter J., Exact Solved Models in Statistical Physics, 1982.

[7] Blanchard P., Bull. Am. Math. Soc. 1184 (1984).

[8] Callen, H.B., Thermodynamics and an Introduction to Thermostatics, John Willey and Sons, 1985.

[9] Curado E. M. F., Tsallis C.; J. of Phys. A; 24 (1991), L69.

[10] Devaney R. L., An Introduction to Chaotic Dynamical Systems, 2nd. ed, AddisonWesley, 1989.

[11] Dorn W.S. e McCracken H, Cálculo Numérico com casos de Estudo em Fortram IV, Ed. Campus e EDUSP, 1978.

[12] Fujisaka H., Inoue M.; Progress of Theoretical Physics; 77, 6 (1987), 1334.

[13] Halsey T. C., Jansem M. H., Kadanoff L. P., Procaccia I., Shariman B. I.; Physical Review A; 33, 2, (1986), 1141. 
[14] Husimi K.; Statistical Mechanics of Condensation; Proceedings of International Conference of Theoretical Physics; Science Concil of Japan; (1953), 531.

[15] Ising E, Z. Phys., 21, 613, (1925).

[16] Ito N. e Tsallis C., Nuovo Cimento, D11 (1989) 907.

[17] Israel R. B., Convexity Relations on Theory of Lattice Gases, Introdução por Wighitman A. S. , Princeton Series in Phisics, 1980.

[18] Kinchim, A.I., Mathematical Foundations of Information Theory, Dover (1957), New York.

[19] Landau L. P. e Lifshits E. M., Course of Theoretical Physics, Vol 5, Statistical Physics Part I, Pergamon Press, 1980.

[20] Mandelbrot B. B.; The Fractal Geometry of Nature; Freeman, San Francisco, 1982.

[21] Motz L. e Hane Weaver J. , The Story of Physics, Plenum Press, 1989.

[22] Onsager L., Phys. Rev. 65117 (1944)

[23] Plastino A., Tsallis C.; Variational Method in Generalized Statistical Mechanics; J. Phys.A 26893 (1993).

[24] Plastino A R, Plastino A.; Tsallis Entropy, Ehrenfest Theorem and Information Theory; Phys. Lett. A 174384 (1993).

[25] Plastino A. R., Plastino A.; Stellar Polytropes and Tsallis' Entropy; Phys. Lett. A 177177 (1993).

[26] Peitgen H. O., Richter P. H.; The Beauty of the Fractals; Springer-Verlag, BerlinHeildelberg, 1986.

[27] Potts R. B.; Proc. Cambridge Philos. Soc. 48 (1952) 106.

[28] Ranshow J. D.; Phys. Lett. A; 175, 3 (1993), 169.

[29] Ranshow, J.D.; Phys. Lett. A;175, 3 (1993), 171. 
[30] Reichel, L. E., A Modern Course in Statistical Physics, Eduard Arnold Ltd (1980), U.K.

[31] Rènyi, A., Probability Theory, North Holland (1970), Amsterdan.

[32] Shannom, C. E., Bell Syst. Tech. J. 27 (1948) 379.

[33] Soares de Aguiar F., Tese de Doutorado, IFQSC-USP, 1992.

[34] Stanley H. E., Introduction to Phase Transition and Critical Phenomena, Oxford University Press 1971.

[35] Silva E. P., Tsallis C., Curado E. M. F.; Specific Heat of a Free Particle in a Generalized Boltzmann-Gibbs Statistics; preprint, 1992.

[36] Tisza, L., Generalized Thermodynamics, MIT Press, 1966.

[37] Tsallis C.; J. Stat. Phys.; 52, 12 (1988), 479.

[38] Wu F. Y.; Rev. Mod. Phys.; 54, (1982), 1, 235. 